\title{
MECHANICAL PROPERTIES OF LAVES PHASES
}

Go Sasaki

(M. S. Thesis)

December 1970

AEC Contract No. W-7405-eng -48
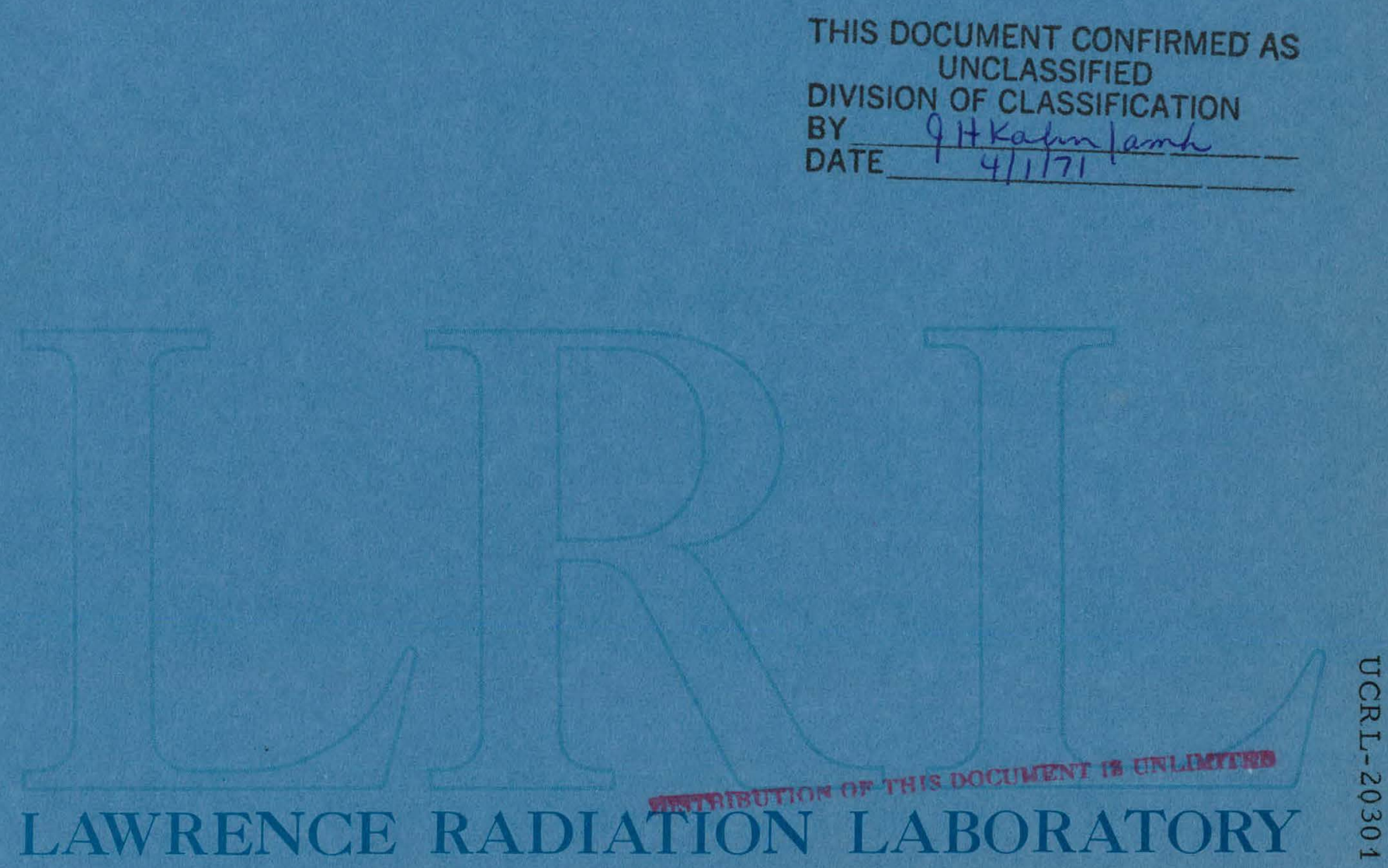
UNIVERSITY Of CALIFORNIA BERKELEY 


\section{DISCLAIMER}

This report was prepared as an account of work sponsored by an agency of the United States Government. Neither the United States Government nor any agency Thereof, nor any of their employees, makes any warranty, express or implied, or assumes any legal liability or responsibility for the accuracy, completeness, or usefulness of any information, apparatus, product, or process disclosed, or represents that its use would not infringe privately owned rights. Reference herein to any specific commercial product, process, or service by trade name, trademark, manufacturer, or otherwise does not necessarily constitute or imply its endorsement, recommendation, or favoring by the United States Government or any agency thereof. The views and opinions of authors expressed herein do not necessarily state or reflect those of the United States Government or any agency thereof. 


\section{DISCLAIMER}

Portions of this document may be illegible in electronic image products. Images are produced from the best available original document. 


\section{PAGES $\mathrm{i}$ to $\mathrm{ii}$ WERE INTENTIONALLY LEFT BLANK}


TABLE OF CONTENTS

\section{Abstract}

I. INTRODUCTION-_- I

II. EXPERIMENTAL PROCEDURE-_ 3

A. Material Preparation- 3

B. X-ray Analysis- 5

C. Optical Microscopy- 5

D. Micro Vickers Hardness Test-_- 6

E. Interference-contrast Method with Reflected Light _...--.- 6

F. Scanning Electron Microscopy-_- 6

G. Tensile Tests-_- 7

III. RESULTS AND DISCUSSION-_- 8

A. Mechanical Properties of Laves Phases-_- 8

B. Effects of Precipitation of $\mathrm{NbFe}_{2}$ and $\mathrm{TaFe}_{2}$ on the Mechanical Properties of Fe-1.78 at.\% $\mathrm{Nb}$ and Fe-1.96 at.\% Ta Alloy--- 13

IV. SUMMARY AND CONCLUSIONS- 17

ACKNOWLEDGEMENTS-_-_- 18

TABLES- 19

REFERENCES- - 23

FIGURE CAPTIONS-_- 25

FIGURES- 29

LEGAL NOTICE

This report was prepared as an account of work sponsored by the United States Government. Neither sponsored Commission, nor any of their employees, nor any of Commission, nor any of their contractors, subcontractors, or the or assumes any makes any warranty, express or implied, or assumes any legal liability or responsibility for the accuracy, completeness or usefulness of any intormation, apparatus,
product or process disclosed, or represents that its use would not infringe privately owned rights. 
MECHANICAL PROPERTIES OF LAVES PHASES

\section{Go Sasaki}

Inorganic Materials Research Division, Lawrence Radiation Laboratory Department of Materials Science and Engineering, College of Engineering University of California, Berkeley, California

\section{ABSTRACT}

Primary interest in Laves phases in iron binary systems with transition elementslies in their effects as dispersed precipitates. The characteristics of Laves phases themselves should be made clear before discussing precipitation hardening. Mechanical properties of Laves phases, $\mathrm{NbFe}_{2}, \mathrm{TaFe}_{2}, \mathrm{TiFe}_{2}, \mathrm{ZrFe}_{2}$ and $\mathrm{HfFe}_{2}$ have been studied by use of a micro Vickers hardness tester. The highest strength (over Hv. 1000) was obtained In $\mathrm{NbFe}_{2}$ and $\mathrm{TaFe}_{2}$, while the strength of $\mathrm{TiFe}_{2}$ and $\mathrm{ZrFe}_{2}$ was comparatively Iow (Hv. 859). The observation of the deformation around the hardness Indentation showed that $\mathrm{TaFe}_{2}, \mathrm{ZrFe}_{2}$ and $\mathrm{HfFe}_{2}$ seemed to deform partially with plastic form.

$\mathrm{NbFe}_{2}$ and $\mathrm{TaFe}_{2}$, which had almost the same strength but deformed differently were chosen for the study of their effects on the mechanical properties of the iron base binary alloys. Both higher strength and better ductility were obtained in the Fe-1.9 at.\% Ta alloy than in Fe-1.78 at.\% Nb alloy. A remarkable denuded zone at the retained $\delta$ grain boundaries was observed in the $\mathrm{Fe}-1.78$ at.\% $\mathrm{Nb}$ alloy. 


\section{INTRODUCTION}

The Laves phase which was first established in the early $1930^{\prime} \mathrm{s}$ by F. Laves is an intermediate compound with a stoichimetric composition of $\mathrm{AB}_{2}$ in which the structure is primarily determined by the relative size of the atoms.

Most binary systems of iron with IVa, Va and VIa transition elements have Laves Phases, which appear as precipitates in useful alloys. In the iron base and nickel base super alloys for example Laves phases with various kinds of morphology always exist and are thought to increase the strength and decrease the ductility and the notch toughness at room temperature. ${ }^{I}$ Laves phases are not confined to the transition metal systems. Many studies on the magnetic properties of Laves phases with non-transition elements have been done. Mainly due to their brittleness, however, only a few works ${ }^{2-4}$ on the mechanical properties of Laves phases have been reported.

Here, the mechanical properties of the iron base Laves phases with IVa transition elements, 1.e. $\mathrm{Ti}, \mathrm{Zr}$ and $\mathrm{Hf}$, and $\mathrm{Va}$ transition elements, i.e. Nb and $\mathrm{Ta}$ were studied by micro Vickers hardness tester. The observation of the deformation around the hardness indentation was carried out by using the interference-contrast method with reflected light and the scanning electron microscope.

G. R. Speich ${ }^{5}$ investigated the precipitation behavior of Laves phases from iron-niobium and iron-titanium solid solution. Unfortunately, the mechanical properties of these alloys, however, were not reported, which makes quantitative analysis difficult due to the unknown relation between yield stress and hardness. 
What kind of precipitate is desirable for designing alloys? Alloys containing strong particles incoherent with matrix can increase workhardening rate because slip dislocations leaves loops around particles that they pass, and the effective interparticle spacing decreases as the number of loops increases. For coherent precipitates, slip dislocations must shear the particles in order to increase the yield stress.

Two high hardness Laves phases, $\overline{\mathrm{NBFe}}{ }_{2}$ and $\overline{\mathrm{TaFe}} \mathrm{F}_{2}$ which showed different types of deformation in micro Vickers test, where chosen for the study of their effects on the mechanfcal properties of the iron base binary alloys. The effect of heat treatment on the morphology of precipitateg was also investigated. 


\section{EXXPERIMENTAL PROCEDURE}

The experiment consists of two parts, (a) the mechanical properties of Laves phases, and (b) their effects as precipitates.

\section{A. Material Preparation}

The material used for the first part of the study was prepared from a button ingot $(20.0$ to $40.0 \mathrm{~g})$ produced by an arc melting furnace (MRC Model AF-92C) and solution treated in quartz capsules evacuated and back filled with high purity argon. High purity raw materials were carefully selected for this study; $99.9 \%$ purity niobium and $99.9 \%$ tantalum powders were used as raw materials, and $99.9 \%$ purity sponges for titanium, zirconium and hafnium, and 99.999\% purity powder for iron respectively. All alloys were turned and remelted from 3 to 6 times in order to prevent segregation. The ingots were invariably brittle. Some materials were shattered during cooling, which is due to the rapid cooling by the water cooled copper mold. Alloy No. $23\left(\mathrm{TaFe}_{2}\right)$ was remelted in the vacuum induction furnace in which the cooling velocity can be controlled to be relatively s.low.

Table I shows the materials, melting method and the condition of the heat treatment.

The materials used for the second part of the study were prepared by vacuum induction melting of electrolytic iron ( $99.8 \%)$, high purity niobium rods $(99.99 \%)$ and high purity tantalum (99.99\%). The melts were vacuum cast as 1.00 to 1.25 in. diameter, 6 to $12 \mathrm{in.} \mathrm{length} \mathrm{ingots,} \mathrm{which} \mathrm{were}$ hot rolled into a bar with $0.50 \mathrm{in.} \mathrm{diameter} \mathrm{in} \mathrm{the} \mathrm{temperature} \mathrm{range}$ 950 to $1000^{\circ} \mathrm{C}$. Specimens of $0.50 \mathrm{in.}$ diameter, $0.075 \mathrm{in}$. thickness were 
TABLE I. Chemical composition, melting method and heat treatment of the Laves phases

\begin{tabular}{|c|c|c|c|}
\hline No. & Composition (at.\%) & Melting Method* & Solution Treatment \\
\hline 11 & $\mathrm{NbFe}_{2}(\mathrm{Nb} 23.0)$ & $A M(4)$ & $1250^{\circ} \mathrm{C}, 24 \mathrm{hr}$. \\
\hline 12 & $\mathrm{NbFe}_{2}(\mathrm{Nb} 33.0)$ & $A M(3)$ & $1300^{\circ} \mathrm{C}, 24 \mathrm{hr}$. \\
\hline 13 & $\mathrm{NbFe}_{2}(\mathrm{Nb} 42.0)$ & $A M(3)$ & $1300^{\circ} \mathrm{C}, 24 \mathrm{hr}$. \\
\hline 21 & TaFe, $_{2}\left(T_{\text {a }}\right.$ ?7. 0$)$ & AM (4) & $1350^{\circ} \mathrm{C}, 24 \mathrm{hr}$. \\
\hline 22 & $\mathrm{TaFe}_{2}(\mathrm{Ta} \mathrm{33.0)}$ & $A M(4)$ & $1350^{\circ} \mathrm{C}, 24 \mathrm{hr}$. \\
\hline 23 & $\mathrm{TaFe}_{2}(\mathrm{Ta} 33.0)$ & $A M(5)-\operatorname{VIM}(1)$ & $1350^{\circ} \mathrm{C}, 24 \mathrm{hr}$. \\
\hline 31 & $\mathrm{TiFe}_{2}(\mathrm{TI} 25.0)$ & AM (4) & $1250^{\circ} \mathrm{C}, 24 \mathrm{hr}$. \\
\hline 32 & $\mathrm{TiFe}_{2}(\mathrm{Ti} 33.0)$ & AM (4). & $1250^{\circ} \mathrm{C}, 24 \mathrm{hr}$. \\
\hline 33 & $\mathrm{TiFe}_{2}(\mathrm{Ti} 35.0)$ & AM (5) & $1250^{\circ} \mathrm{C}, 24 \mathrm{hr}$. \\
\hline 41 & $\mathrm{ZrFe}_{2}(\mathrm{Zr} 23.0)$ & AM (4) & $890^{\circ} \mathrm{C}, \quad 7$ days. \\
\hline 42 & $\mathrm{ZrFe}_{2}(\mathrm{Zr} 33.0)$ & $A M(6)$ & $890^{\circ} \mathrm{C}, 7$ days. \\
\hline 51 & $\mathrm{HfFe}_{2}$ (Hf 33.0) & AM (4) & $1250^{\circ} \mathrm{C}, 24 \mathrm{hr}$. \\
\hline
\end{tabular}

*AM: Arc Melting, VIM: Vacuum Induction Melting. The number in parenthesis shows the times of remelting.

TABLE II. Chemical composition of the alloys

\begin{tabular}{lccccc}
\hline Alloy & At.\% Nb & Wt.\% $\mathrm{Nb}$ & At.\% Ta & Wt.\% Ta & Solution Treatment \\
\hline $\mathrm{Nb2}$ & 1.78 & 2.80 & - & - & $1380^{\circ} \mathrm{C}, 1 \mathrm{hr}$. \\
$\mathrm{Ta2}$ & - & - & 1.96 & 6.04 & $1400^{\circ} \mathrm{C}, 1 \mathrm{hr}$. \\
\hline
\end{tabular}


cut from the rolled bar, sealed in quartz capsules evacuated and back filled with high purity argon gas, and heated in the $\delta$ phase region. The iron-nlobium alloy and the iron-tantalum alloy were solution treated for 60 minutes at $1380^{\circ} \mathrm{C}$ and $1400^{\circ} \mathrm{C}$, respectively, and quenched by smashing the capsules into $10 \%$ salt solution. In order to spheroidize the grain boundary precipitates, a transformation treatment i.e., $\alpha+$ Laves $\rightarrow \gamma+$ Laves $\rightarrow$ $\alpha+$ Laves, was carried out for 10 and 60 minutes at $1000^{\circ} \mathrm{C}, 1050^{\circ} \mathrm{C}$ and $1100^{\circ} \mathrm{C}$, followed by air cooling. ASTM standard $0.25 \mathrm{in}$. round tension test specimens which were prepared by machining of the rolled bar were heat. treated exactly in the same way.

The compositions of the alloy investigated were selected so that the alloys should have the same amount of precipitates at equilibrium condition. Alloy compositions and solution treatment are given in Table II.

\section{B. X-Ray Analysis}

Using Norelco type 12045 diffractometer with $\mathrm{CuKa} \alpha_{1}(\lambda: 1.54050 \AA)$ radiation and monochromator, the crystal structure of Laves phases was checked. A powder of 100 mesh was prepared for the test. The diffraction patterns were determined by taking the average of at least two measured "d" (interplanar spacing) values. The analytical method ${ }^{6}$ and Hull-Davey chart were used for indexing patterns of hexagonal, and cubic crystals respectịvely.

\section{Optical Microscopy}

Specimens prepared for microscopy were mechanically polished with emery papers and $1.0 \mu$ diamond paste, and then finished with $0.5 \mu \mathrm{Al}_{2} \mathrm{O}_{3}$ particles. The echant used for No. $11 \mathrm{NbFe}_{2}$ (Nb 23.0 at.\%), No. $21 \mathrm{TaFe}_{2}$ 
(Ta.27.0 at.\%), No. $31 \mathrm{TiFe}_{2}$ (Ti 25.0 at.\%) and No. $41 \mathrm{ZrFe}_{2}$ ( $\mathrm{Zr} 23.0$ at.\%) was $\mathrm{FeCl}_{3}$ solution and for other materials was Keller's concentrated eching solution and/or or $50 \% \mathrm{H}_{3} \mathrm{PO}_{4}$ plus $50 \% \mathrm{HF}$ solution.

The echant used for $\mathrm{Nb} 2$ and $\mathrm{Ta} 2$ was $2 \%$ and/or $5 \%$ Nital, depending on the condition of the heat treatment.

\section{Micro Vickers Hardness Test}

Hardness of Laves phases was measured at least ten times by using Leitz's MINILOAD hardness tester mostly with 300 gram load. A 100g load was used for No. $I I \mathrm{NbFe}_{2}$ ( $\mathrm{Nb} 23.0$ at.\%), No. $21 \mathrm{TaFe}_{2}$ (Ta 27.0 at.\%), and No. $4 \mathrm{ZrFe}_{2}(\mathrm{Zr} 23.0 \mathrm{at. \%}): 1000 \mathrm{~g}$ and $2000 \mathrm{~g}$ loads were also used for the observation of the deformation around the hardness indentation. Hardness of the aged specimens of $\mathrm{Nb} 2$ and $\mathrm{Ta} 2$ was determined from the average of five indentations made with $300 \mathrm{~g}$ load.

E. Interference-Contrast Method with Reflected Light

The interference-contrast method with reflected light(Zeiss' Ultraphot II) was employed for determining whether the deformation around the hardness indentation was due to slipping or cracking.

\section{F. Scanning Electron Microscopy}

Using JSM-U3 Scanning Electron Microscope (25 kV), the observation. of the deformation around the indentation was carried out at higher magnifications $(1,000 \times$ to 10,000$)$.

This was widely used for the observation of the grain boundaries and the morphology of the precipitates in $\mathrm{Nb} 2$ and $\mathrm{Ta} 2$. The fracture surface of tensile specimen was also observed by the scanning electron microscope. 


\section{G. Tensile Test}

An Instron (TT-Model, Instron Eng. Coop) was used for the tensile testing of $\mathrm{Nb} 2$ and $\mathrm{Ta} 2$. A. cross head speed of $0.1 \mathrm{~cm}$ per second was employed. The tensile test specimens were ASTM standard 0.25 in. round bar type with 1.000 in. gage length. The yield stress was determined by taking the $0.2 \%$ offset strain. 


\section{RESULTS AND DISCUSSION}

\section{A. Mechanical Properties of Laves Phases}

\section{Phase Diagram}

Figures 1 to 5 show the latest equilibrium phase diagrams ${ }^{7-9}$ of the systems, on which the compositions used for this study are marked. The theoretical range of Laves phase based on the high temperature phase diagram proposed by I. Brewer ${ }^{10}$ is also shown. In the Iron binary system with $\mathrm{IV}, \mathrm{Va}$ and $\mathrm{VIa}$ elements, there exist Laves phases, $\mathrm{TIFe}_{2}, \mathrm{ZFFe}_{2}, \mathrm{HfFe}_{2}$, $\mathrm{NbFe}_{2}, \mathrm{TaFe}_{2}$ and $\mathrm{WFe}_{2}$. The compound $\mathrm{MoFe}_{2}$ has not been decisively confirmed. Pure $\mathrm{WFe}_{2}$ is hard to obtain because of the many intermetallic compounds in the system. Several attempts to make a pure $\mathrm{WFe}_{2}$ had been done by the author, however, several other phases were formed which could not be eliminated even with a long time heat treatment.

Five systems were chosen for this study. As shown in Figs. 1 to 5 $\mathrm{TiFe}_{2}, \mathrm{HfFe}_{2}$ and $\mathrm{NbFe}_{2}$ have large solubility ranges, and $\mathrm{ZrFe} 2$ and $\mathrm{TaFe}_{2}$ have pin-point solubility. Brewer ${ }^{10}$ proposed a large solubility ranges for $\mathrm{ZrFe}_{2}\left(\mathrm{Zr} 28\right.$ to 37 at.\%) and $\mathrm{TaFe}_{2}$ ( $\mathrm{Ta} 26$ to 35 at.\%).

Figures 6 to 10 show the microstructures of the material used for this study. Specimens No. 11 (Nb 23.0 at.\%), No. 21 (Ta 27.0 at.\%), No. 31 ( $\mathrm{Ti} 25.0$ at.\%) and No. $41(\operatorname{Zr} 23.0$ at.\%) consisted of two phases ( $\alpha-\mathrm{Fe}$ and Laves phase) as shown clearly in the microstructures. The difference of microstructures between No. 22 and No. 23 which contain the same amount of tantalum is considered to be due to the difference of the melting process. Number $42(\mathrm{Zr} 33.0$ at.\%) seems to have two different phases. However, it is likely to be a purer Laves phase since the 
X-ray diffraction pattern does not show any distinct evidence of the existence of another phase. Specimens No. 12 ( $\mathrm{Nb} 33.0$ at.\%), No. 13 (Nb 42.0 at.\%), No. 22 and 23 (both $\mathrm{Ta} 33.0$ at.\%), No. 32 (Ti 33.0 at.\%), No. 33 (T1 35.0 at.\%) and No. 51 (Hf 33.0 at.\%) are considered to be pure Laves phases.

The hardness measurement of the material is given in Table III, and also graphed in Fig. il. Yields between before and after casting were almost $100 \%$. Figure $I$ shows that the $\mathrm{NbFe}_{2}$ Laves phase has a solubility extending from 23.0 to 42.0 at.\%. The present work indicates that the minimum solubiltty of niobium in $\mathrm{NbFe}_{2}$ may be larger than 23.0 at.\%. For Fig. 6 (a) shows the existence of a fairly large amount of $\alpha-F e$. Similarly, as shown in Fig. 3 the $\mathrm{TiFe}_{2}$ Laves phase has a solubility of 25.0 to 35.0 at.\%. This work indicates that the iron-rich side of $\mathrm{TiFe}_{2}$ is actually larger than 25.0 at.\%, which is clearly shown by the microstructure (Fig. $8(a))$.

\section{Crystal Structure}

The Laves phase are characterized by three crystal structures, i.e. $\mathrm{MgCu}_{2}$, cubic Cl5 type (Fig. 12), $\mathrm{MgZn}_{2}$, hexagonal C14 type (Fig. 13a, b) and $\mathrm{MgNI}_{2}$, hexagonal $\mathrm{C} 36$ type (Fig. 13c).

As shown in Fig. 12b, Fig. $13 \mathrm{a}$ and $13 \mathrm{~b}$, the $\mathrm{MgCu}_{2}$ structure consists of the atomic layers stacked PQRPQR, while $\mathrm{MgZn}_{2}$ consists of those PQPQPQ. $\mathrm{MgNi}_{2}$ may be regarded as a transition phase between $\mathrm{MgCu}_{2}$ and $\mathrm{MgZn}_{2}$ with a stacking of PQPRPQPR.

The crystal structure, the electron per atom ratio and the lattice parameter of the material for this study are given in Table IV. $\mathrm{NbFe}_{2}$, $\mathrm{TaFe}_{2}$ and $\mathrm{TiFe}_{2}$ have the hexagonal $\mathrm{MgZn}_{2}$ type structure, while $\mathrm{ZrFe} \mathrm{f}_{2}$ has. 
the cubic $\mathrm{MgCu}_{2}$ type. The crystal structure of $\mathrm{HfFe}_{2}$ has not been determined as yet. Hansen et $a I^{7}$ and W. B. Pearson ${ }^{11}$ reported that $\mathrm{HfFe}_{2}$ exhibited a duplex structure of $\mathrm{MgZn}_{2}$ with $\mathrm{MgCu}_{2}$. On the other hand, R. P. Elliott ${ }^{12}$ reported that $\mathrm{HfFe}_{2}$ showed a diffraction pattern isomorphous with the $\mathrm{MgNi}_{2}$ structure.

The X-ray diffraction patterns of each Laves phase are shown in Figs. 14 to 18. $\mathrm{NbFe}_{2}, \mathrm{TaFe}_{2}, \mathrm{TiFe}_{2}$ and $\mathrm{HfFe}_{2}$ were confirmed to have a hexagonal unit cell structure and $\mathrm{ZrFe}_{2}$ was cublc. A slight difference of "d" (Interplanar spacing) values in $\mathrm{NbFe}_{2}$ (Fig. 14) and $\mathrm{TiFe}_{2}$ (Fig. 16) between the present work and ASTM data is probably due to the difference of nlobium and tantalum contents between the two works, i.e. the difference of lattice parameters. ASTM data originally given by Speich $^{5}$ is on the precipitates extracted from Fe-1.67 wt.\% $\mathrm{Nb}$ and Fe-5.8 wt.\% T1 alloys, 1.e., the Iron-rich sides of Laves phases. The diffraction patterns of $\mathrm{ZrFe}_{2}$ (FIg. 17) agreed with that of ASTM. Though crystallographic data for $\mathrm{TaFe}_{2}$ has not been described in the ASTM card files, the present work (Fig. 15) shows that it has a hexagonal structure, the interplanar spacing values of which are similar to that of $\mathrm{TiFe}_{2}$. Figure 18 suggests that $\mathrm{HFFe}_{2}$ has a $\mathrm{MgZn}_{2}$ type structure.

R. P. Elllott and W. Rostoker, ${ }^{14}$ A. G. Dwight, ${ }^{15}$ and V. M. Nevitt ${ }^{16}$ have discussed in detail the various factors which determine the occurrence of Laves phase. It is now quite evident that the atomic size and the electron per atom ratio are two major factors for the occurrence of the phase. A. G. Dwight ${ }^{15}$ showed that Laves phases form in the range of Goldschmidt radius ratios from 1.06 to 1.65 for the cubic $\mathrm{MgCu}_{2}$ type structure, 1.05 to 1.40 for the hexagonal $\mathrm{MgZn}_{2}$ and the hexagonal $\mathrm{MgNi}_{2}$ 
type structures, and reported that the major factor controlling the formation of Laves phases is the ability of the partner elements to contract or expand so that the ideal ratio 1.225 is approached. As shown in Table IV, the Goldschmidt radius ratios of the Laves phases obtained in this study satisfy his criterion.

For the second factor, Decker et $a l^{l}$ reported that there exists a distinct boundary of electron per atom ratio under 8.0 for the appearance of Laves phase.

\section{Hardness}

The measured hardness is given in Table III, and graphed in Fig. 11. As shown in Fig. Il, the hardness of $\mathrm{MbFe}_{2}$ was the highest in all the materials (Hv. 1063). TaFe 2 also showed high hardness (Hv. 1010). The hardness of $\mathrm{TiFe}_{2}$ and $\mathrm{ZrFe}_{2}$, on the other hand, was relatively low (Hv. 859 for both). $\mathrm{HfFe}_{2}$ showed Hv. 943. In the Laves phases with IVa element, the greater the atomic number of transition element, the higher the hardness. The hardness of Va group was much higher than that of IVa group.

\section{Observation of the Deformation around the Hardness Indentation}

The observation of the deformation around the micro Vickers hardness indentation was carried out by using both the interferencecontrast technique with reflected light and the scanning electron microscope. Higures 19 to 23 and Figs. 24 to 32 show typical examples to 1llustrate the deformation around the hardness indentation observed by the interference-contrast method and the scanning electron microscope, respectively. 
As shown in the photographs, clear-cut slip bands or slip lines colld not be observed around the hardness indentation of all specimens. It is, however, evident that the types of deformation between $\mathrm{NbFe}_{2}$ and $\mathrm{TaFe}_{2}$, for example, are quite different. It can be said that relative ductility can be evaluated qualitatively from the shape and the length of the deformation. If there is no plastic deformation, the hardness cannot be measured.

The work done by the hardness testing, $W$, consists of the three terms, i.e., the work compensated in making indentation, $w_{1}$, the work compensated in other things raising the heat, for example, $w_{3}$, which can be negligible In this case. When the hardness of two specimens are almost the same, then these $w_{2}$ terms should not be different because $w, w_{1}$ and $w_{3}$ are the same. The term $w_{2}$ can be expressed by the energy terms, i.e., the energy for crack nucleation, $E_{1}$ and the energy for a crack propagation, $E_{2} \cdot E_{2}$ consists of the work in making free surface $w_{4}$, and the work epent in plastic deformation, $w_{5}$. If $\mathrm{E}_{1}$ does not change much in two specimens, the one with short cracks has greater $w_{5}$, and is actually less brittle then the one with longer cracks.

First, the cracks observed in $\mathrm{NbFe}_{2}$ started at four corners which have highest stress concentration, and propagated straightly to a length of approximately $90 \mu$. We shall call this type nf deformation "A".

Second, the cracks of $\mathrm{TaFe}_{2}$, the hardness of which was nearly the same as that of $\mathrm{NbFe}_{2}$, started mainly at the corners, but their shapes became wavy and their length relatively short (average $38.8 \mu$ ). We shall call this type "B". And as shown in Figs. 20 and 26, some regions which seemed to deform plastically were observed. We shall call this type "C". TaFe 2 
could be more ductile at room temperature than $\mathrm{NbFe}_{2}$ because of the shorter crack length.

Third, the cracks in $\mathrm{TiFe}_{2}$ started not only at the corners but the edges, and became wavièr, (type B). Its crack length was $4 I \mu$. The types of deformation observed in $\mathrm{ZrFe}_{2}$ and $\mathrm{HfFe}_{2}$ were quite similar. Both

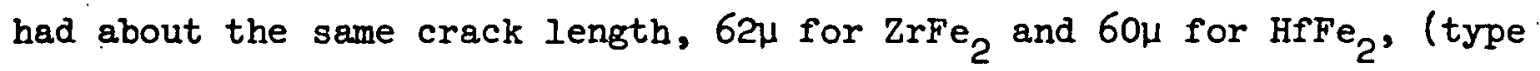
A) and also type C deformation.

The summary of those observation is given in Table $V$.

No reports on the plastic deformation of Laves phase at room temperature have been made except a short note on $\mathrm{HoZn}_{2^{\cdot}}{ }^{3}$ D. J. Michel and E. Ryba conducted compression tests on $\mathrm{HoZn}_{2}$ at room temperature and showed that the specimen after testing revealed considerable cross-twinning as well as additional other type twins. This was concluded as a direct evidence for a small amount of localized plastlc deformation. The same authors reported in recent work ${ }^{4}$ that there was no detectable plastic deformation since a plot of stress against the average strain above the low stress-low strain region was found to be linear. D. J. Moran ${ }^{2}$ found that the compressive ductility of a single crystal of $\mathrm{MgCu}_{2}$ began at $450^{\circ} \mathrm{C}$ $\left(0.65 \mathrm{~T} / \mathrm{T}_{\mathrm{m}}\right)$. The tensile ductility was characterlzed by an abrupt brittleductile transition at $600^{\circ} \mathrm{C}\left(0.8 \mathrm{~T} / \mathrm{T}_{\mathrm{m}}\right)$.

B. The Effects of Precipitation of $\mathrm{MbFe}_{2}$ and $\mathrm{TaFe}_{2}$ on the Mechanical Properties of Fe-1.78 at.\% Nb and Fe-1.96 at.\% Ta Alloys

Two high hardness Laves phases, $\mathrm{NbFe}_{2}$ which deformed (type A) and $\mathrm{TaFe}_{2}$ (types $B$ and $C$ ) were chosen. The iron-rich side of those phase diagrams is shown in Fig. 33. No other precipitates except Laves phases $\mathrm{NbFe}_{2}$ for $\mathrm{Nb2}$ and $\mathrm{IaFe}_{2}$ for $\mathrm{Ta} 2$, form in these systems. 


\section{Aging Kinetics}

The structures of $\mathrm{Nb} 2$, i.e., Fe-1.78 at.\% $\mathrm{Nb}$ alloy and Ta2, i.e., Fe-1.96 at.\% Ta alloy when quenched from $\delta$ phase region consisted of homogeneous ferrite with a grain size of about ASTM No. 1 (Fig. 34).

As shown in Figs. 35 and 36, the precipitation-hardening behavior of $\mathrm{Nb} 2$ and $\mathrm{Ta} 2$ are quite similar except that the hardness peaks of $\mathrm{Nb} 2$ ure shifted to a shorter time... Aging at $600^{\circ} \mathrm{C}, 700^{\circ} \mathrm{C}$, and $800^{\circ} \mathrm{C}$ in both alloys showed single peaks. Figure 37 shows the microstructures of these alloys which correspond to the aging peak at $700^{\circ} \mathrm{C}$.

Spelch ${ }^{5}$ who worked on Fe-3.80 wt.\% $\mathrm{Nb}$ alloy, reported that precipitation occurs first at grain boundary, then dislocations and finally in the matrix. The precipitates were found to be plate-like and formed on $\{110\}_{\alpha}$.

2. Mechanical Properties of Fe-1.78 at.\% Nb and Fe-1.96 at.\% $\mathrm{Ta}$ Alloys

As shown in Fig. 37, both alloys have massive continuous precipitates at grain boundary, which are detrimental to the ductility of the material. In order to make the massive grain boundary precipitates discontinuous and spheroidized, the transformation treatment suggested by R. H. Jones ${ }^{17}$ was employed. Materials were heated in the $\gamma+$ Laves phase region, i.e. at temperatures of $1100^{\circ} \mathrm{C}, 1050^{\circ} \mathrm{C}$ and $1000^{\circ} \mathrm{C}$, and held for 10 and 60 minutes, followed by air cooling.

The mechanical properties of these materials are given in Table VI. Ta2 specimens displayed higher strength and better ductility than Nb2. The longer the transformation treatment and the higher the temperature of the transformation treatment, the better the ductility of the specimens. This tendency is evident in $\mathrm{Ta}$. 
Figures 38 and 39 show the optical microstructures of $\mathrm{Nb} 2$ and $\mathrm{Ta} 2$, which were air cooled from $1100^{\circ} \mathrm{C}$ and $1000^{\circ} \mathrm{C}$. Here, the matrix transforms twlce, i.e. the ferrite with bcc structure first changes to austenite (with fcc structure), which transforms again to ferrite (with bcc structure) by slow cooling from the austenite region.

The morphology of the precipitates is shown more clearly in the scanning electron microstructure; Fig. 40 for Nb2 and Fig. 41 for Ta2. The grain boundary precipitate of $1100^{\circ} \mathrm{C}$ for 60 minutes treatment was almost completely spheroidized, while that of $1000^{\circ} \mathrm{C}$ treatment was only partially spheroidized. That of $1050^{\circ} \mathrm{C}$ was the intermediate stage between these two. Coarsening of the precipitates was more dominant in. Nb2 than Ta2.

There are no diffusion data available for niobium and tantalum in iron, but it is considered that their activation parameters including the diffusion coefficient would not differ much due to the small difference of atomic radius between the two elements. Furthermore, as shown in Fig. 40 a large number of needle-like precipitates which are considered to be unstable, were observed in the $\mathrm{Nb} 2$ specimen of $1000^{\circ} \mathrm{C}, 60 \mathrm{~min}$. transformation treatment. It turns out that drastic change of morphology of the precipitate in $\mathrm{Nb} 2$ would not be explained simply by the diffusion theory. The difference of the matrix-precipitate interface reaction and the surface energy of the precipitates between the two alloys is thought to play an important role in the transformation treatment. Jones et al. ${ }^{18}$ reported the existence of a precipitate-free zone lying adjacent to the grain boundary and adjacent to clusters of dislocationnucleated precipitate in aged Fe-1.8 wt.\% $\mathrm{Nb}$ alloy. As shown in Figs. 40 
and 41 , the denuded zone at the retained $\delta$ grain boundary is predominant in Nb2. Figure 42 shows the niobium change across a retained $\delta$ grain boundary which was analyzed continuously with $0.5 \mu$ steps by an electron microprobe analyzer (MAC's Model 400). In case of Ta2, the tantalum change could not be observed because of the narrow depleted zone. Figure 43 shows the scanning electron mircographs of the fractured surface. The fracture of $\mathrm{Nb} 2$ occurred at the retained $\delta$ grain boundary. Figure $43(\mathrm{~b})$ shows a lot of dimples in the Ta matrix. Tensile specimens of $\mathrm{Mb} 2$ fractured intergranularly at the retained $\delta$ grain boundary is the main cause of low strength and low ductility. Those of Ta2, on the other hand, Practured transgranularly (at the $\delta$ grain boundary), resulted in higher elongation and higher reduction of area. 


\section{SUMMARY AND CONCLUSIONS}

The mechanical properties of the Laves phase, $\mathrm{NbFe}_{2}, \mathrm{TaFe}_{2}, \mathrm{TiFe}_{2}$, $\mathrm{ZrFe}_{2}$ and $\mathrm{HFFe}_{2}$ have been studied by using a micro Vickers hardness tester.

1. The highest strengths, over $\mathrm{Hv} .1000$, was obtained in $\mathrm{NbFe}_{2}$ and $\mathrm{TaFe}_{2}$. The hardness of $\mathrm{TiFe}_{2}$ and $\mathrm{ZrFe}_{2}$ was relatively low (Hv. 859). $\mathrm{HfFe}_{2}$ showed intermediate hardness (Hv. 943).

2. From the observation of the deformation around the hardness indentation, $\mathrm{TaFe}_{2}$ is considered to be more ductile than $\mathrm{NbFe}_{2} \cdot \mathrm{NbFe}_{2}$ deformed in more brittle way, while $\mathrm{TaFe}_{2}, \mathrm{ZrFe}_{2}$ and $\mathrm{HfFe}_{2}$ appeared to deform plastically.

The effects of $\mathrm{NbFe}_{2}$ and $\mathrm{TaFe}_{2}$ on the mechanical properties of the $\mathrm{Fe}-1.78$ at.\% $\mathrm{Nb}$ and $\mathrm{Fe}-1.96$ at.\% $\mathrm{Ta}$ alloys have been investigated.

3. By a transformation treatment, continuous grain boundary precipitates can be spheroidized.

4. Both the strength and ductility of the Fe-1.96 at.\% Ta alloy were superior to those of the $\mathrm{Fe}-1.78$ at.\% $\mathrm{Nb}$ alloy. The former fractured transgranularly at the retained $\delta$ grain boundaries and the latter fractured intergranularly.

5. A remarkable grain boundary denuded zone was observed in the Fe1.78 at.\% $\mathrm{Nb}$ alloy, while not in the Fe-1.96 at.\% $\mathrm{Ta}$ alloy.

6. For future work, an investigation of the thermo-mechanical treatment a and the heat treatment of binary and ternary alloys might be studied in order to improve the mechanical properties. The high temperatures properties (creep rupture, oxidation, etc.) as well as the room temperature properties in ternary or quartinary systems would be of interest. 


\section{ACKNOWLEDGEMENTS}

The author wishes to express his appreciation and deep gratitude to Professor Victor F. Zackay and Professor Earl R. Parker for their continued guidance, support and encouragements throughout the course of this investigation. Special thanks are due to Mr. George Golden and Mr. Russel H. Johns for the helpful suggestions and discussions.

Thanks are also due to Mrs. Gloria Pelatowski for her help in preparing the art work and to Mrs. Shlrley Ashley, Miss Jane Bell and Mrs. Linda LeBorgne for their help in typing.

This work, was performed under the auspices of the U.S. Atomic Energy Commission through the Inorganic Materials Research Division of the Lawrence Radiation Laboratory, Berkeley. 
TABLE III. Structure and hardness of the Laves phase

\begin{tabular}{|c|c|c|c|c|}
\hline No. & Compositions (at.\%) & Structure & Range & $\begin{array}{l}\text { Hardness (Hv) } \\
\text { Average }\end{array}$ \\
\hline \multirow[t]{2}{*}{1.1} & $\mathrm{Nb} 23.0$ & $\alpha-F e$ & $308-390$ & 349.0 \\
\hline & & $\mathrm{NbFe}_{2}$ & $582-762$ & 672.0 \\
\hline 12 & $\mathrm{Nb} 33.0$ & $\mathrm{NbFe}_{2}$ & $1051-1097$ & 1076.3 \\
\hline 13 & $\mathrm{Nb} 42.0$ & $\mathrm{NbFe}_{2}$ & $1028-1097$ & 1049.0 \\
\hline \multirow[t]{2}{*}{21} & $\mathrm{Ta} 27.0$ & $\alpha-F e$ & $322-472$ & 397.0 \\
\hline & & $\mathrm{TaFe}_{2}$ & $685-762$ & 736.3 \\
\hline 22 & Ta 33.0 & $\mathrm{TaFe}_{2}$ & $954-1019$ & 983.3 \\
\hline 23 & Ta 33.0 & $\mathrm{TaFe}_{2}$ & $998-1089$ & 1035.7 \\
\hline \multirow[t]{2}{*}{31} & $\mathrm{Ti} 25.0$ & $\alpha-\mathrm{Fe}$ & $346-501$ & 424.0 \\
\hline & & $\mathrm{TiFe}_{2}$ & $730-810$ & 770.7 \\
\hline 32 & $\mathrm{Ti} 33.0$ & $\mathrm{TiFe}_{2}$ & $792-845$ & 821.2 \\
\hline 33 & $\mathrm{Ti} 35.0$ & $\mathrm{TiFe}_{2}$ & $845-923$ & 886.4 \\
\hline \multirow[t]{2}{*}{41} & $\mathrm{Zr} 23.0$ & $\begin{array}{l}\alpha-F e \\
\text { (entectic) }\end{array}$ & $420-493$ & 461.1 \\
\hline & & $\mathrm{ZrFe}_{2}$ & $864-940$ & 914.2 \\
\hline 42 & $\mathrm{Zr} 33.0$ & $\mathrm{ZrFe}_{2}$ & $826-894$ & 859.3 \\
\hline 51 & He 33.0 & $\mathrm{HFFe}_{2}$ & $898-982$ & 942.9 \\
\hline
\end{tabular}


TABLE IV. Crystal structure, electron-atom ratio and lattice parameter of the Laves phases.

\begin{tabular}{|c|c|c|c|c|c|c|}
\hline $\begin{array}{l}\text { Laves } \\
\text { Phase }\end{array}$ & $\begin{array}{l}\text { Crystal } \\
\text { Structure }\end{array}$ & $\begin{array}{l}\text { Electron: } \\
\text { Atom Ratio }\end{array}$ & $\begin{array}{l}\text { Lattic } \\
(\AA) \\
c\end{array}$ & $\begin{array}{c}\text { e Param } \\
(\AA) \\
A\end{array}$ & $\begin{array}{l}\operatorname{ter}^{* I} \\
\mathrm{C} / \mathrm{A} \\
\end{array}$ & $\begin{array}{c}\text { Goldschmidt Radius } \\
\text { Ratio }\end{array}$ \\
\hline $\mathrm{NbFe}_{2}$ & $\mathrm{MgZn}_{2}$ & 7.00 & 7.880 & 4.834 & 1.630 & 1.137 \\
\hline $\mathrm{TaFe}_{2}$ & $\mathrm{MgZn}_{2}$ & 7.00 & 7.838 & 4.827 & 1.624 & $1.138^{\circ}$ \\
\hline $\mathrm{TiFe}_{2}$ & $\mathrm{MgZn}_{2}$ & 6.67 & 7.761 & 4.799 & 1.624 & 1.137 \\
\hline $\mathrm{ZrFe}_{2}$ & $\begin{array}{l}\mathrm{MgCu}_{2} \\
\mathrm{MgCu}_{2} *^{3}\end{array}$ & $\begin{array}{l}6.67 \\
6.67\end{array}$ & $\begin{array}{l}- \\
-\end{array}$ & $\begin{array}{l}7.053 \\
7.025\end{array}$ & $\begin{array}{l}- \\
-\end{array}$ & 1.250 \\
\hline $\mathrm{HfFe}_{2}$ & $\begin{array}{l}\mathrm{MgZn}_{2} \\
\mathrm{MgNi}_{2}\end{array}$ & 6.67 & 16.167 & $\begin{array}{r}4.978 \\
4.968\end{array}$ & $\begin{array}{l}1.631 * \\
3.254 * 5\end{array}$ & 1.236 \\
\hline
\end{tabular}

*I From "Handbook of Lattice Spacing and Structure of Metals and Alloys"ll

*2 From (7). Radii of $\mathrm{Zr}$ and Hf are from (13)

*3 Allotropic modification occuring at low temperature

*4 From (7)

*5 From (12) 
TABLE V. Observation of deformation around the hardness Indentations

\begin{tabular}{|c|c|c|c|}
\hline $\begin{array}{l}\text { Lavés } \\
\text { Phase }\end{array}$ & observation of Deformation & $\begin{array}{l}\text { Crack length } \\
\text { at the: corner } \\
\quad(\mu)\end{array}$ & $\begin{array}{l}\text { Type of } \\
\text { Deformation }\end{array}$ \\
\hline $\mathrm{NbFe}_{2}$ & $\begin{array}{l}\text { Long straight cracks at the } \\
\text { corners }\end{array}$ & $\begin{array}{l}159.6-66.4 \\
\text { av. } 91.2\end{array}$ & A \\
\hline $\mathrm{TaFe}_{2}$ & $\begin{array}{l}\text { Short wavy cracks mainly at } \\
\text { the corners }\end{array}$ & $\begin{array}{l}30.2-47.3 \\
\text { av. } 38.8\end{array}$ & $B$ and $C$ \\
\hline $\mathrm{T}_{1 F e_{2}}$ & $\begin{array}{l}\text { Short wavy cracks at the } \\
\text { corners and the edges }\end{array}$ & $\begin{array}{l}37.5-50.0 \\
\text { av. } 40.8\end{array}$ & B \\
\hline $\mathrm{ZrFe}_{2}$ & $\begin{array}{l}\text { Long straight cracks at the } \\
\text { corners } \\
\text { Plastically deformed region }\end{array}$ & $\begin{array}{l}57 \cdot 3-74.5 \\
\text { av. } 62.2\end{array}$ & $A$ and $C$ \\
\hline $\mathrm{HfFe}_{2}$ & $\begin{array}{l}\text { Long straight cracks at the } \\
\text { corners } \\
\text { Plastically deformed region }\end{array}$ & $\begin{array}{l}44.3-77.6 \\
\text { av. } 60.2\end{array}$ & $A$ and $C$ \\
\hline
\end{tabular}

Type A refers to specimens with long straight cracks at the corners

Type B refers to specimens with wavy short cracks both at the corners and edges.

Type C refers to specimens which appear to deform plastically. 
TABLE VI. Tensile properties of the alloys

\begin{tabular}{|c|c|c|c|c|c|}
\hline Material & $\begin{array}{l}\text { Heat } \\
\text { Treatment } \\
\left({ }^{\circ} \mathrm{C}, \text { min. }\right)\end{array}$ & $\begin{array}{l}\text { Yield } \\
\text { Stress } \\
0.2 \% \text { psi }\end{array}$ & $\begin{array}{l}\text { Tensile } \\
\text { Strength } \\
\quad \text { psi }\end{array}$ & Elongation \% & $\begin{array}{l}\text { Reduction } \\
\text { of area \% }\end{array}$ \\
\hline $\mathrm{Nb} 2$ & $\begin{aligned} 1380, & 60 W Q \\
700, & 30 A C \\
1100, & 10 A C\end{aligned}$ & 49,400 & 58,800 & 3.2 & 8.8 \\
\hline $\mathrm{Nb} 2$ & $\begin{array}{r}1380,60 W Q \\
700, \text { 30AC } \\
1100,60 A C\end{array}$ & 51,700 & 58,300 & 5.1 & 33.9 \\
\hline $\mathrm{Nb} 2$ & $\begin{array}{r}1380,60 W Q \\
700,30 \mathrm{AC} \\
1050,60 \mathrm{AC}\end{array}$ & 47,700 & 61,900 & 7.4 & 20.6 \\
\hline $\mathrm{Nb2}$ & $\begin{array}{r}1380,60 \mathrm{WQ} \\
700,30 \mathrm{AC} \\
1000,60 \mathrm{AC}\end{array}$ & 42,200 & 47,200 & 3.2 & 11.5 \\
\hline $\mathrm{Ta2}$ & $\begin{array}{r}1400,60 \mathrm{WQ} \\
700,40 \mathrm{AC} \\
1100,10 \mathrm{AC}\end{array}$ & 50,200 & 69,600 & 18.9 & 33.9 \\
\hline $\mathrm{Ta} 2$ & $\begin{array}{r}1400,60 \mathrm{WQ} \\
700,40 \mathrm{AC} \\
1100,60 \mathrm{AC}\end{array}$ & 48,600 & 68,200 & . 31.1 & 68.8 \\
\hline
\end{tabular}


REFTERENCES

1. R. E. Decker and S. Floreen, Copyright AIMR, p. 69, (1965).

2. J. B. Moran, Trans. of Met. Society of AIMR, Vol. 233, p. 1473 (1965).

3. D. J. Michel and E. Ryba, Trans. of Met. Society of AIME, Vol. 235, p.436, (1969).

4. D. J. Michel and E. Ryba, Met. Trans, Vol. 1, p. 544 (1970).

5. G. R. Speich, Trans, of Met. Society of AIME, Vol. 224, p. 850 (1962).

6. T. B. Massalski and H. E. King, Tables of Crystallographic Functions for Calculating Lattice Parameters of hep Metals and Alloys from X-ray Diffraction Data, Mellon Institute (1960).

7. M. Hansen, and K. Anderko, Constitution of Binary Alloys, McGrawHill, New York (1958).

8. R. P. Elliott, ibid. Suppl. (1965).

9. F. A. Shunk, ibid. Suppl. (1969).

10. L. Brewer, Prediction of High Temperature Metallic Phase Diagrams, UCRL-10701, (1965).

11. W. B. Pearson, Handbook of Lattice Spacings and Structures of Metals and Alloys, Pergamon Press, New York (1958).

12. R. P. Elliott, Trans, of ASM, Vol. 53, p. 321 (1961).

13. E. D. Gibson, B. A. Loomis and O. H. Carlson, Trans. of ASM, Vol. 20, p. 178 (1953).

14. R. P. WIliott and E. Rostoker, Trans. of ASM, Vol. 50, p. 617 (1958).

15. A. E. Dweight, Trans. of ASM, Vol. 53, p. 476 (1961).

16. V. M. Nevitt, "Alloy Chemistry of Transition Elements", paper in Electronic Structure and Alloy Chemistry of the Transition Elements, P. A. Beck, Ed., Interscience Publ., New York, 1963. 
17. R. H. Jones, to be published.

18. R. M. F. Jones and D. R. F. West, Journal of the Iron and Steel Institute, p. 270 (March 1970). 
FIGURE CAPTIONS

Fig. 1. Equilibrium phase diagram: Fe-Nb system. 8

Fig. 2. Equilibrium phase diagram: Fe-Ta system. 7

Fig. 3. Equilibrium phase diagram: Fe-Ti system. 8

Fig. 4. Equilibrium phase diagram: Fe-Zr system. 7

Fig. 5. Equilibrium phase diagram: Fe-Hf system. 9

Fig. 6. Micrograph: (a) Nb 23.0 at.\%, (b) Nb 33.0 at. \%,

(c) Nb 42:0 at.\%, 150x

F1g. 7. Micrograph: (a) Ta 27.0 at.\%, (b) Ta 33.0 at. \%,

(c) Ta 33.0 at. $\%, 150 x$

Fig. 8. Micrograph: (a) Ti 25.0 at. $\%$, (b) Ti 33.0 at. \%,

(c) Ti 35.0 at. $\%, 150 x$

F1g. 9. Micrograph: (a) $\mathrm{Zr} 23.0$ at. \%, (b) $\mathrm{Zr} 33.0$ at. \%, 150x

Fig. 10. Micrograph: Hf 33.0 at. $\%$, $150 x$

Fig. 11. Micro Vickers hardenss of Laves phases.

Fig. 12. (a) Crystal structures of $\mathrm{MgCu}_{2}$

(b) Rows of $\mathrm{Mg}$ atoms

Fig. 13. (a) Crystal structure of $\mathrm{MgZn}_{2}$

(b) Rows of $\mathrm{Mg}$ atoms in $\mathrm{MgZn}_{2}$

(c) Rows of $\mathrm{Mg}$ atoms in $\mathrm{MgNi}_{2}$

Fig. 14. X-ray diffraction data for $\mathrm{NbFe}_{2}$

Fig. 15. X-ray diffraction data for $\mathrm{TaFe}_{2}$.

Fig. 16. X-ray diffraction data for $\mathrm{TiFe}_{2}$.

Fig. 17. X-ray diffraction data for $\mathrm{ZrFe}_{2}$,

Fig. 18. X-ray diffraction data for $\mathrm{HFFe}_{2}$.

Fig. 19. Interference micrograph of the hardenss indentation:

$\mathrm{NbFe}_{2} \quad(\mathrm{Nb} 33.0$ at. \%), 300 g load, 1000x. 
Fig. 20. Interference micrograph of the hardenss indentation:
(a) $\mathrm{TaFe}_{2}$ (Ta 27.0 at. \%), 100 \& load, $800 x$
(b) $\mathrm{TaFe}_{2}$ (Ta 33.0 at. \%), $2000 \mathrm{~g}$ load, 800x

Fig. 21. Interference micrograph of the hardness indentation:

$\mathrm{TiFe}_{2}$ (Ti 35.0 at. \%), $300 \mathrm{~g}$ load, 800x

Fig. 22. Interference micrograph of the hardness indentation:

$\mathrm{ZrFe}_{2}(\mathrm{Zr} 33.0$ at: \%), 300 g load, $800 x$

Fig. 23. Interference micrograph of the hardness indentation:

Ilf Te 2 (Hf 33.0 ut. \%), 300 g logd, $800 x$

Fig. 24. Scanning electron micrograph of the hardness indentation:

(a) $\mathrm{NbFe}_{2}(\mathrm{Nb} 33.0$ at. \%), 300 g load, 2000x,

(b) higher magnification of (a), 4000x

Fig. 25. Scanning electron micrograph of the hardness indentation:

(a) $\mathrm{NbFe}_{2}$ (Nb 42.0 at. \%), $500 \mathrm{~g}$ load, $1000 x$

(b) higher magnification of (a), 5000x

Fig. 26. Scanning electron micrograph of the hardness indentation:

(a) $\mathrm{TaFe}_{2}$ ( $\mathrm{Ta} 33.0$ at. \%), $300 \mathrm{~g}$ load, 2000x

(b) higher magnification of (a), 5000x

Fig. 27. Scanning electron micrograph of the hardness indentation:

(a) $\mathrm{TaFe}_{2}(\mathrm{Ta} 33.0$ at. \%), $300 \mathrm{~g}$ load, $2000 x$

(b) TaFe (Ta 33.0 at. \%), $300 \mathrm{~g}$ load, 2000x

Fig. 28. Scanning electron micrograph of the hardness indentation:

(a) $\mathrm{TiFe}_{2}$ (Ti 25.0 at. \%), $300 \mathrm{~g}$ load, 2000x

(b) higher magnification of (a), 10,000x

Fig. 29. Scanning electron micrograph of the hardness indentation:

(a) $\mathrm{TiFe}_{2}$ (Ti 33.0 at. \%), 300 g load, 2000x

(b) higher magnification of (a), 4000x 
Fig. 30. Scanning electron micrograph of the hardness indentation:
(a) $\mathrm{TiFe}_{2}$ (Ti 35.0 at. $\%$ ), 300 g load, 2000x
(b) $\mathrm{TiFe}_{2}$ (Ti 35.0 at. \%), $300 \mathrm{~g}$ load, 2000x

Fig. 31. Scanning electron micrograph of the hardness indentation:

(a) $\mathrm{ZrFe}_{2}(\mathrm{Zr} 33.0$ at. \%), $300 \mathrm{~g}$ load, 2000x

(b) $\mathrm{ZrFe}_{2}$ ( $\mathrm{Zr} 33.0$ at. \%), $300 \mathrm{~g}$ load, 2000x

Fig. 32. Scanning electron micrograph of the hardness indentation:

(a) $\mathrm{HfFe}_{2}$ (Hf 33.0 at. \%), $300 \mathrm{~g}$ load, $2000 \mathrm{x}$

(b) $\mathrm{HfFe}_{2}$ (Hf 33.0 at. \%), $300 \mathrm{~g}$ load, 2000x

Fig. 33. Phase diagrams (iron-rich sides) of $\mathrm{Fe}-\mathrm{Nb}$ and $\mathrm{Fe}-\mathrm{Ta}$ systems.

Fig. 34. Micrograph: (a) $\mathrm{Nb}_{2}$, solution treated, $200 x$

(b) $\mathrm{Ta}_{2}$, solution treated, 200x

Fig. 35. Aging kinetics of $\mathrm{Nb}_{2}$.

Fig. 36. Aging kinetics of $\mathrm{Ta}_{2}$.

Fig. 37. Scanning electron micrograph: (a) $\mathrm{Nb}_{2}, 700^{\circ} \mathrm{C}$ for 30 min., 10,000x,

(b) $\mathrm{Ta}_{2}, 700^{\circ} \mathrm{C}$ for $40 \mathrm{~min} ., 10,000 \mathrm{x}$

Fig. 38. Micrograph: (a) $\mathrm{Nb}_{2}, 700^{\circ} \mathrm{C}$ for $30 \mathrm{~min}$, and $1100^{\circ} \mathrm{C}$ for $60 \mathrm{~min}$. $\mathrm{AC}, 2000 \times$, (b) $\mathrm{Nb}_{2}, 700^{\circ} \mathrm{C}$ for $30 \mathrm{~min} . \mathrm{AC}$ and $1000^{\circ} \mathrm{C}$ for $10 \mathrm{~min}$. $A C, 2000 x$

Fig. 39. Micrograph: (a) $\mathrm{Ta}_{2}, 700^{\circ} \mathrm{C}$ for $40 \mathrm{~min}, \mathrm{AC}$ and $1100^{\circ} \mathrm{C}$ for $60 \mathrm{~min} . \mathrm{AC}, 2000 \times(\mathrm{b}) \mathrm{Ta}_{2}, 700^{\circ} \mathrm{C}$ for $40 \mathrm{~min} . \mathrm{AC}$ and $1000^{\circ} \mathrm{C}$ for $10 \mathrm{~min} . \mathrm{AC}, 2000 x$

Fig. 40. Scanning electron micrograph of $\mathrm{Nb}_{2}$ :
(a) $700^{\circ} \mathrm{C}$ for $30 \mathrm{~min} . \mathrm{AC}$ and $1100^{\circ} \mathrm{C}$ for $60 \mathrm{~min} . \mathrm{AC}, 7000 \mathrm{x}$
(b) $700^{\circ} \mathrm{C}$ for $30 \mathrm{~min} . \mathrm{AC}$ and $1050^{\circ} \mathrm{C}$ for $60 \mathrm{~min} . \mathrm{AC}, 7000 \mathrm{x}$
(c) $700^{\circ} \mathrm{C}$ for $30 \mathrm{~min} . \mathrm{AC}$ and $1000^{\circ} \mathrm{C}$ for $60 \mathrm{~min}, \mathrm{AC}, 7000 \mathrm{x}$ 
F1g. 41. Scanning electron micrograph of $\mathrm{Nb}_{2}$ :
(a) $700^{\circ} \mathrm{C}$ for $40 \mathrm{~min} . \mathrm{AC}$ and $1100^{\circ} \mathrm{C}$ for $60 \mathrm{~min} . \mathrm{AC} ; 7000 \mathrm{x}$,
(b) $700^{\circ} \mathrm{C}$ for $40 \mathrm{~min}$. $\mathrm{AC}$ and $1050^{\circ} \mathrm{C}$ for $60 \mathrm{~min} . \mathrm{AC}, 7000 x$
(c) $700^{\circ} \mathrm{C}$ for $40 \mathrm{~min} . \mathrm{AC}$ and $1000^{\circ} \mathrm{C}$ for $60 \mathrm{~min} . \mathrm{AC}, 7000 \times$

F1g. 42. Niobium change at the grain boundary of $\mathrm{Nb}_{2}$ (microprobe analyzer).

F16.43. Scanning electron micrographs of the fractured surface: (a) $\mathrm{Nb}_{2}, 700^{\circ} \mathrm{C}$ for $30 \mathrm{~min} . \mathrm{AC}$ and $1100^{\circ} \mathrm{C}$ for $60 \mathrm{~min} . \mathrm{AC}$, 100x, (b) $\mathrm{Ta}_{2}, 700^{\circ} \mathrm{C}$ for $40 \mathrm{~min}$. $\mathrm{AC}$ and $1100^{\circ} \mathrm{C}$ for $60 \mathrm{~min}$. $A C, 100 x$. 


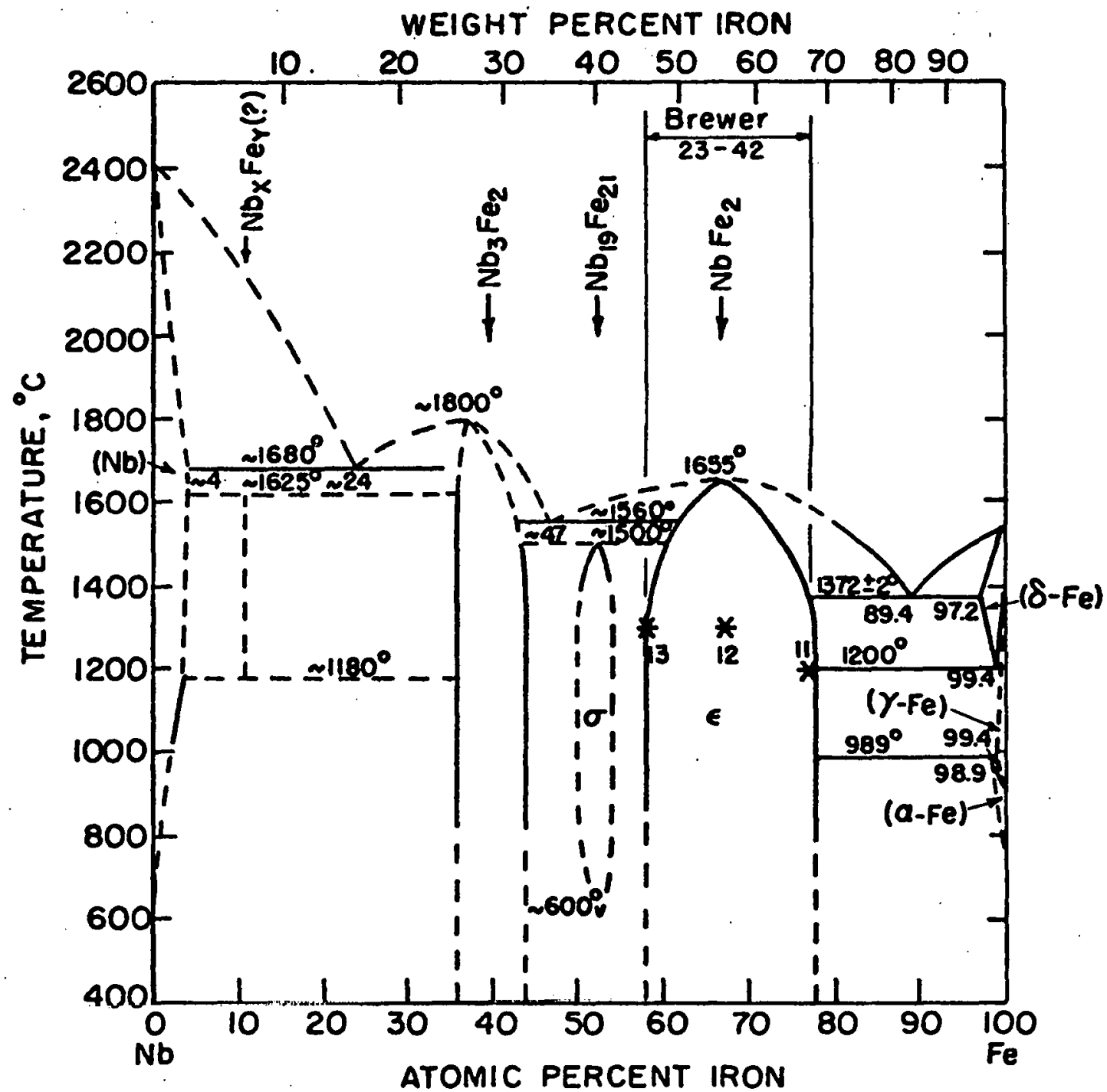

XBL $7012-7237$

Figure 1 


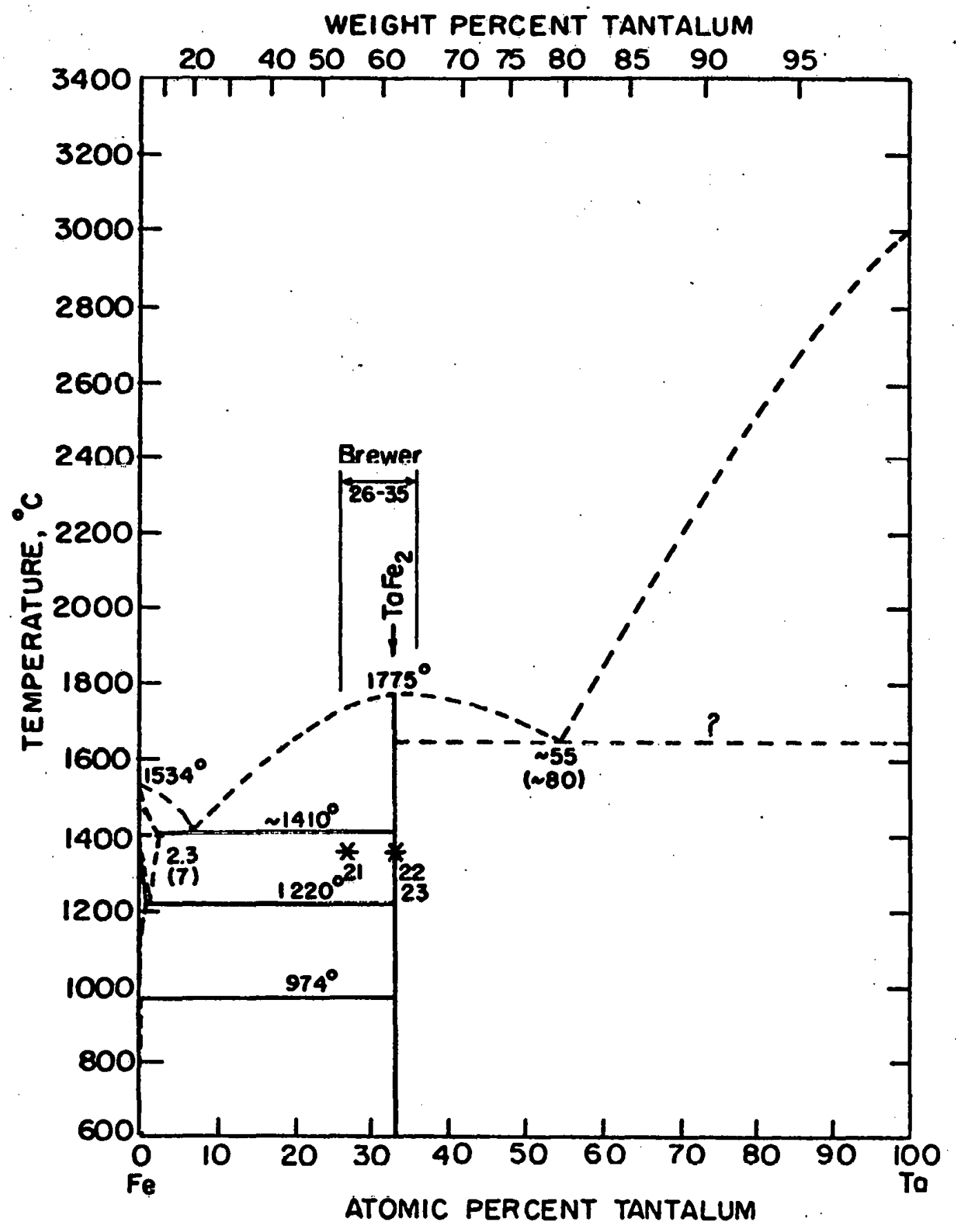

XBL $7012-7238$

Figure 2 


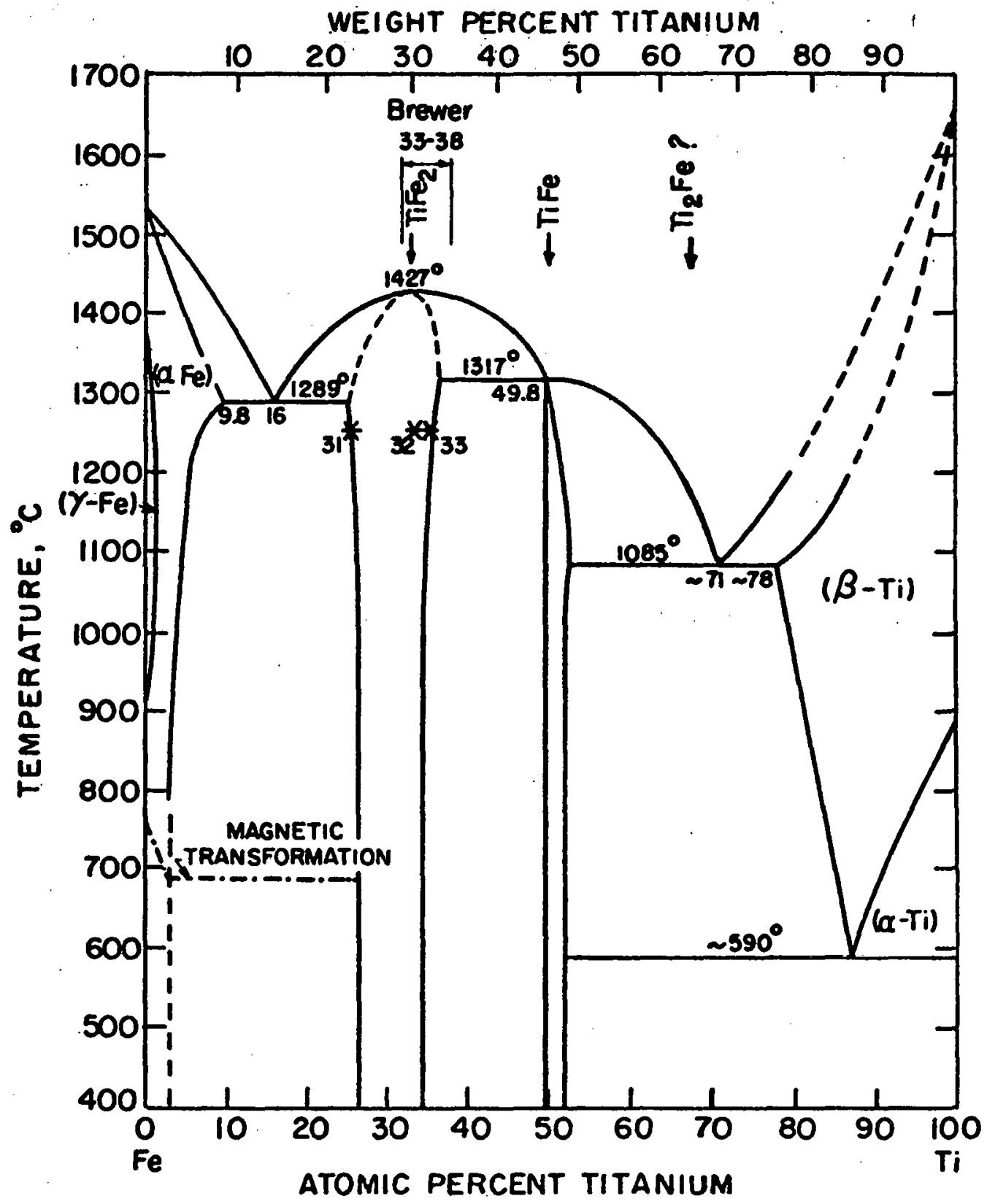

XBL $7012-7239$

Figure 3 


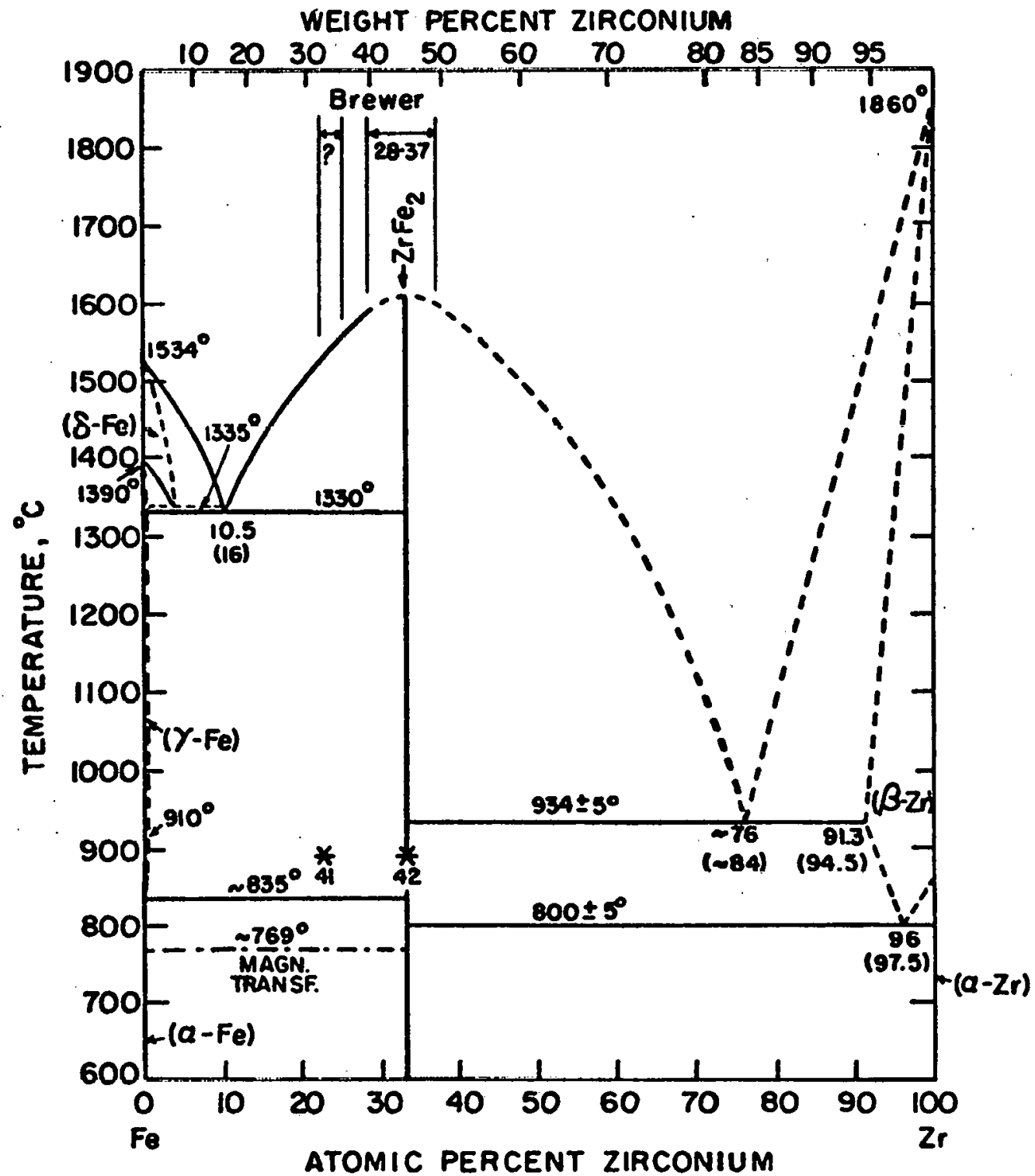

XBL $7012-7240$

Figure 4 


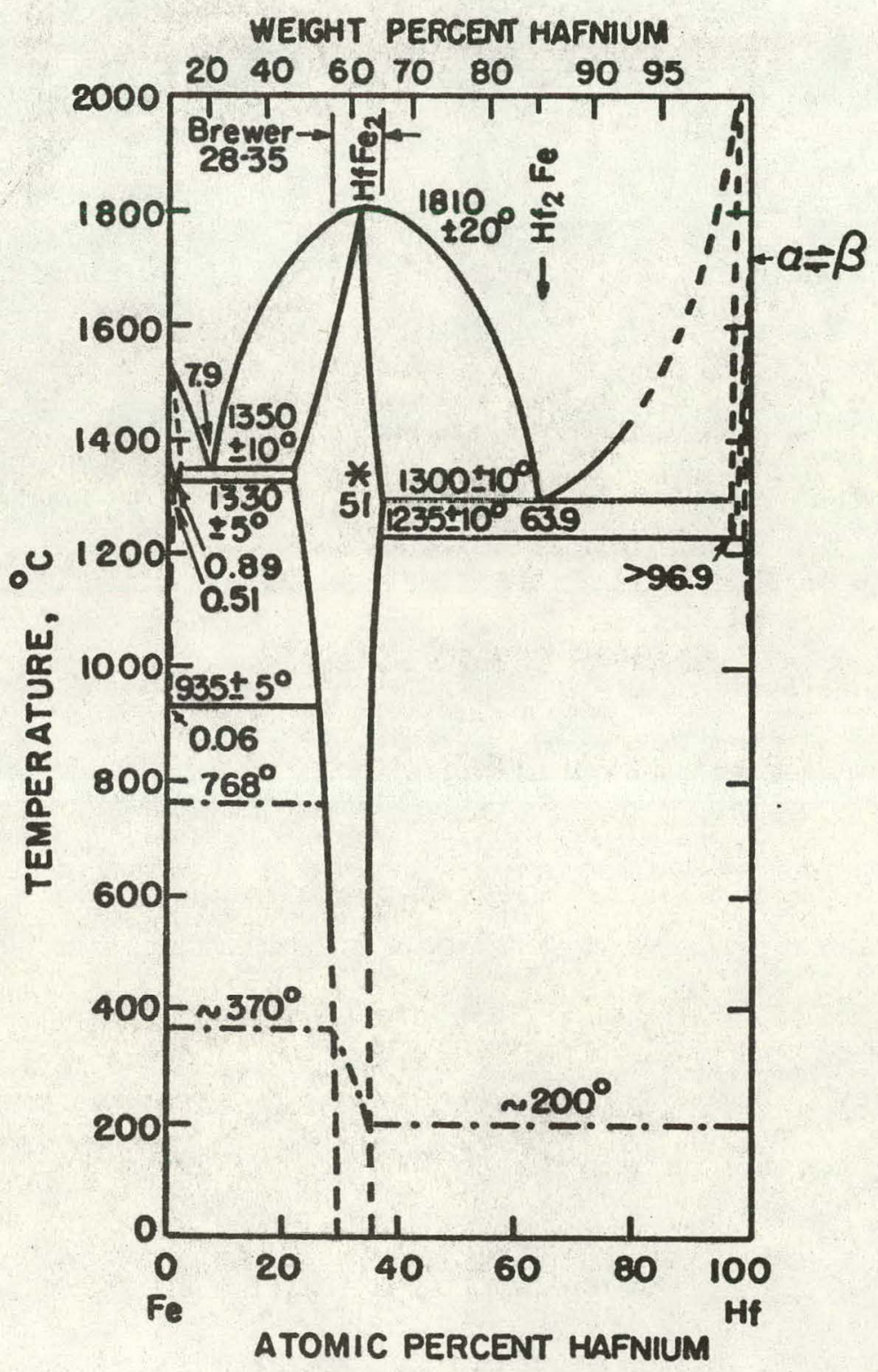

XBL $7012-7241$

Figure 5 


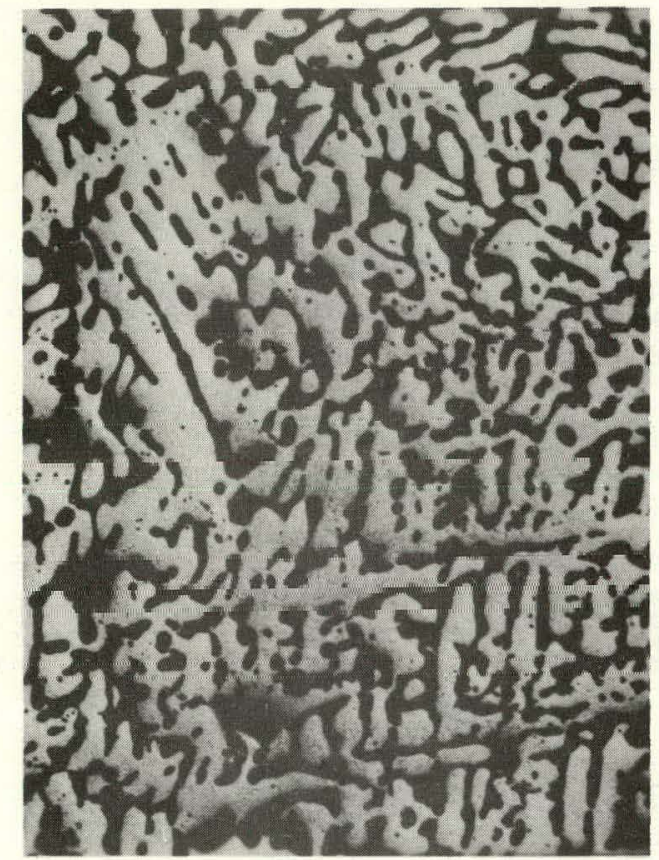

(a)

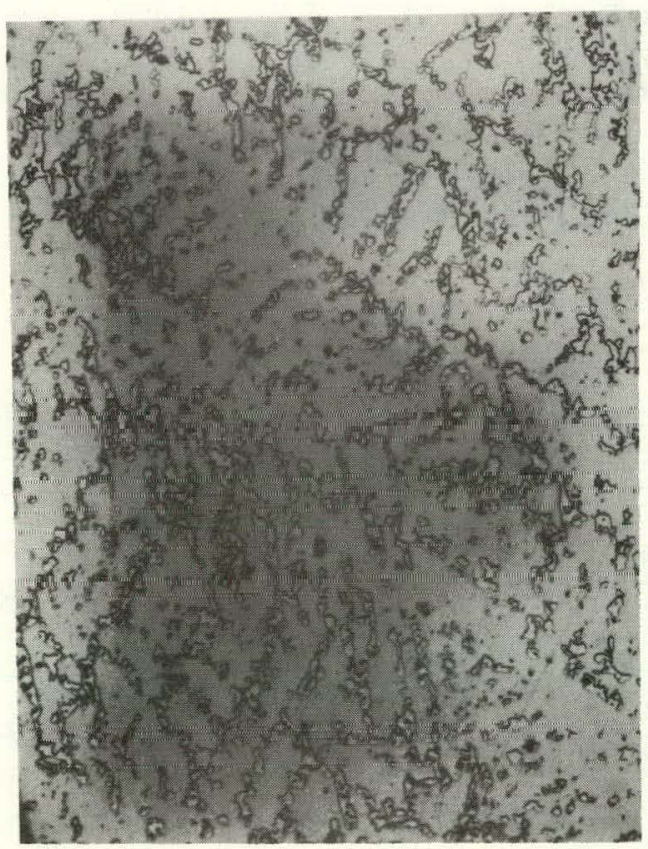

(c)

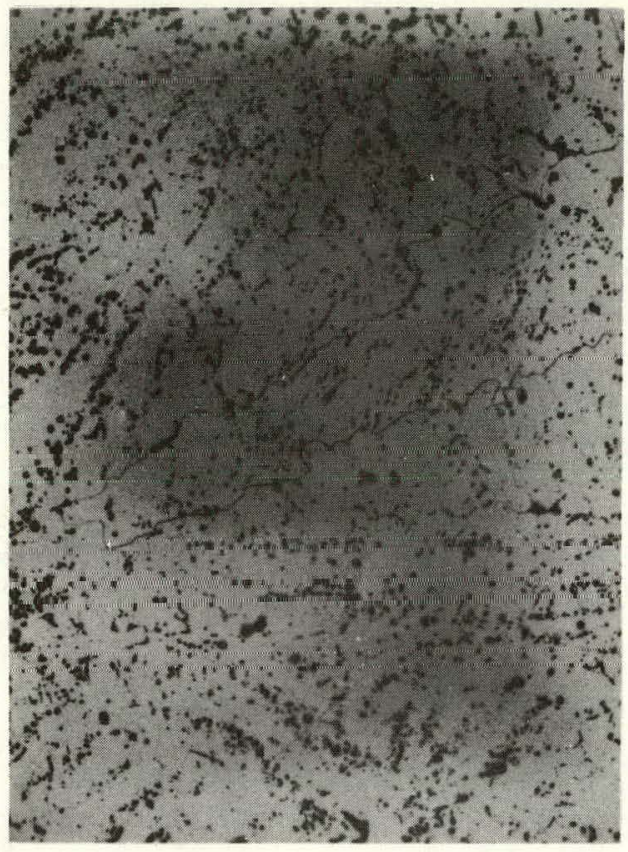

(b) 


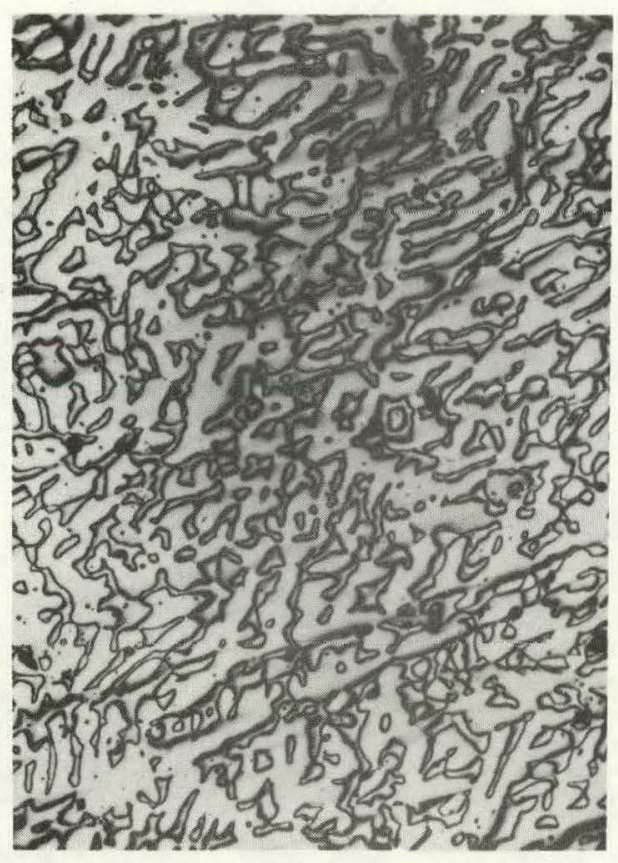

(a)

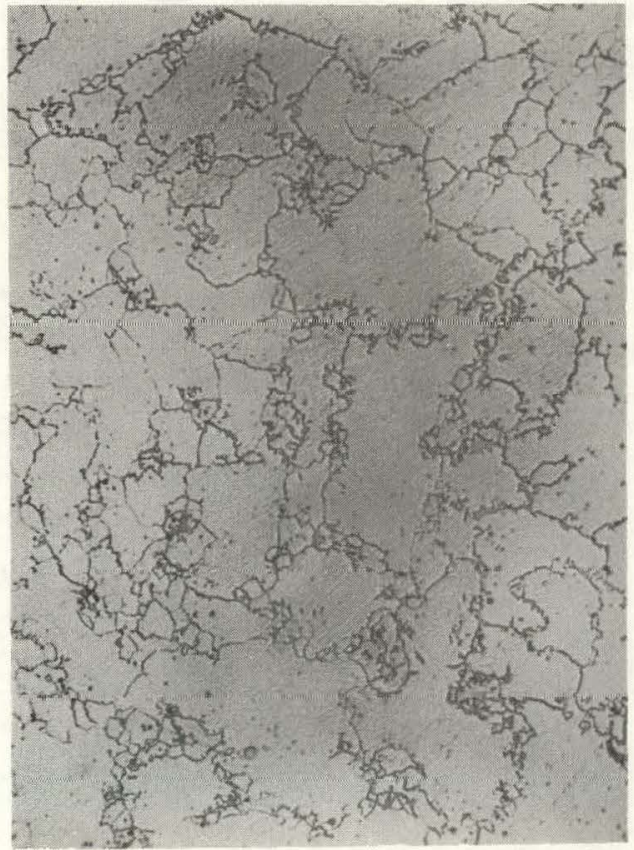

(c)

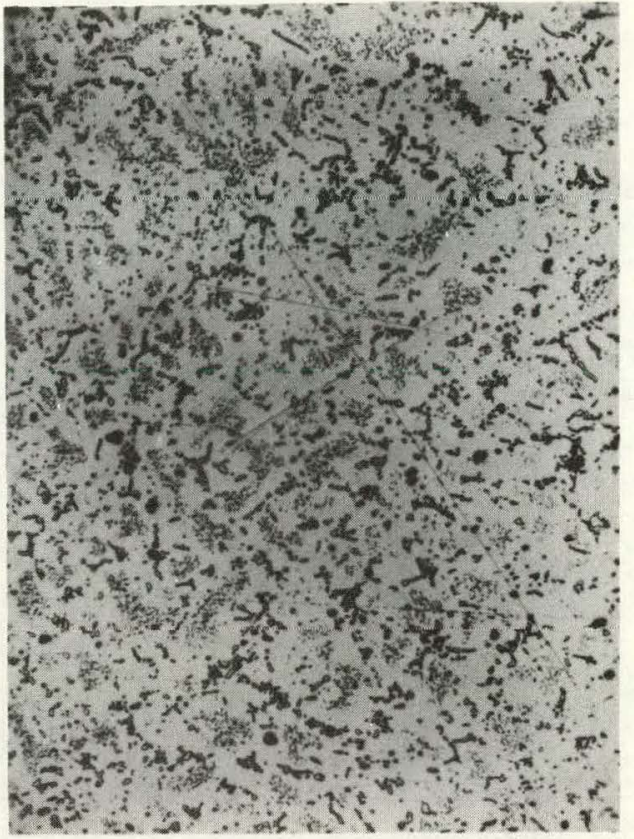

(b)

XBB7012-5408 


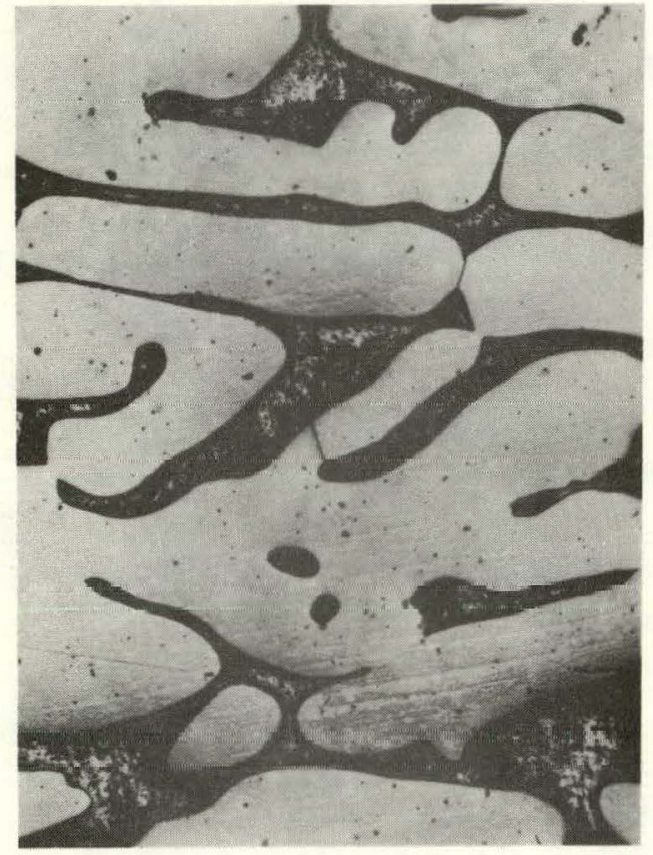

(a)

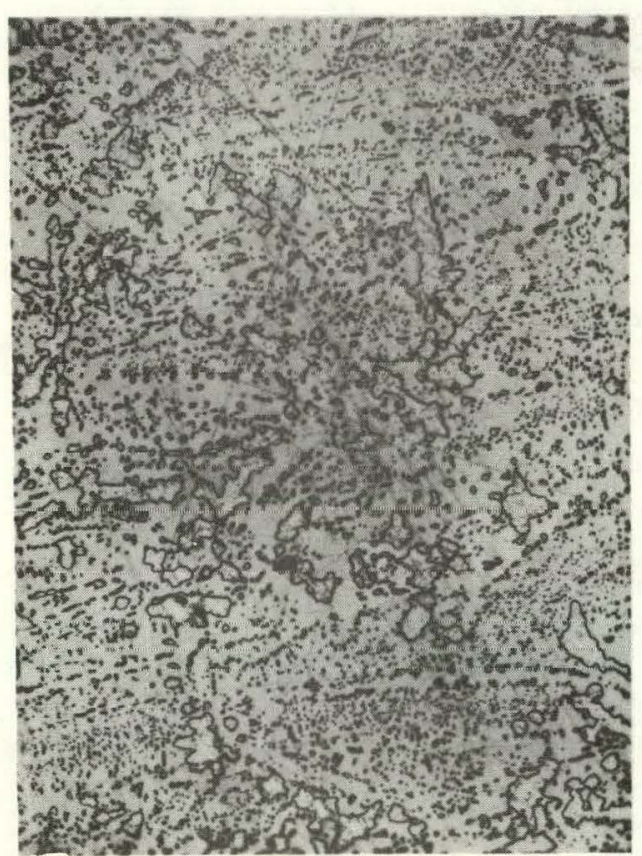

(c)

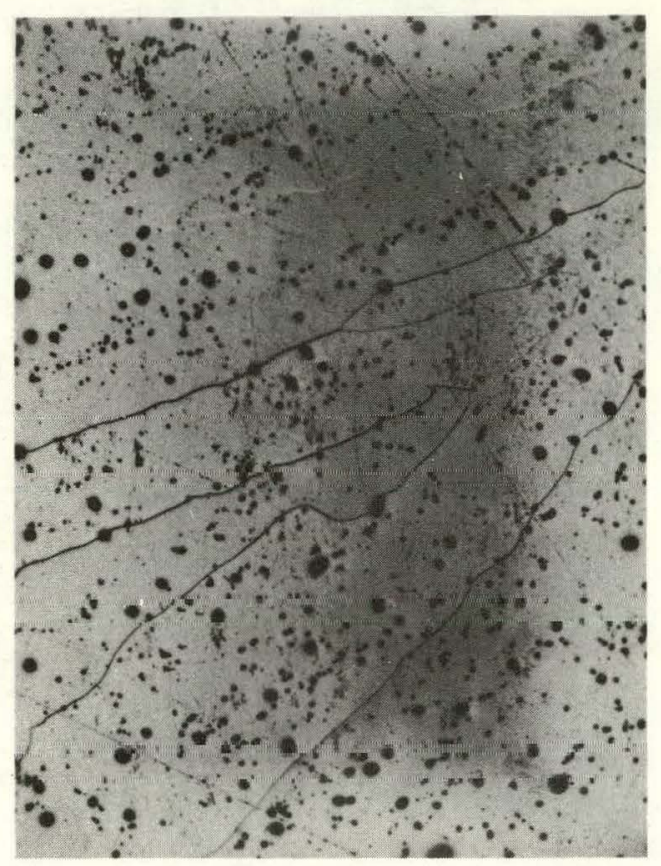

(b) 


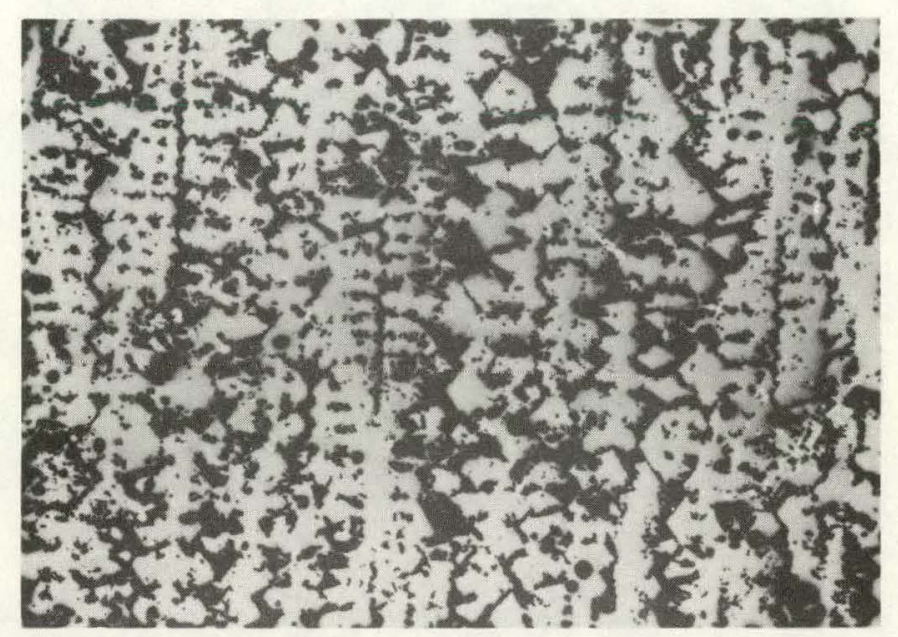

(a)

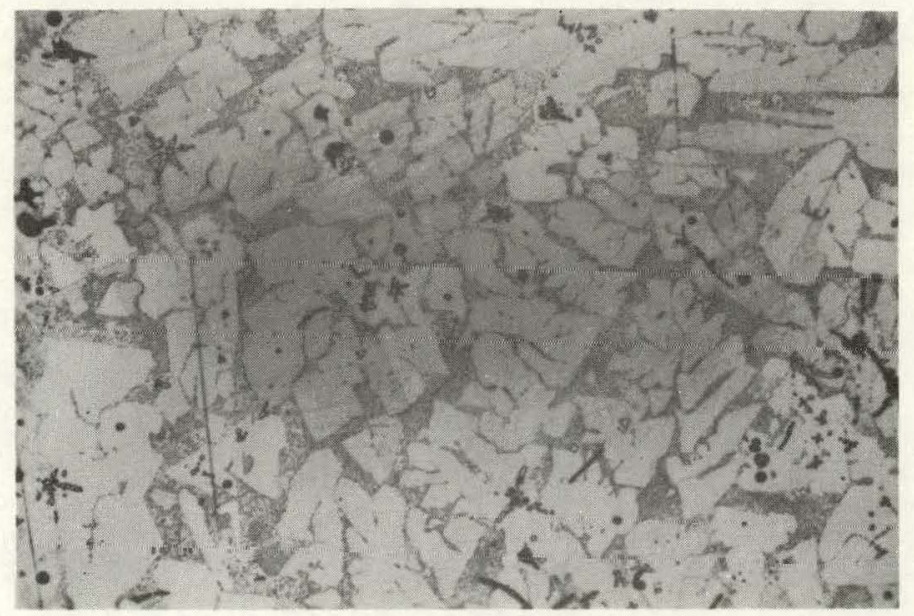

(b)

XBB7012-5407

Figure 9 


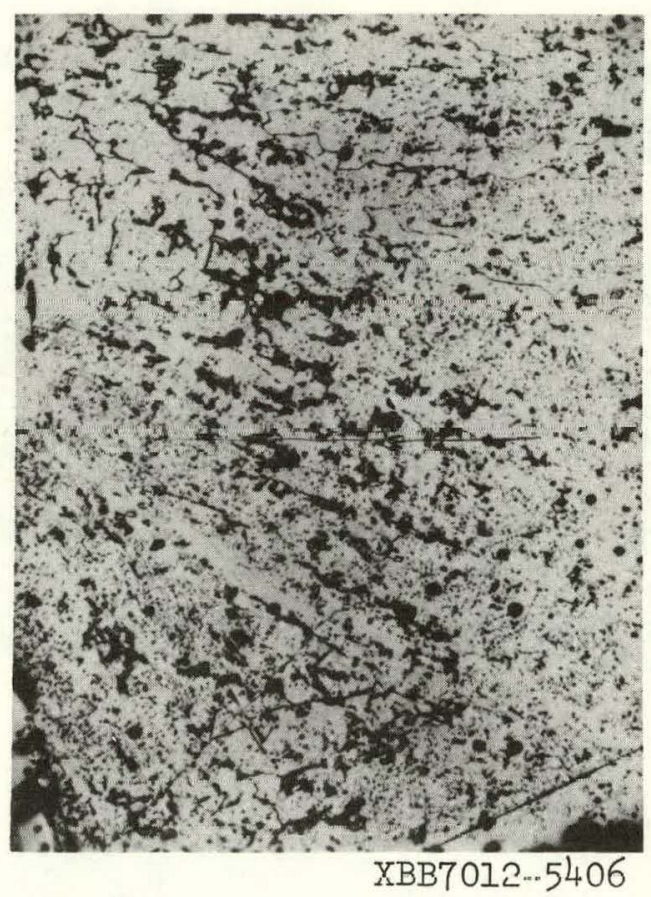

Figurc 10 


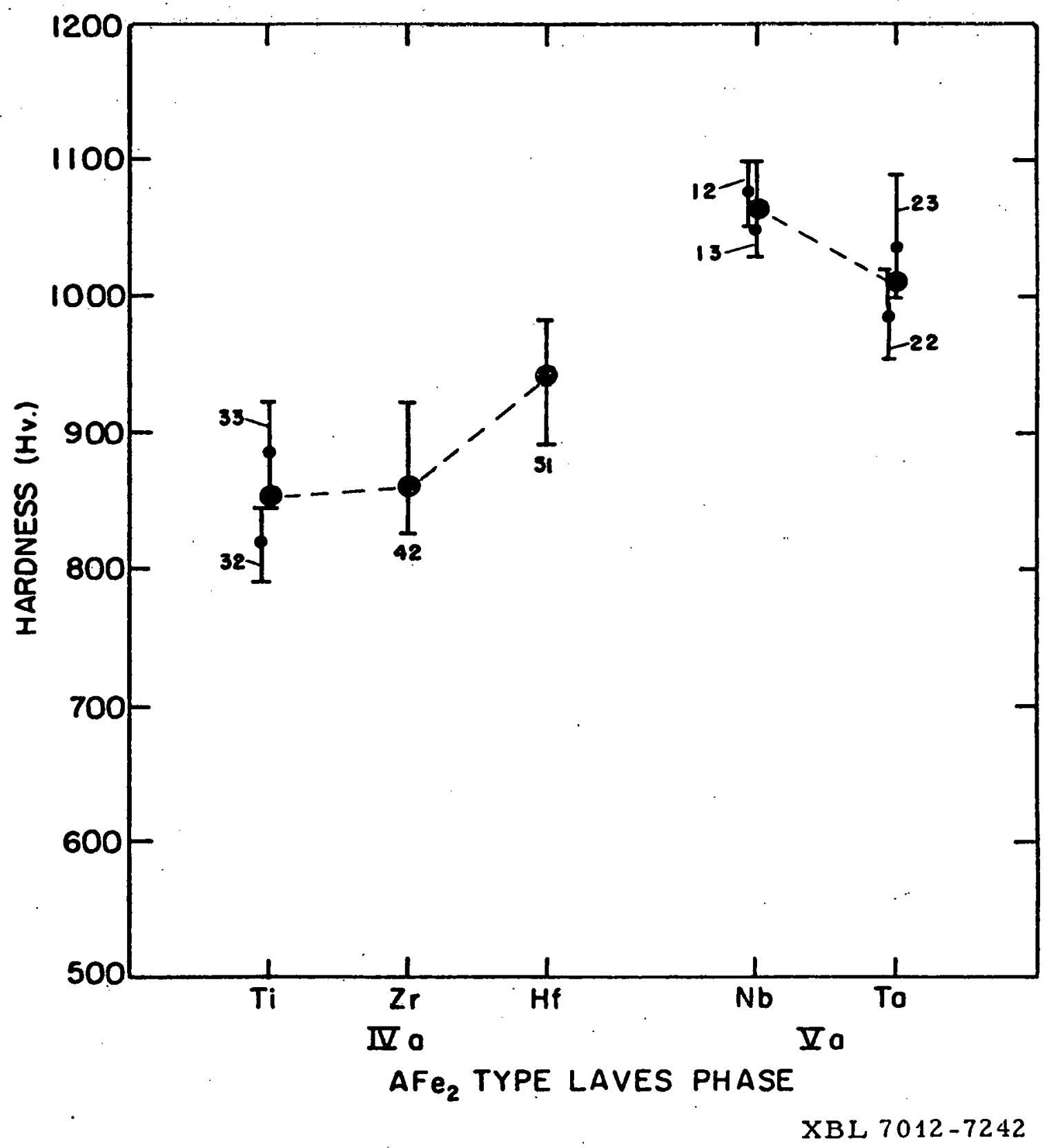

Figure 11 

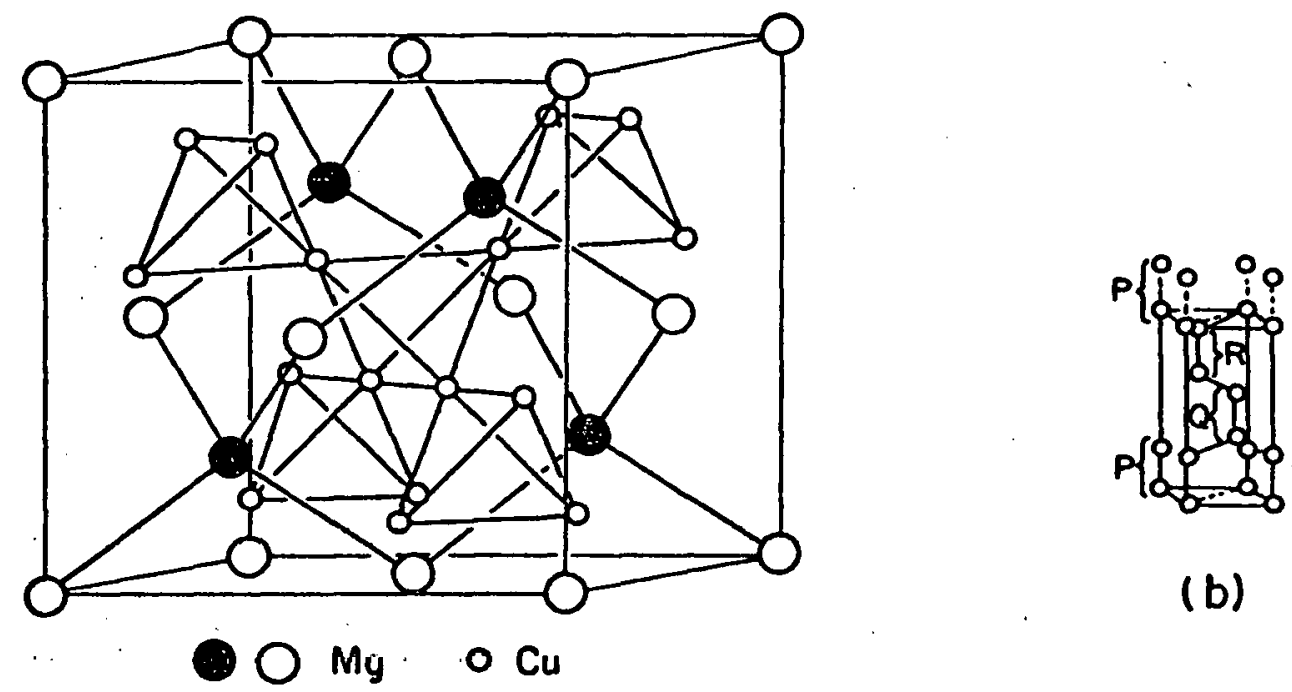

(o)

Figure 12

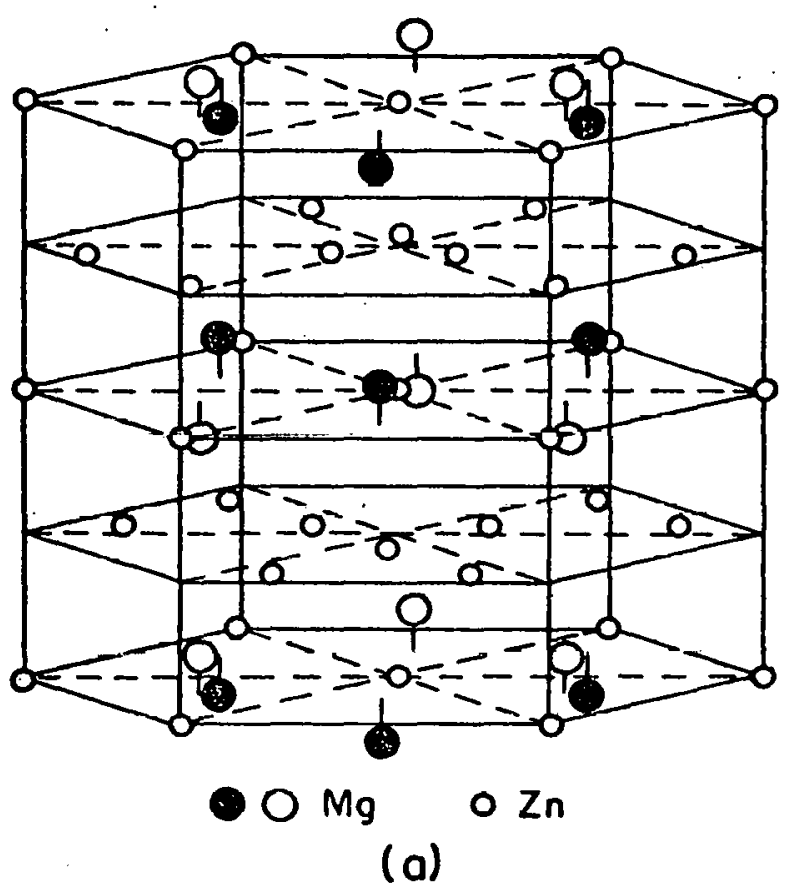

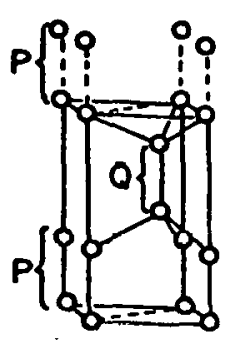

(b)

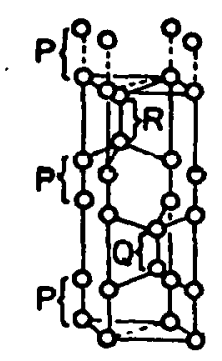

(c)

Figure 13 

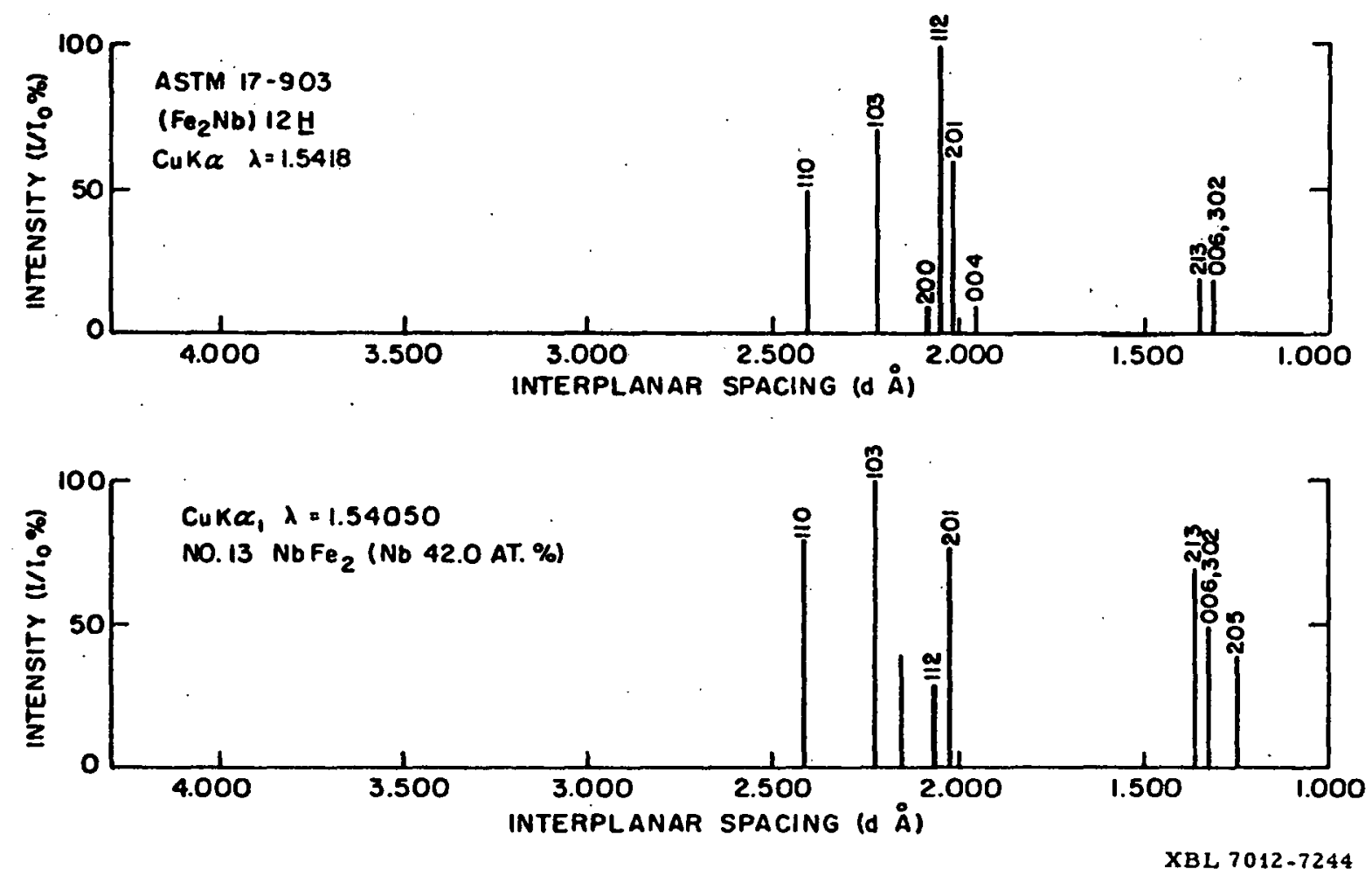

Figure 14 


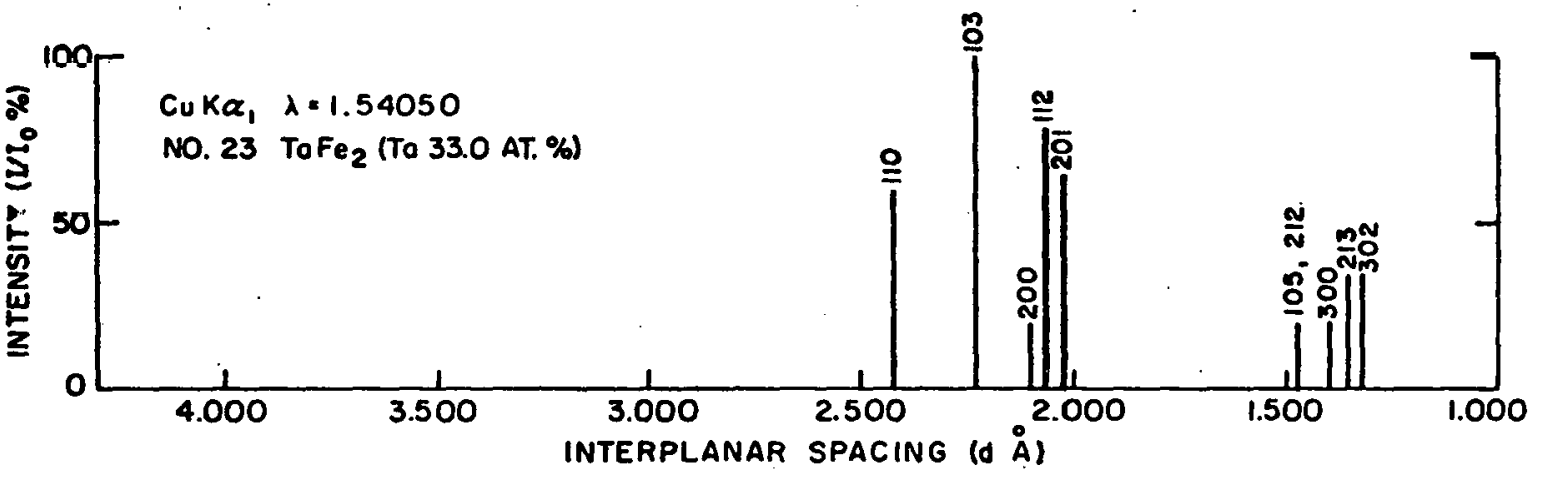

XBL 7012-7245

Figure 15 

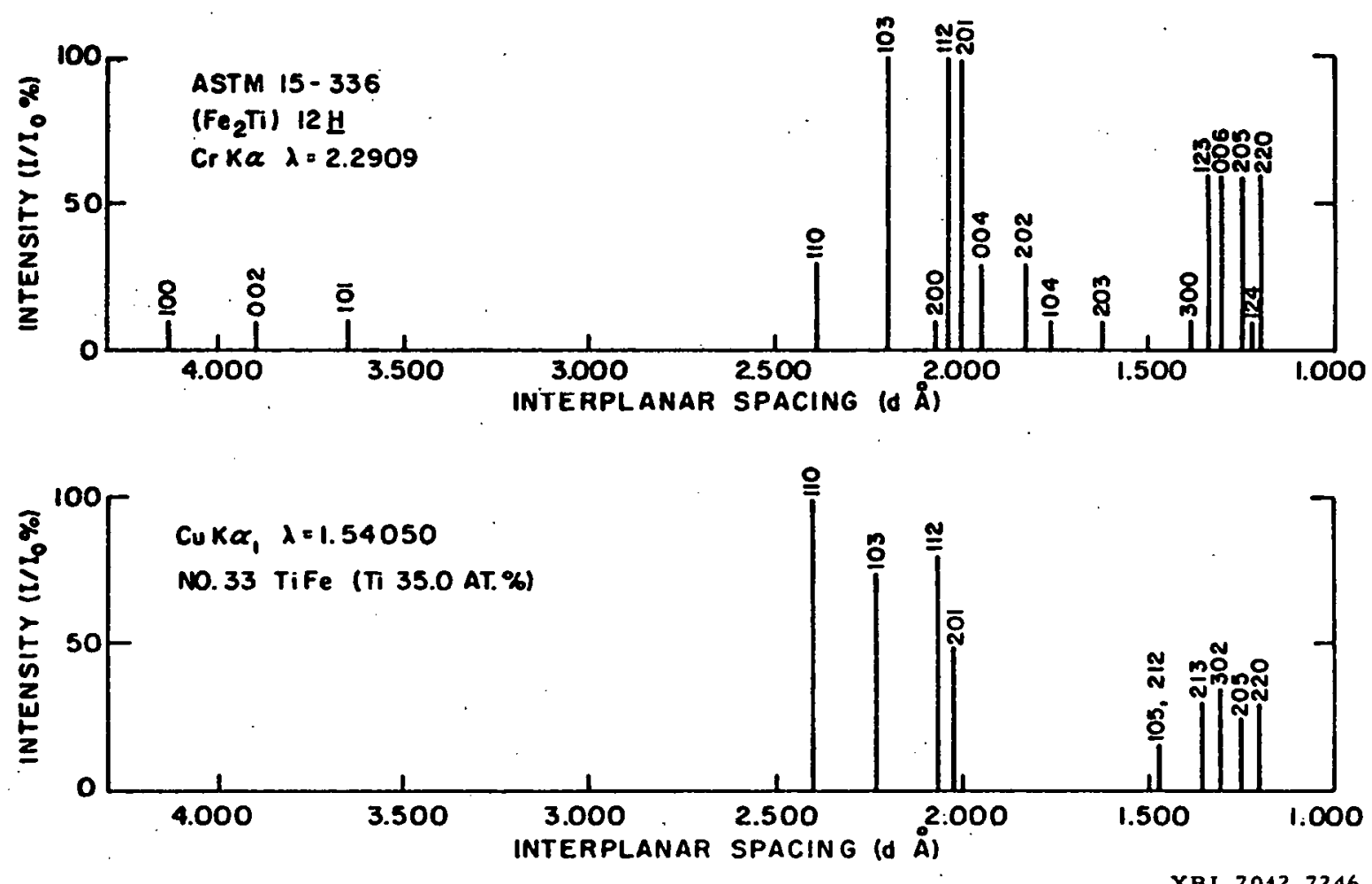

Figure 16 

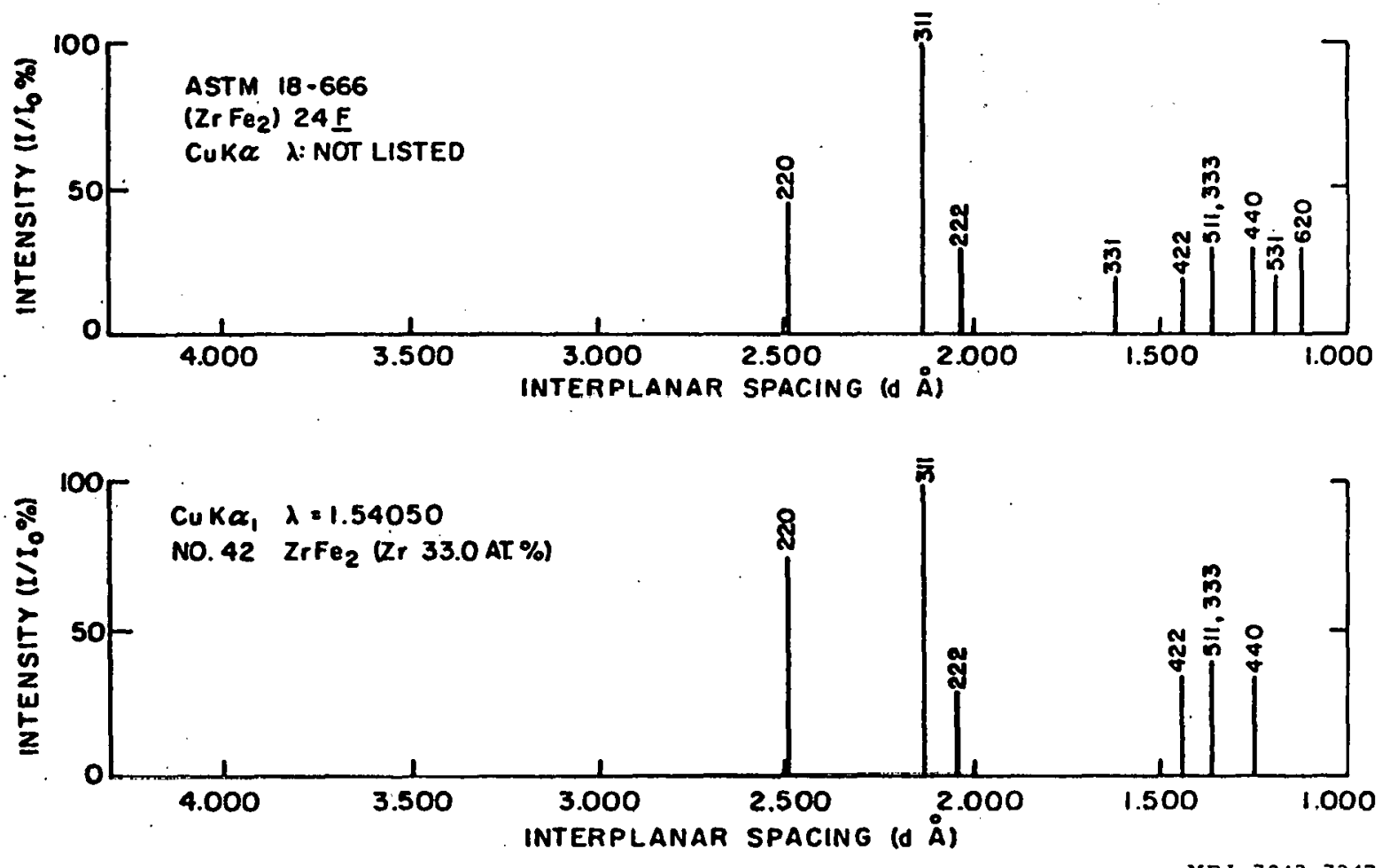

Figure 17 

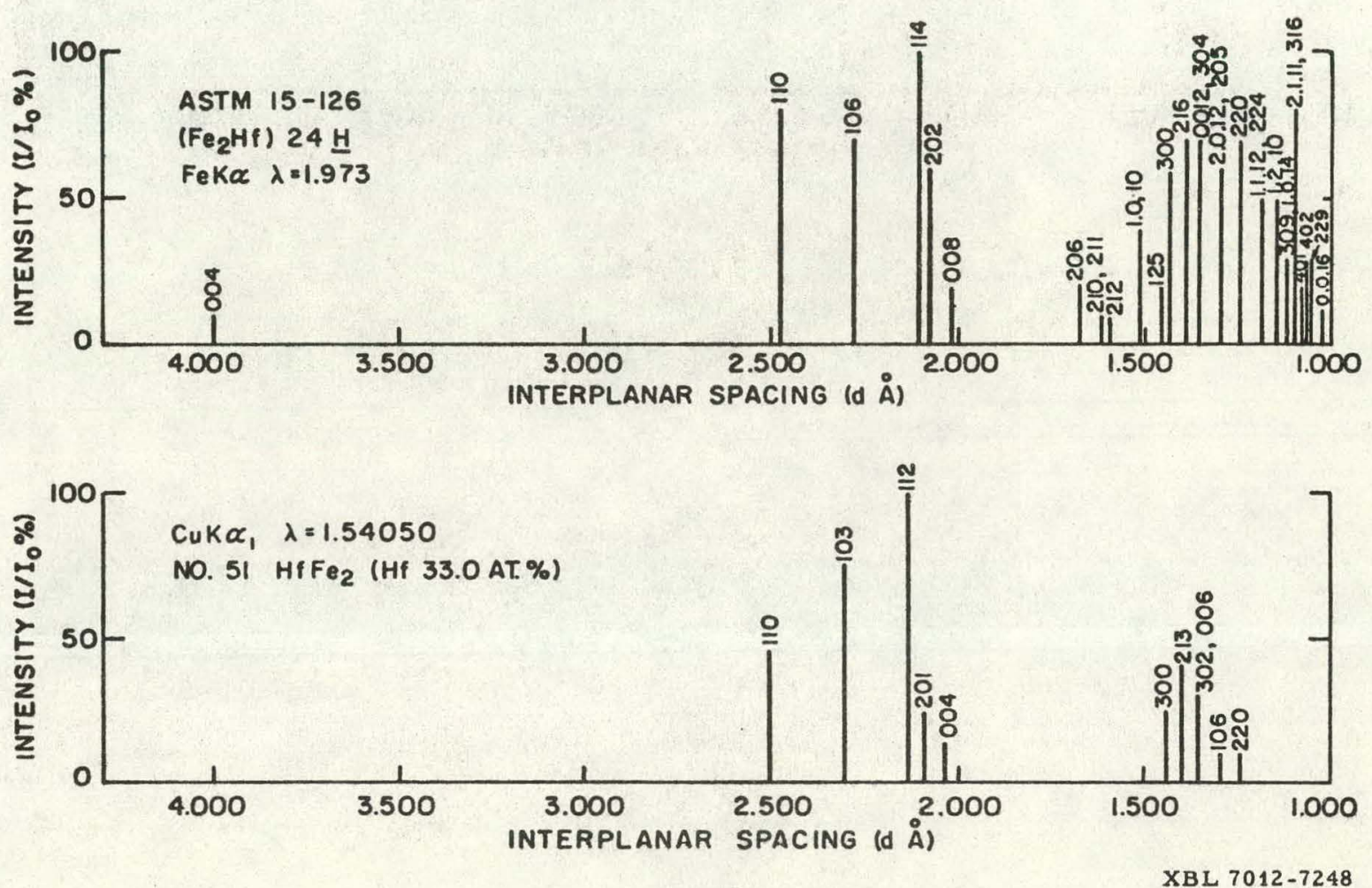

Figure 18 


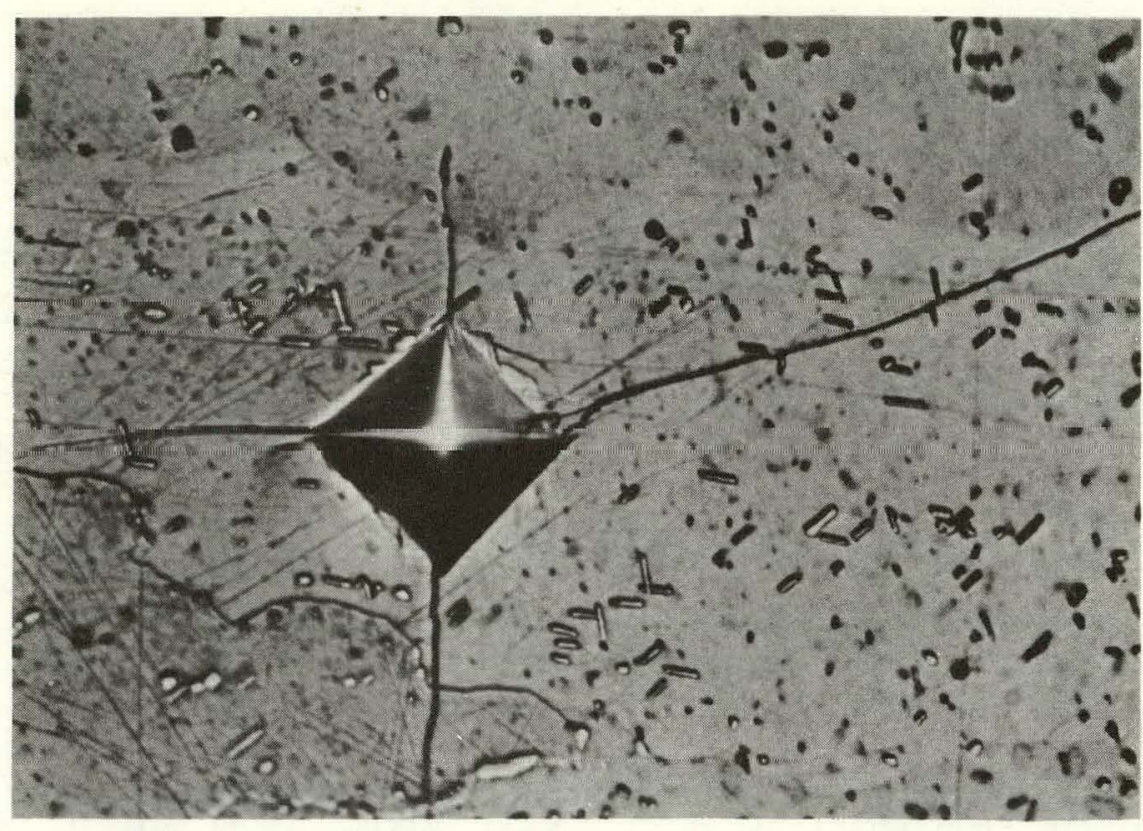

XBB7012-5422

Figure 19 


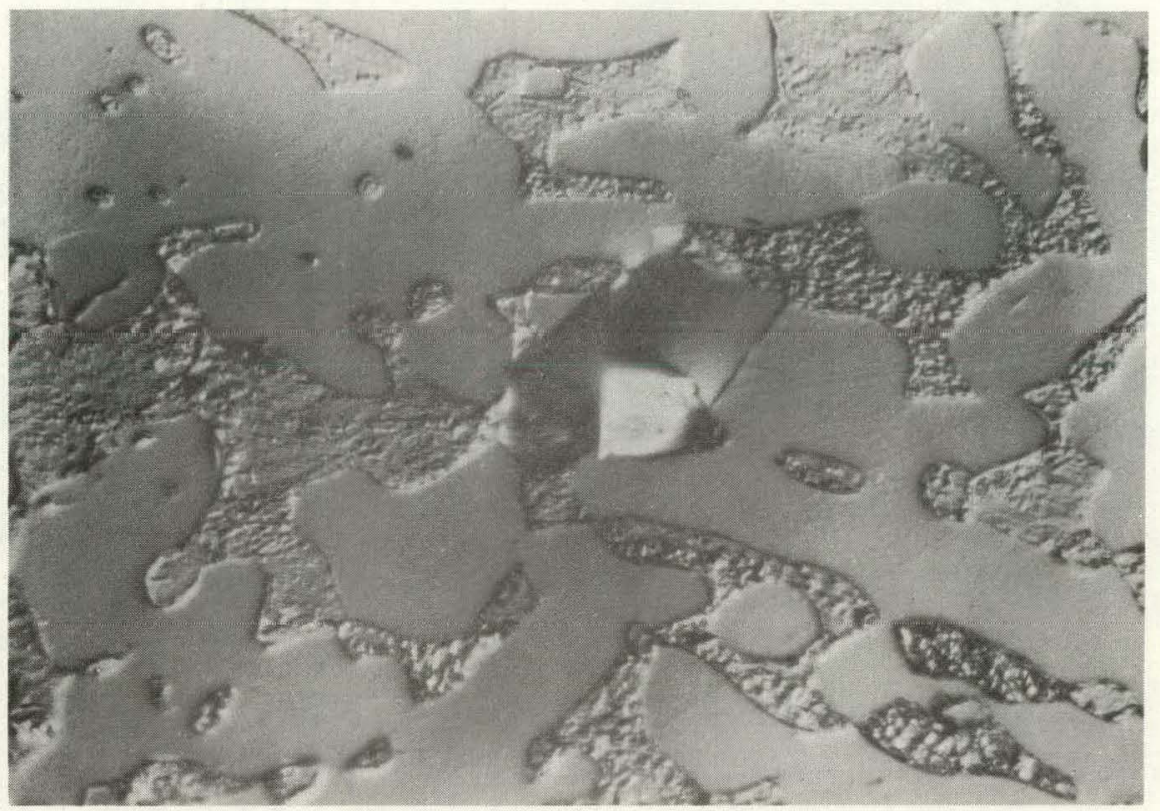

(a)

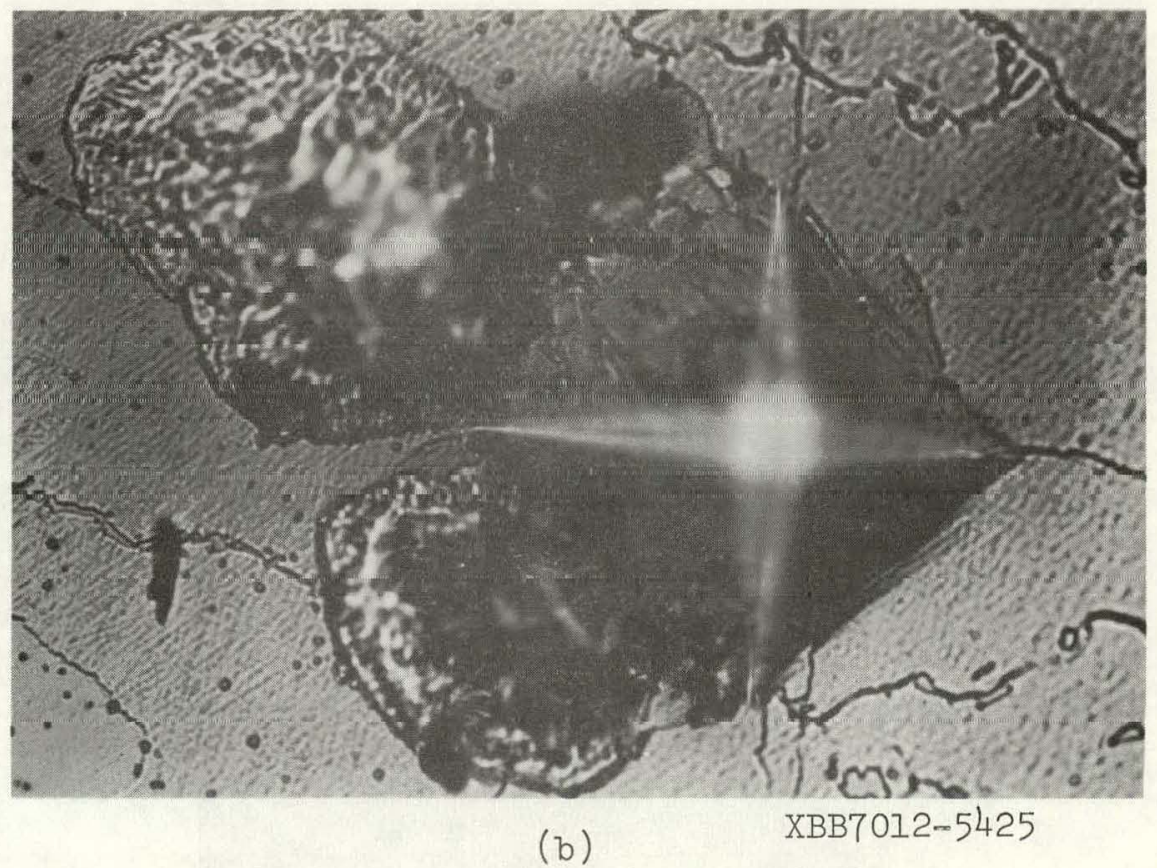

Figure 20 


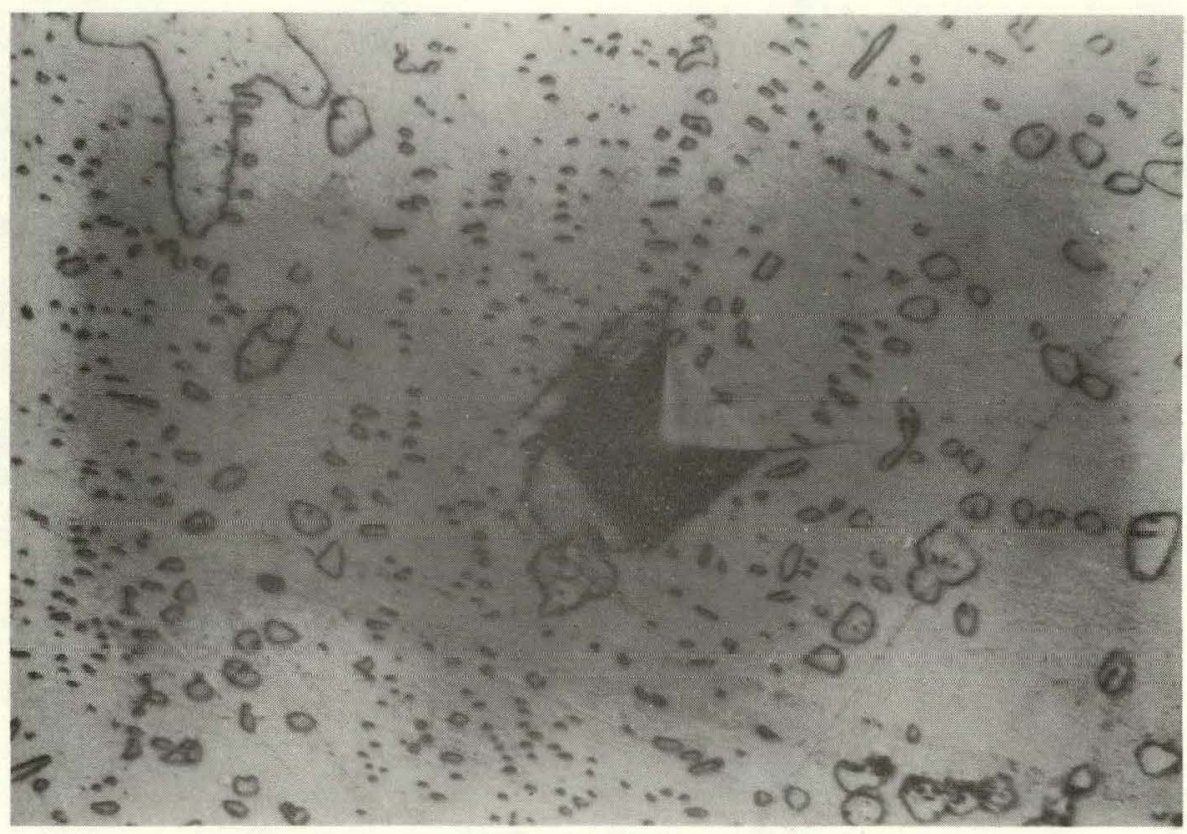

Figure 21

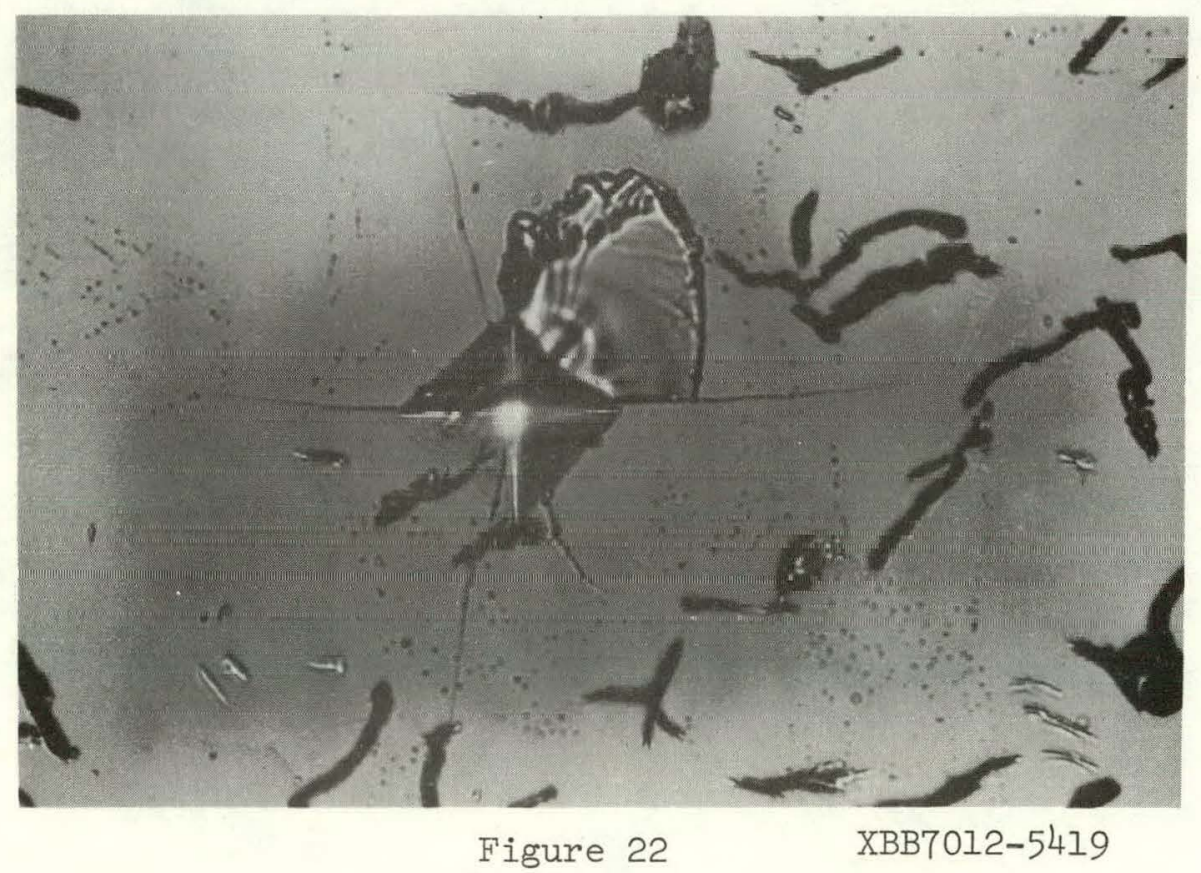




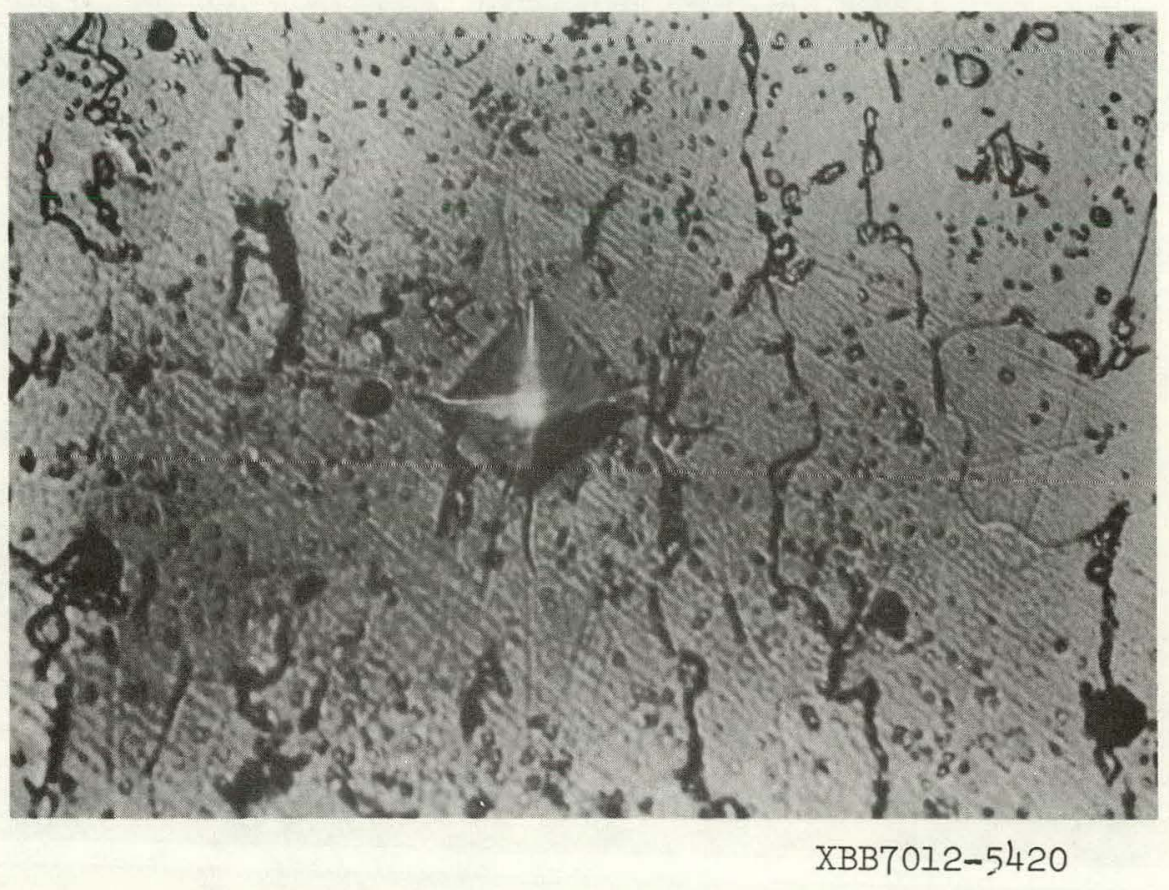

Figure 23 


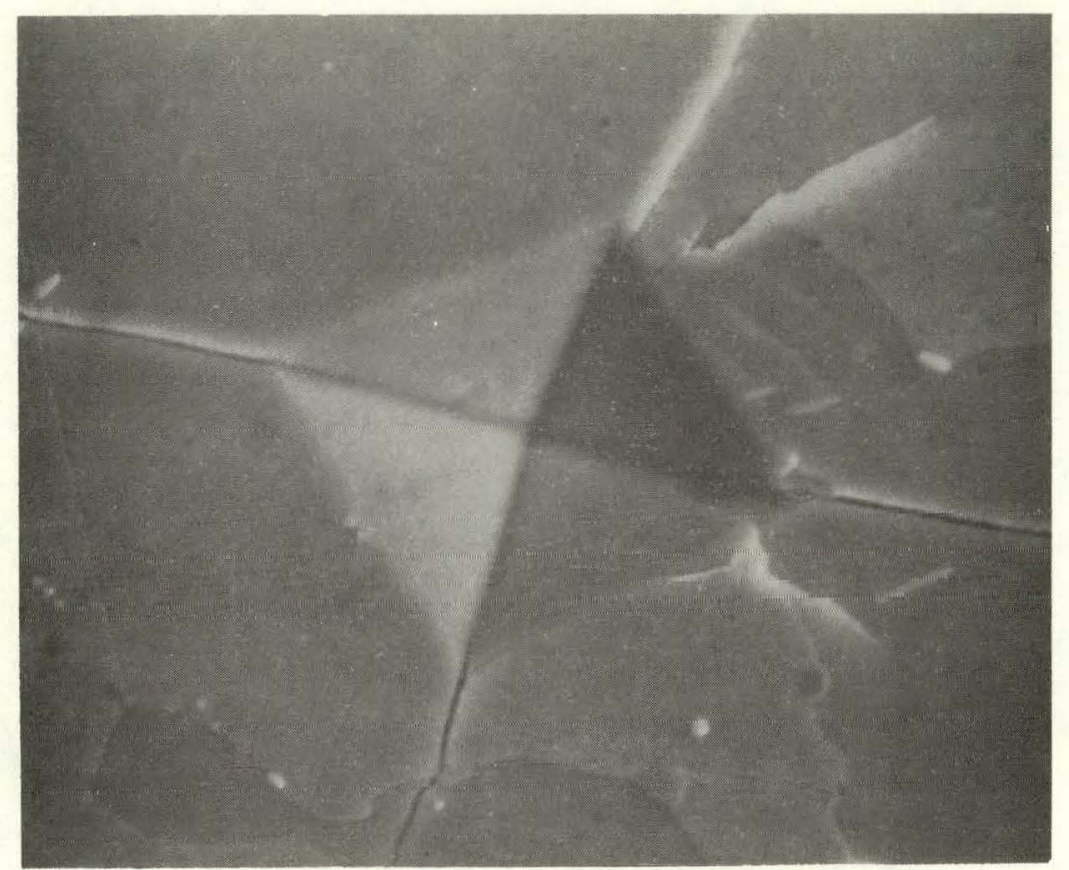

(a)

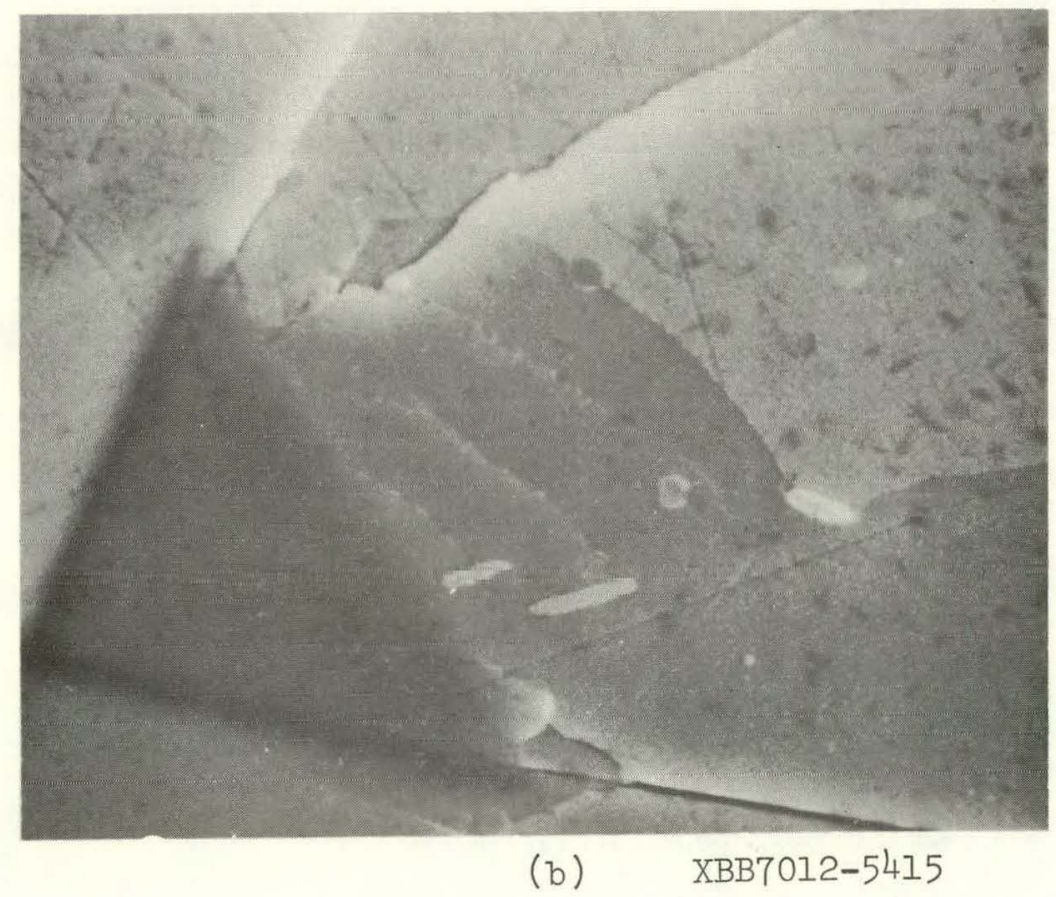

Figure 24 


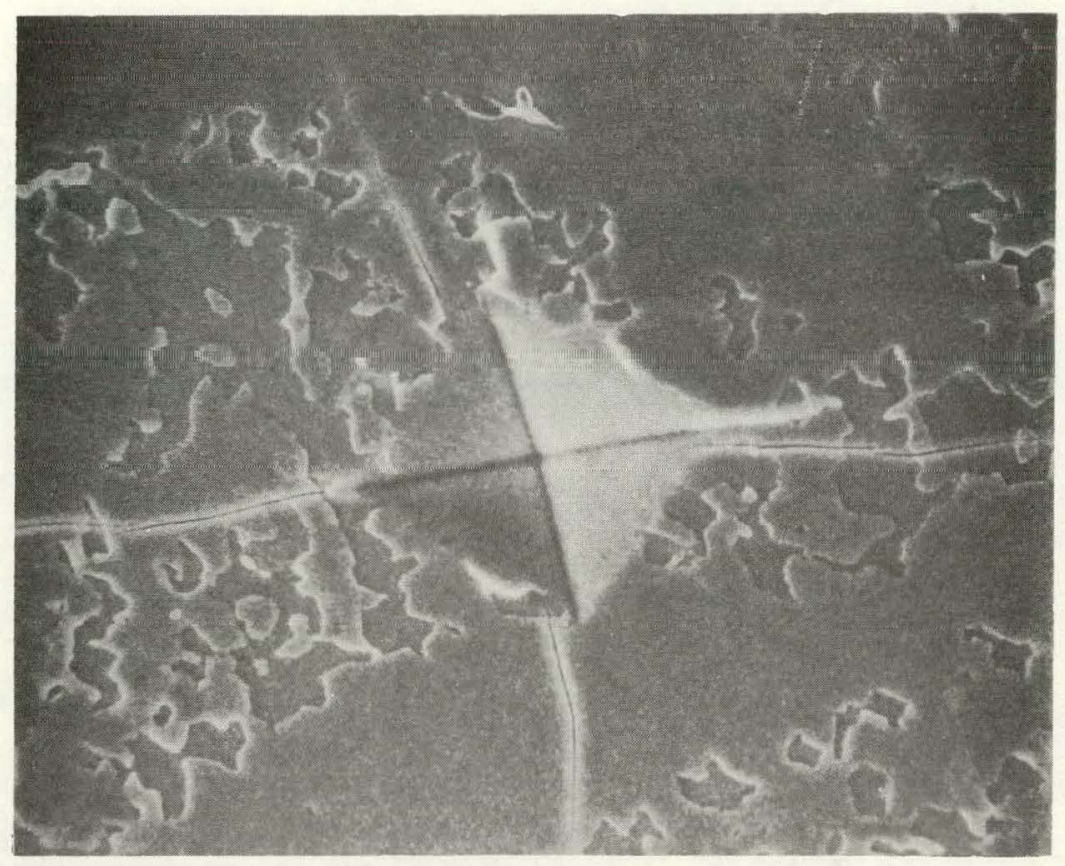

(a)

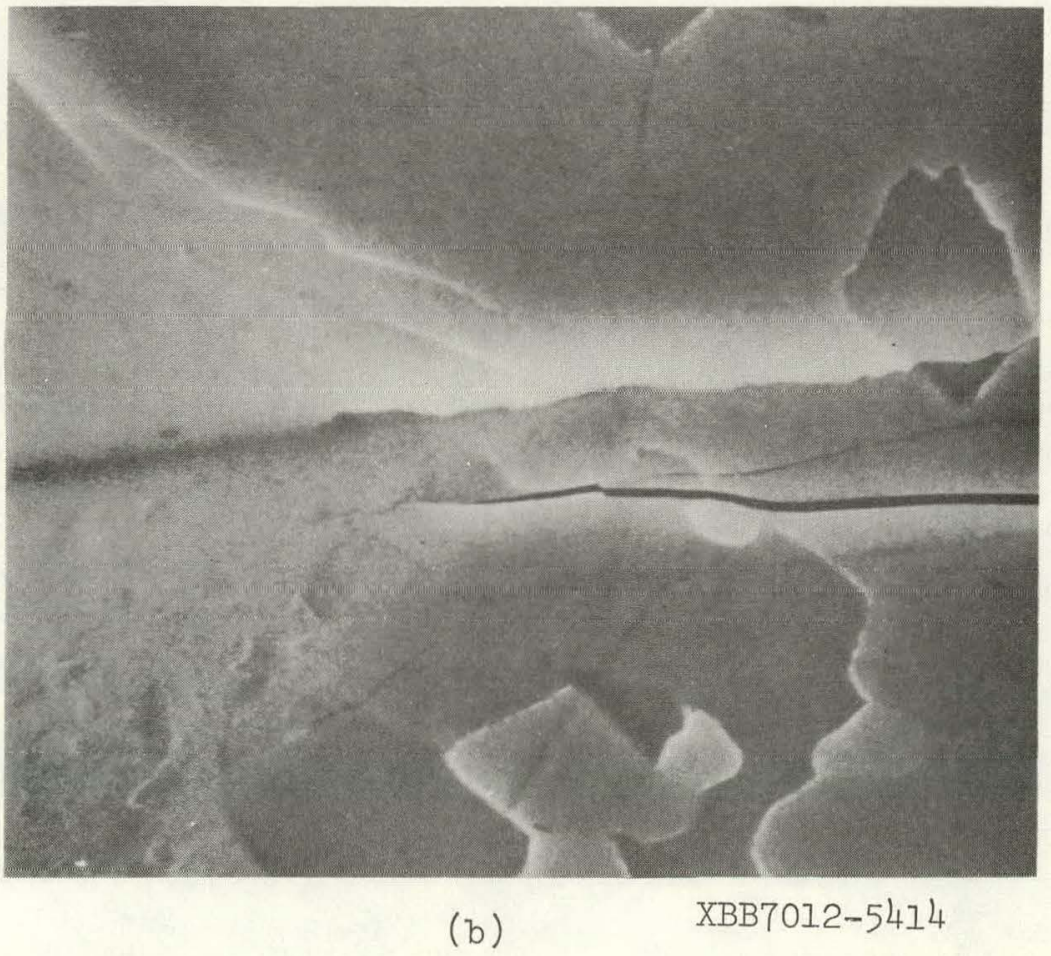

Figure 25 
$-52-$

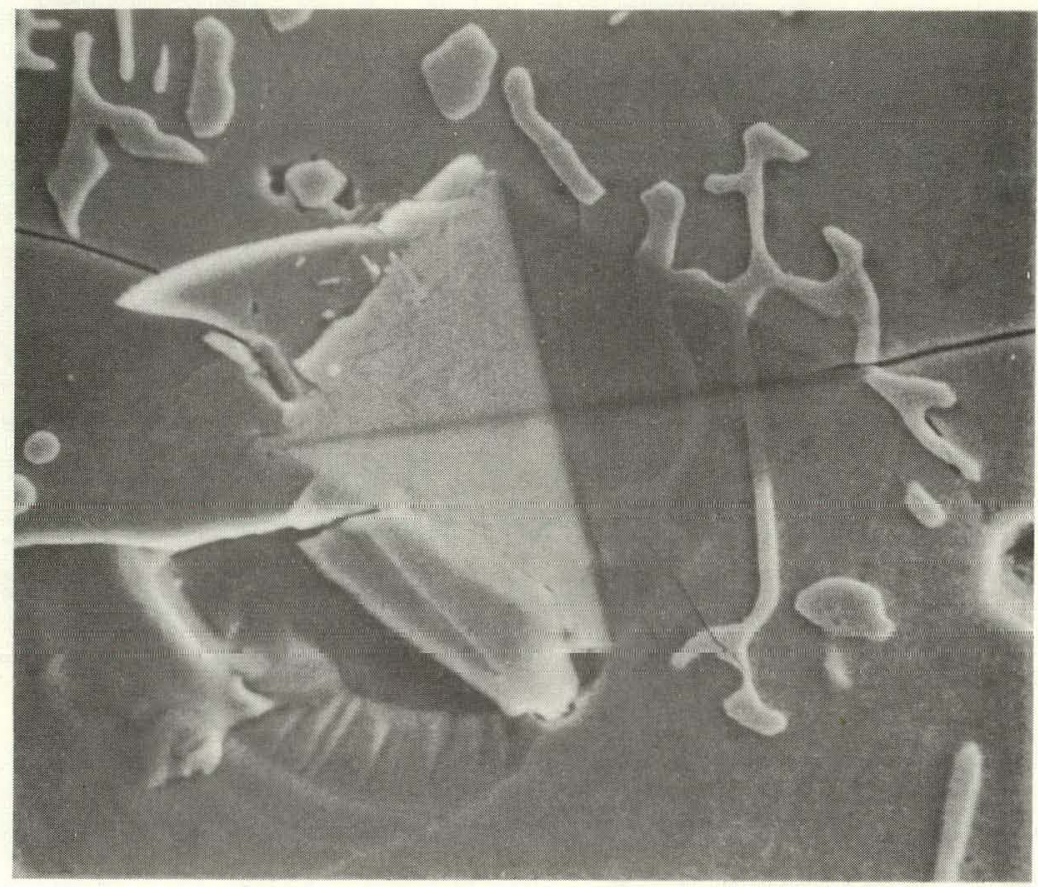

(a)

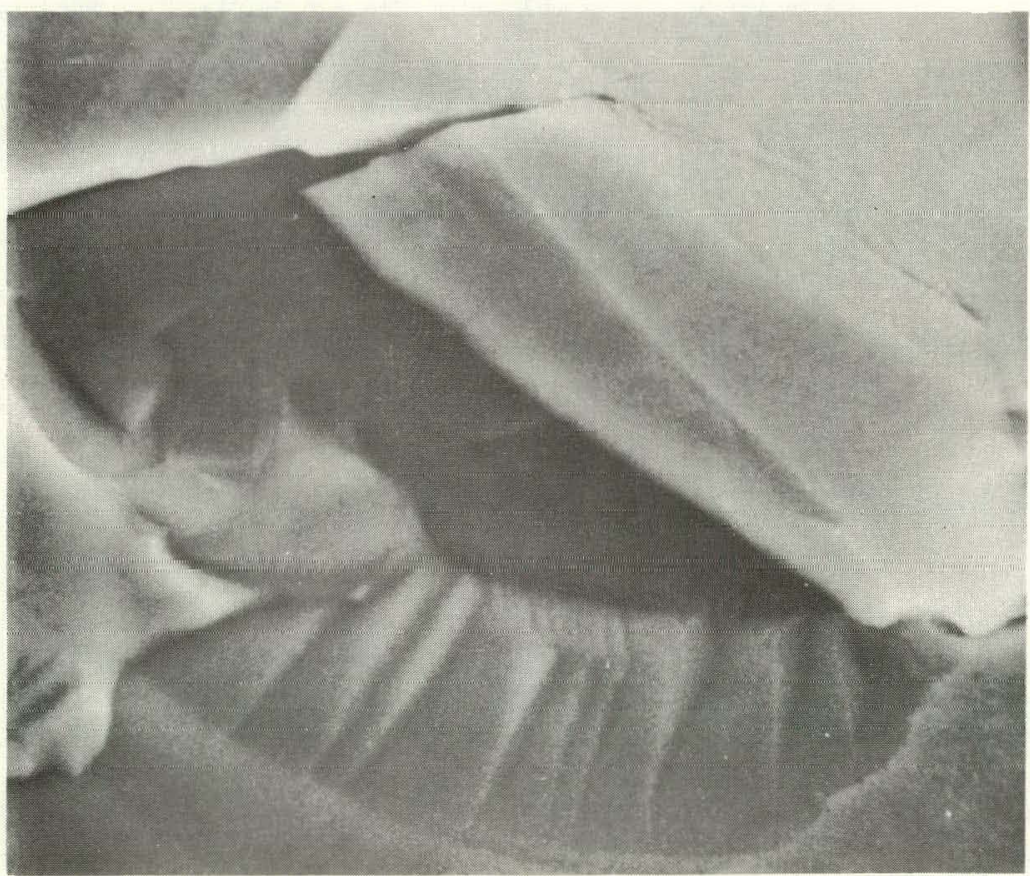

(b)

XBB7012-5417

Figure 26 


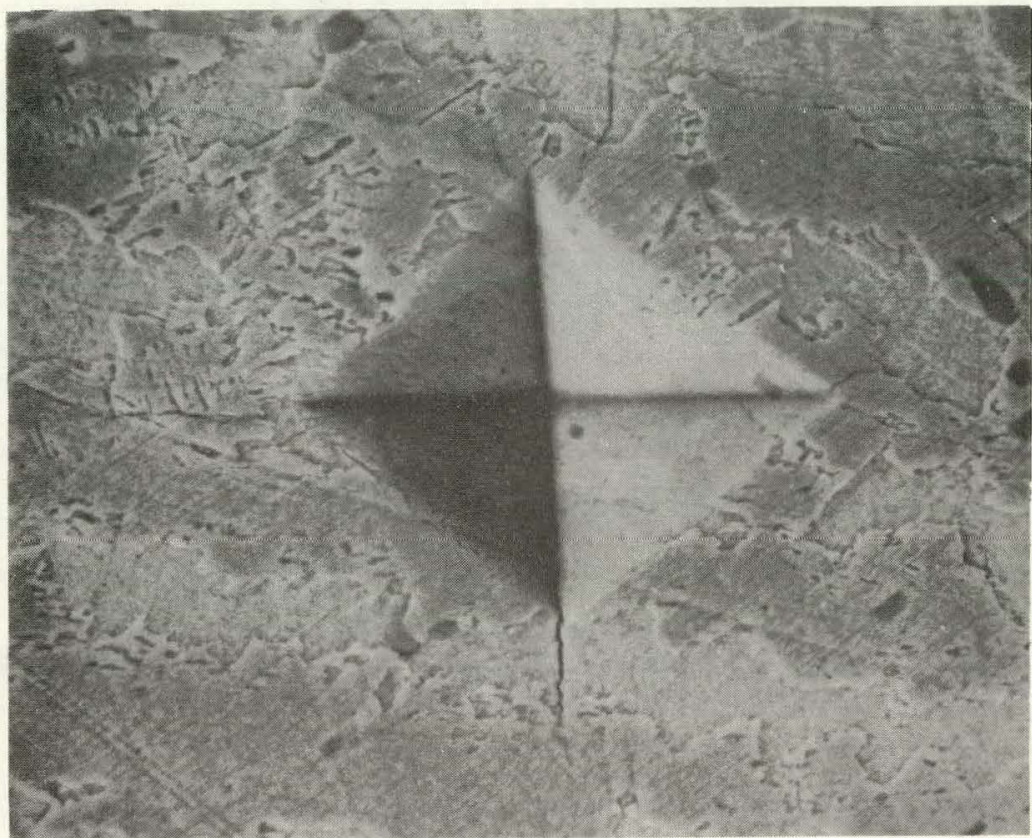

(a)

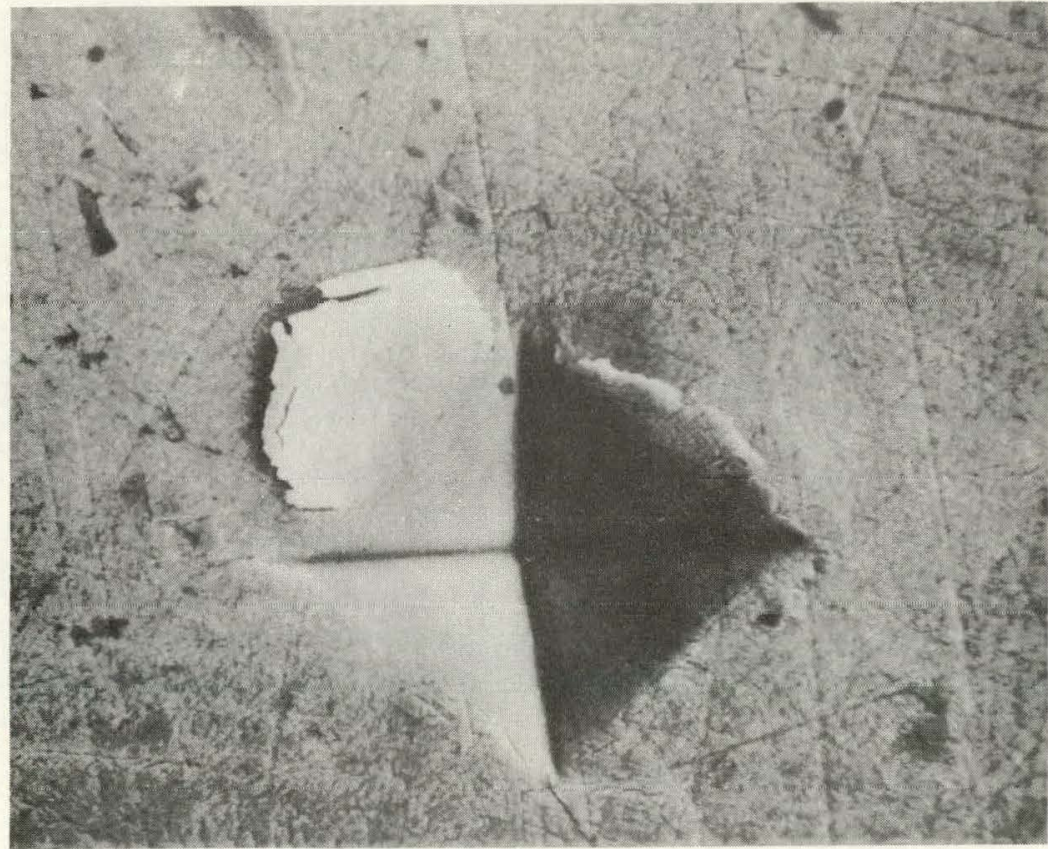

(b)

XBB7012-5424

Figure 27 
$-54-$

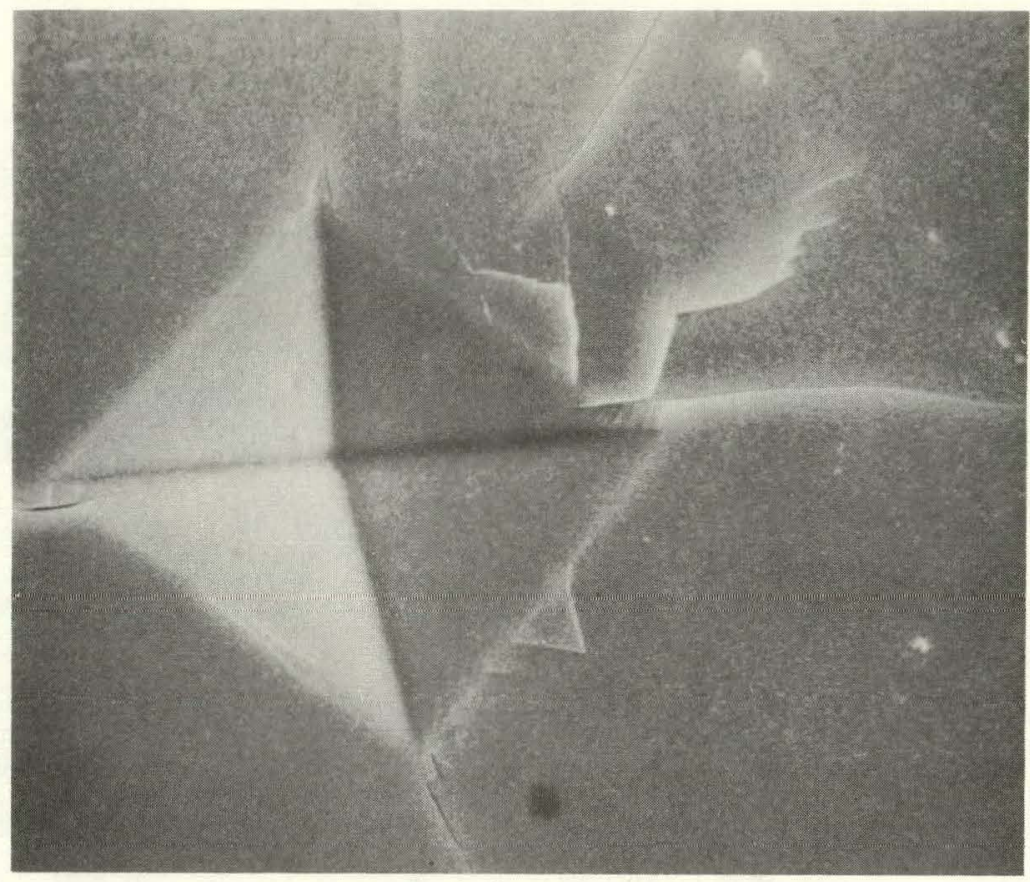

(a)

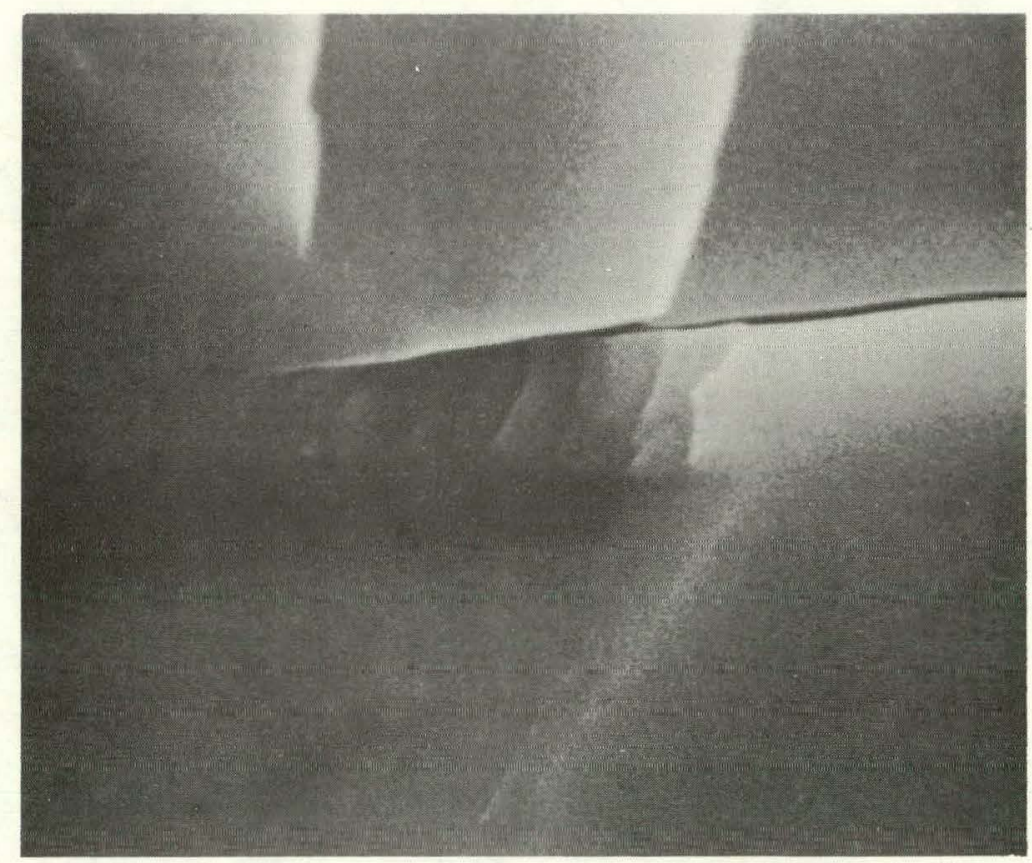

(b)

XBB7012-5426

Figure 28 
$-55-$

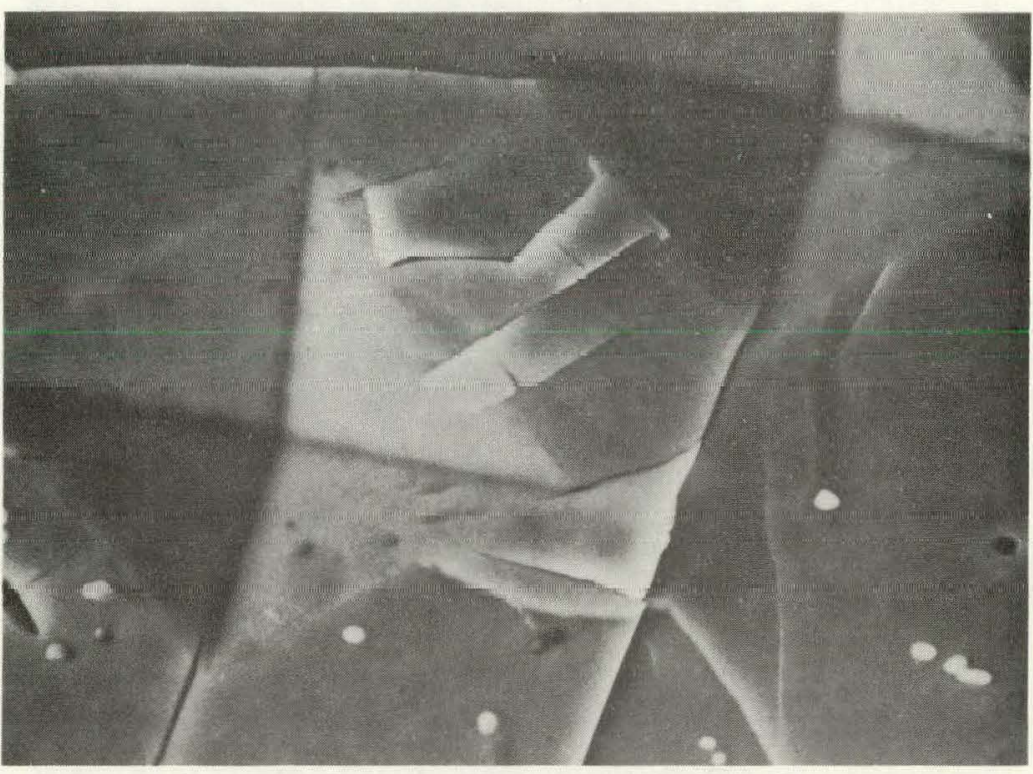

(a)

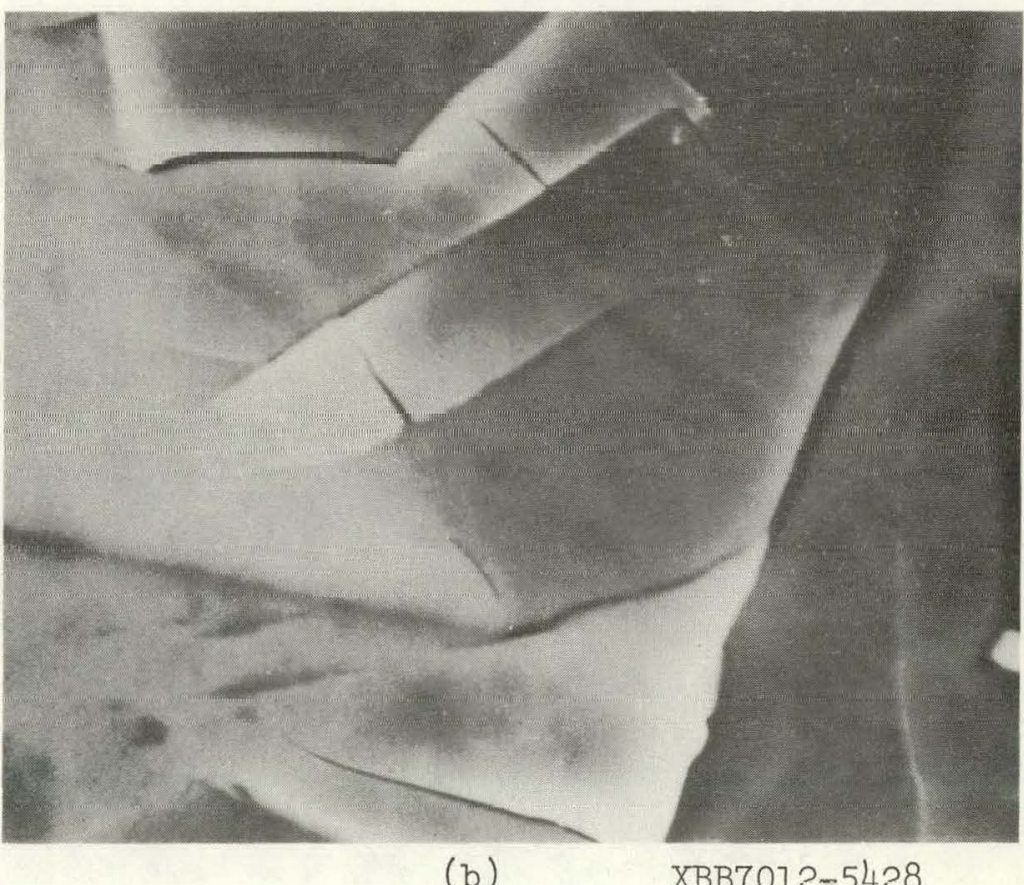

Figure 29 


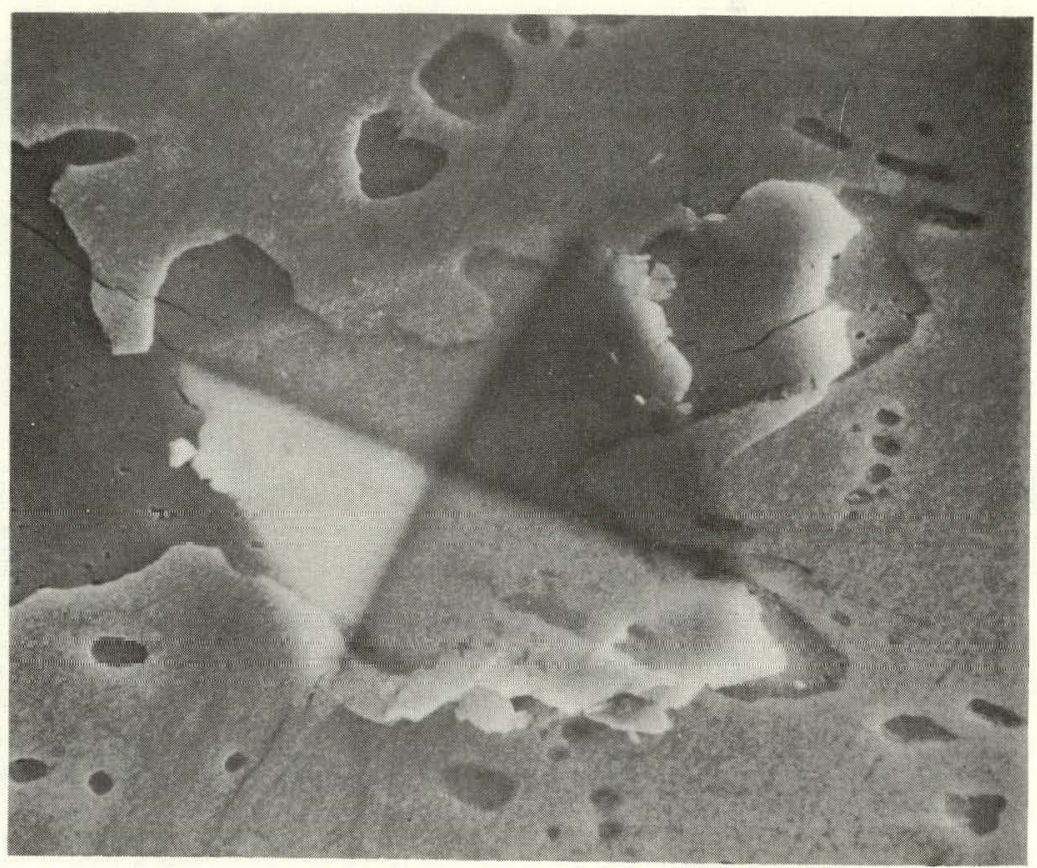

(a)

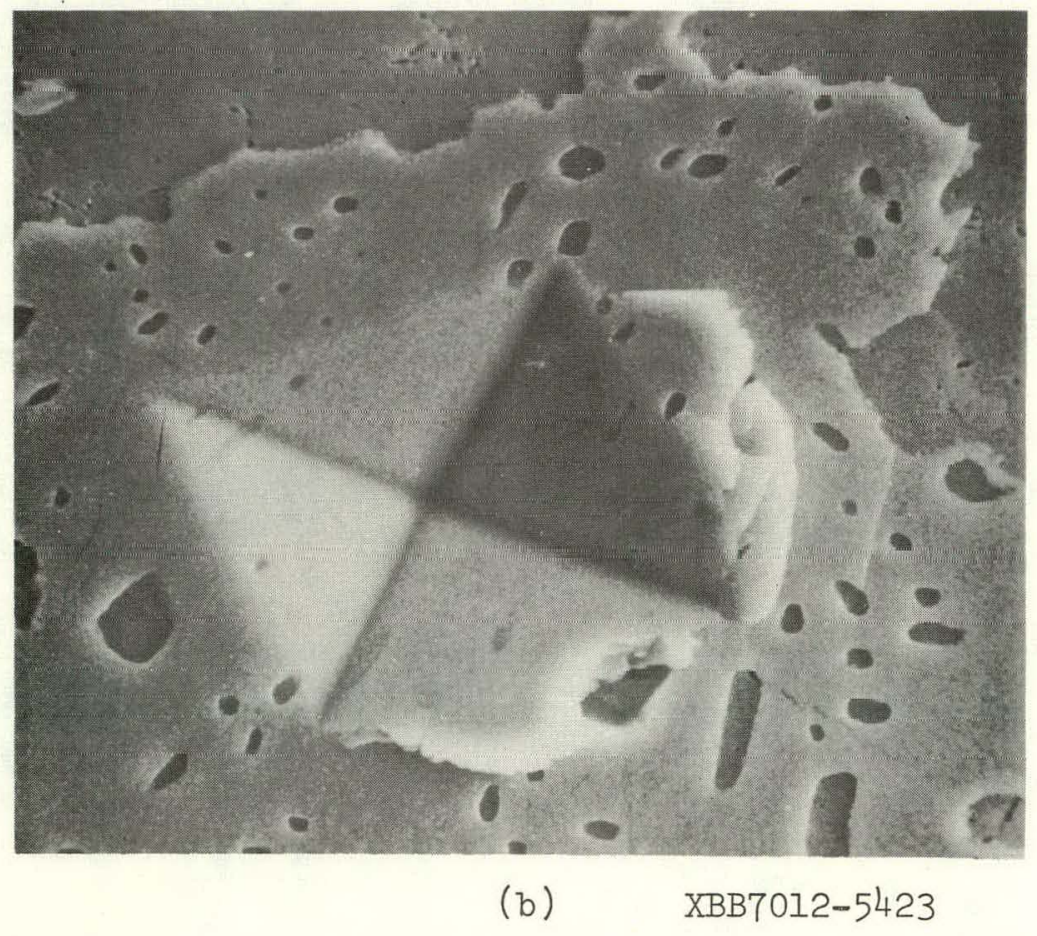

Figure 30 


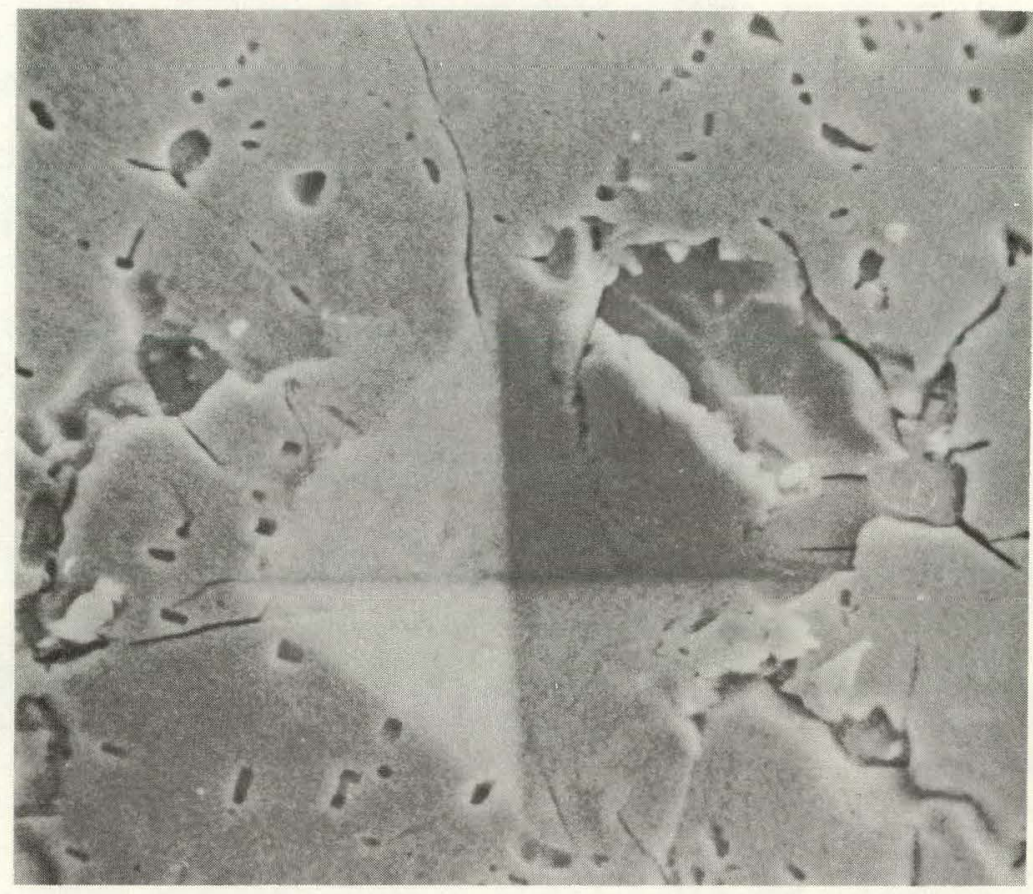

(a)

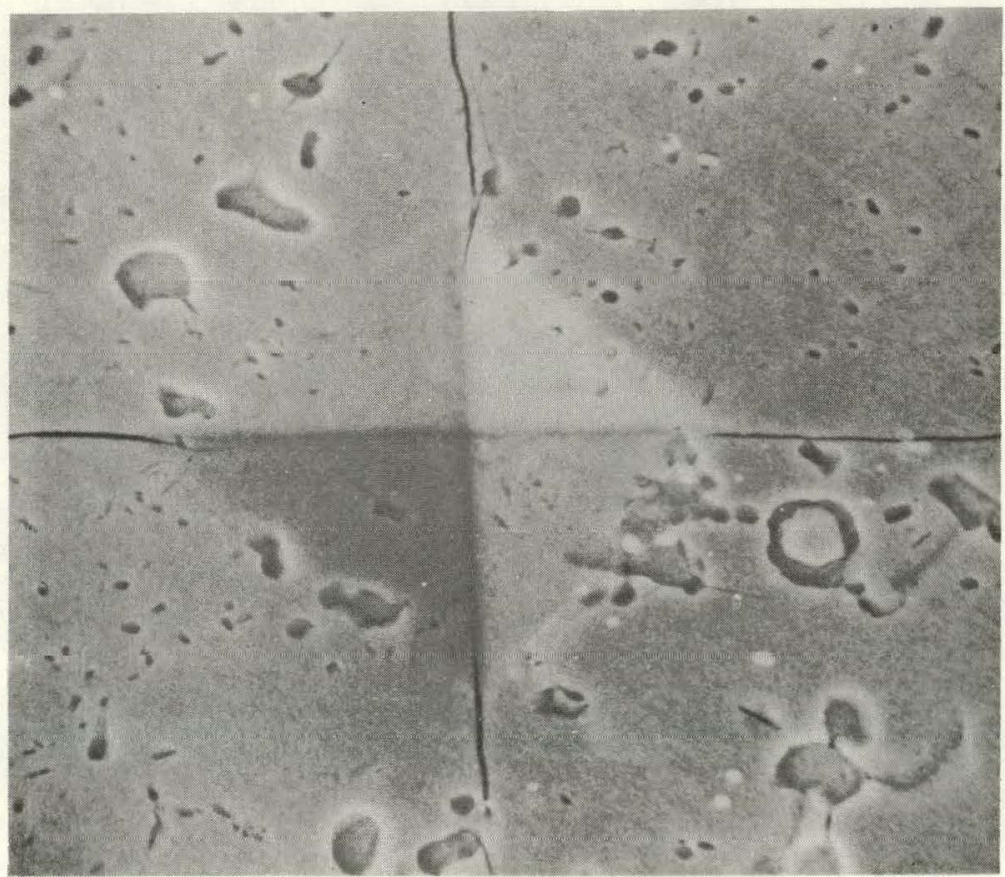

(b)

XBB7012-5427

Figure 31 
$-58-$

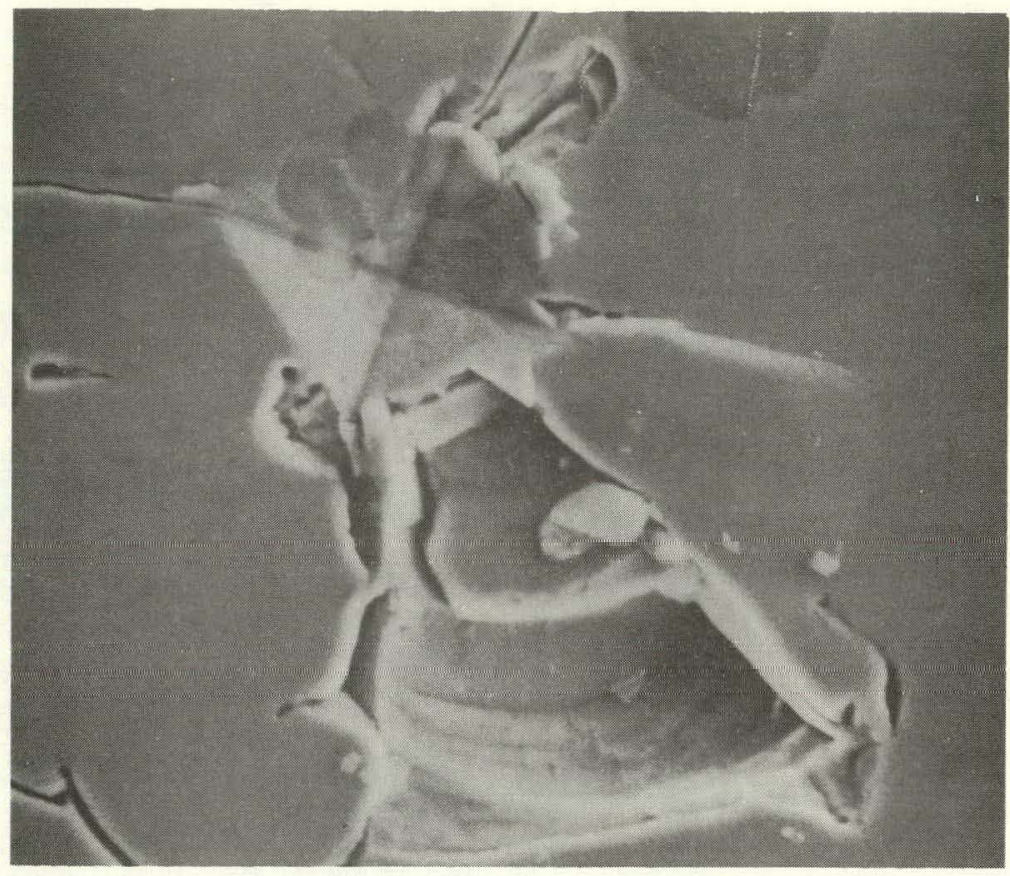

(a)

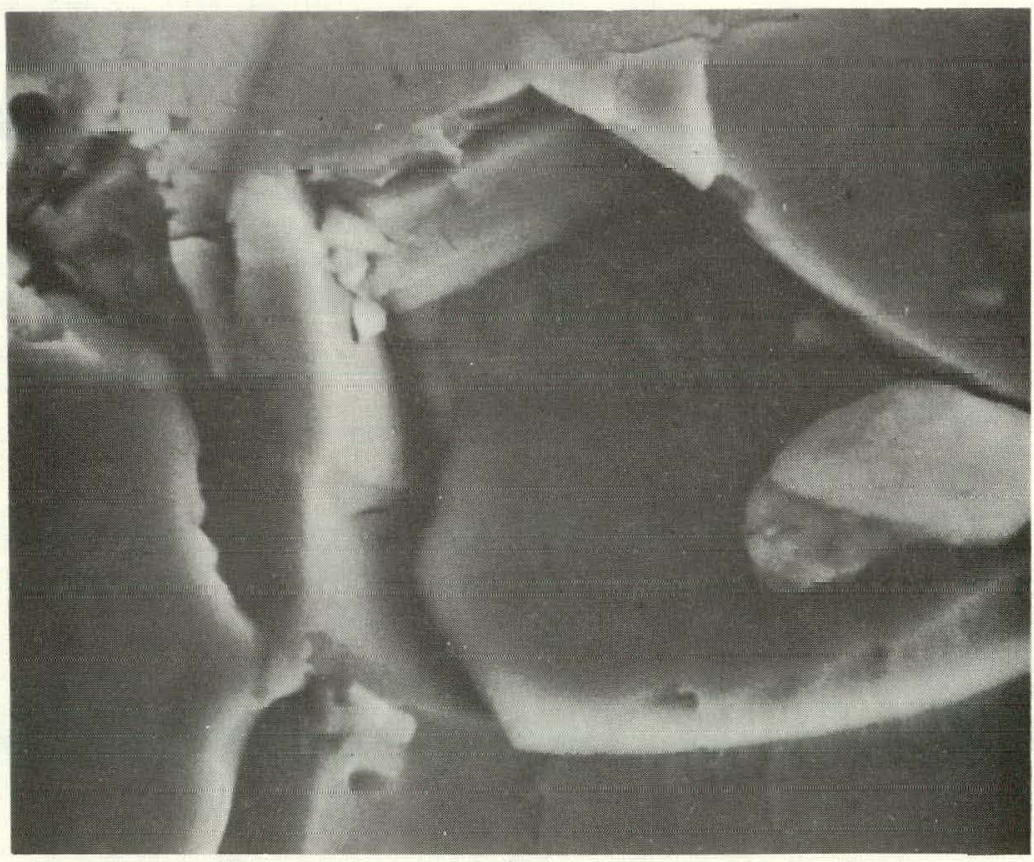

(b) XBB7012-5413

Figure 32 

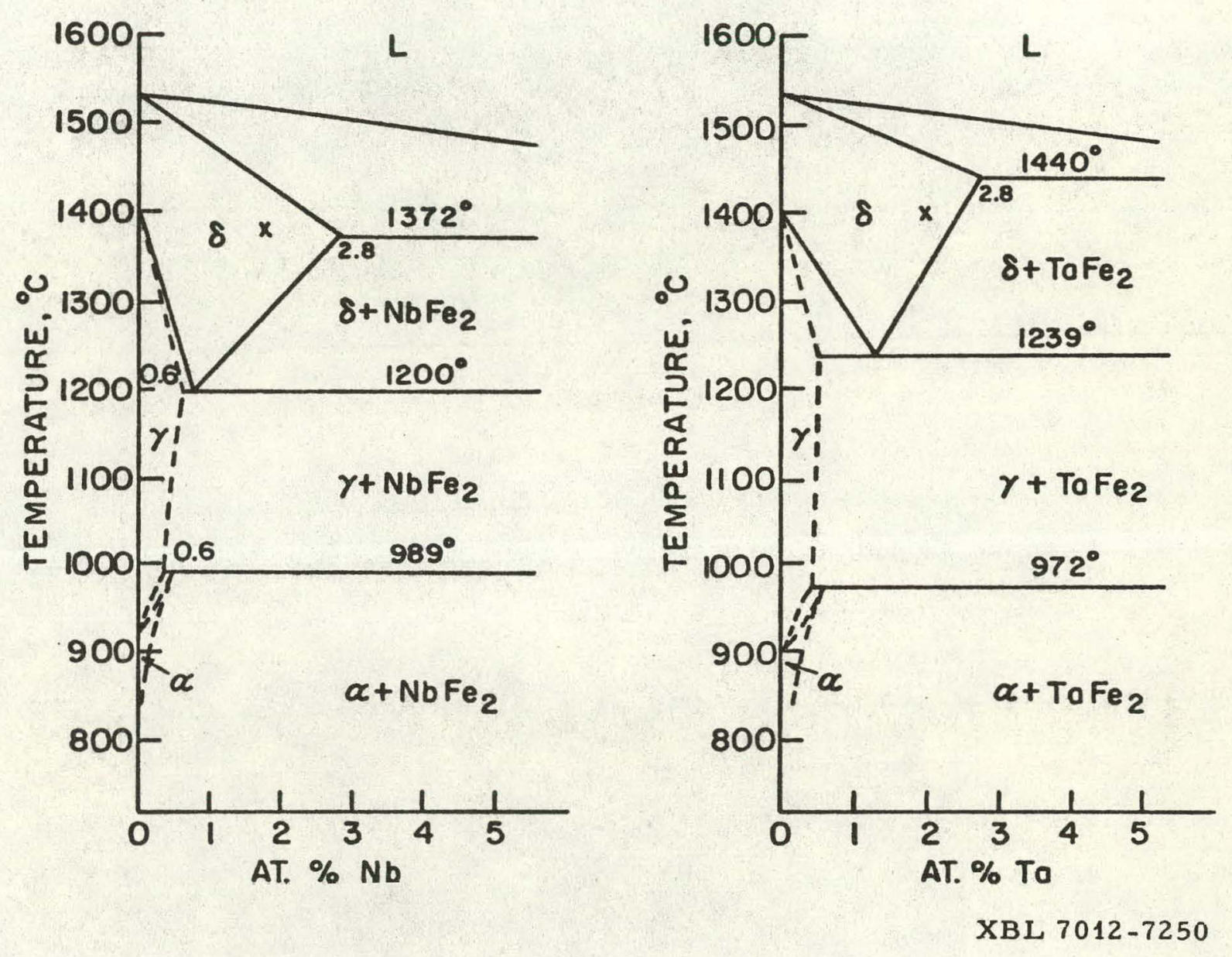

Figure 33 
$-60-$

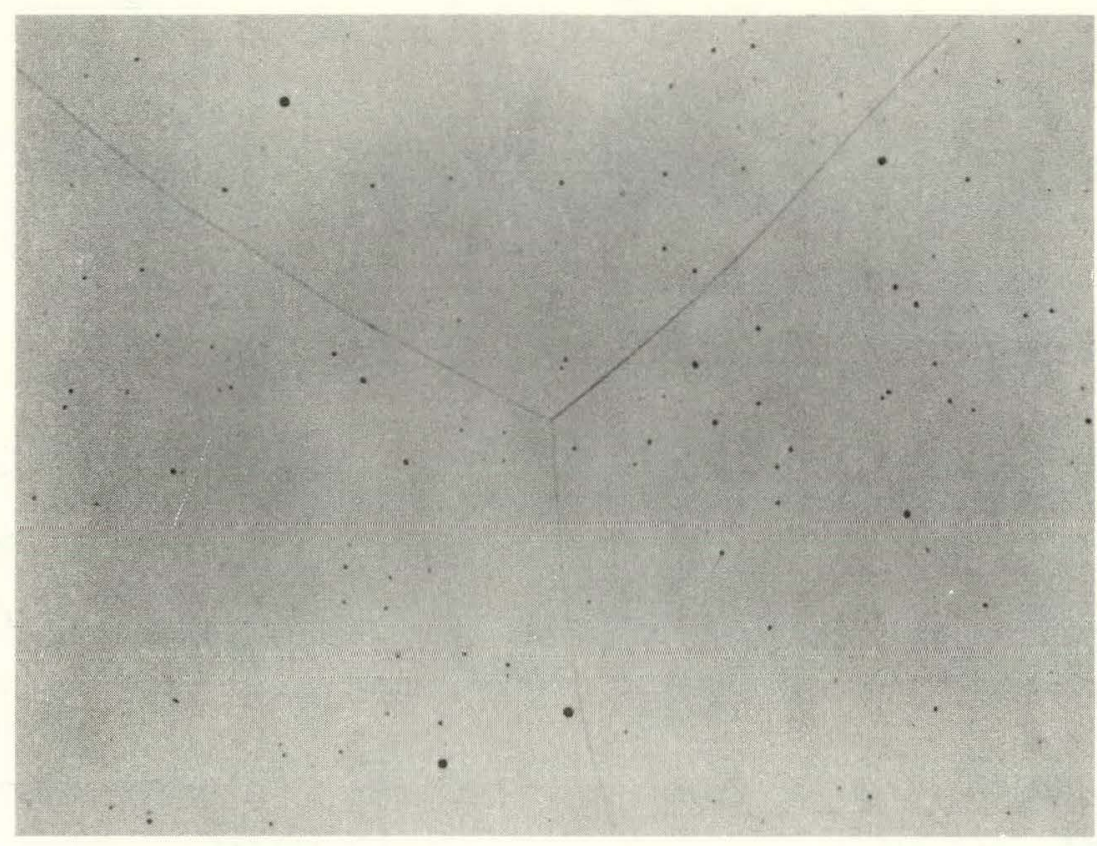

(a)

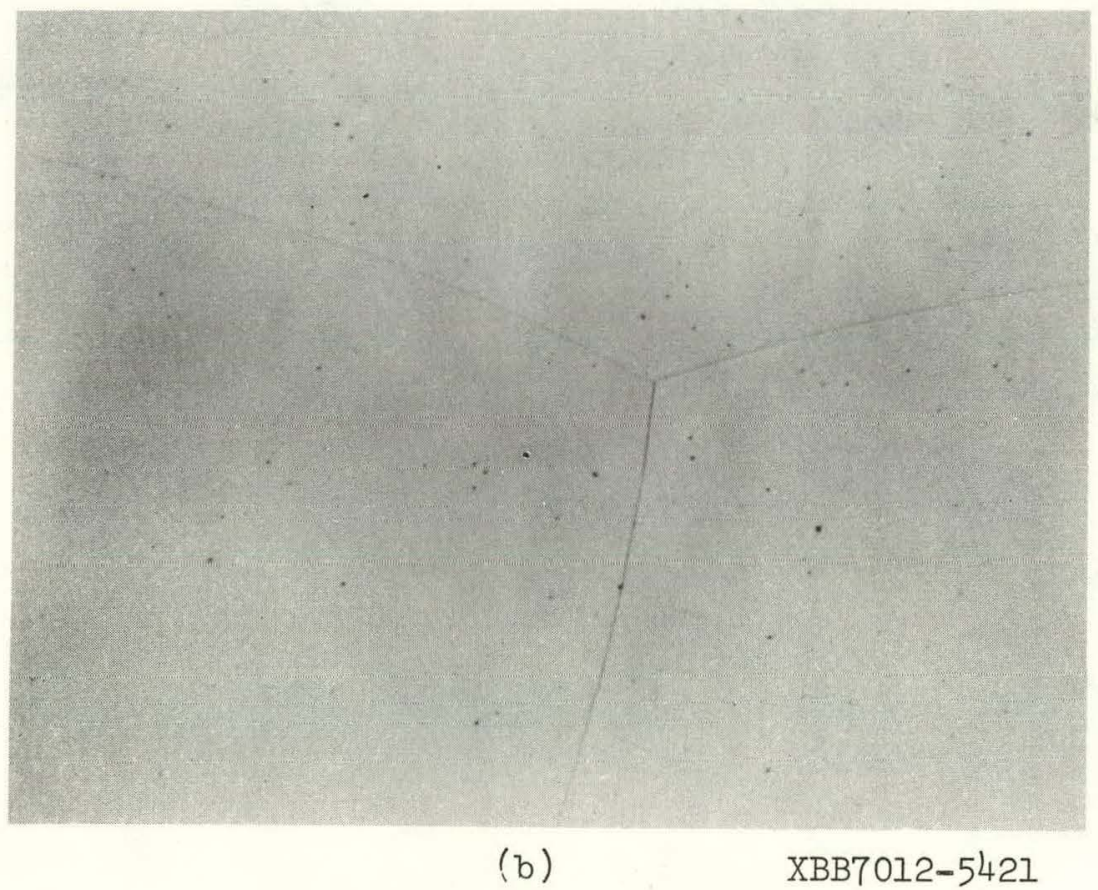

Figure 34 
$-61-$

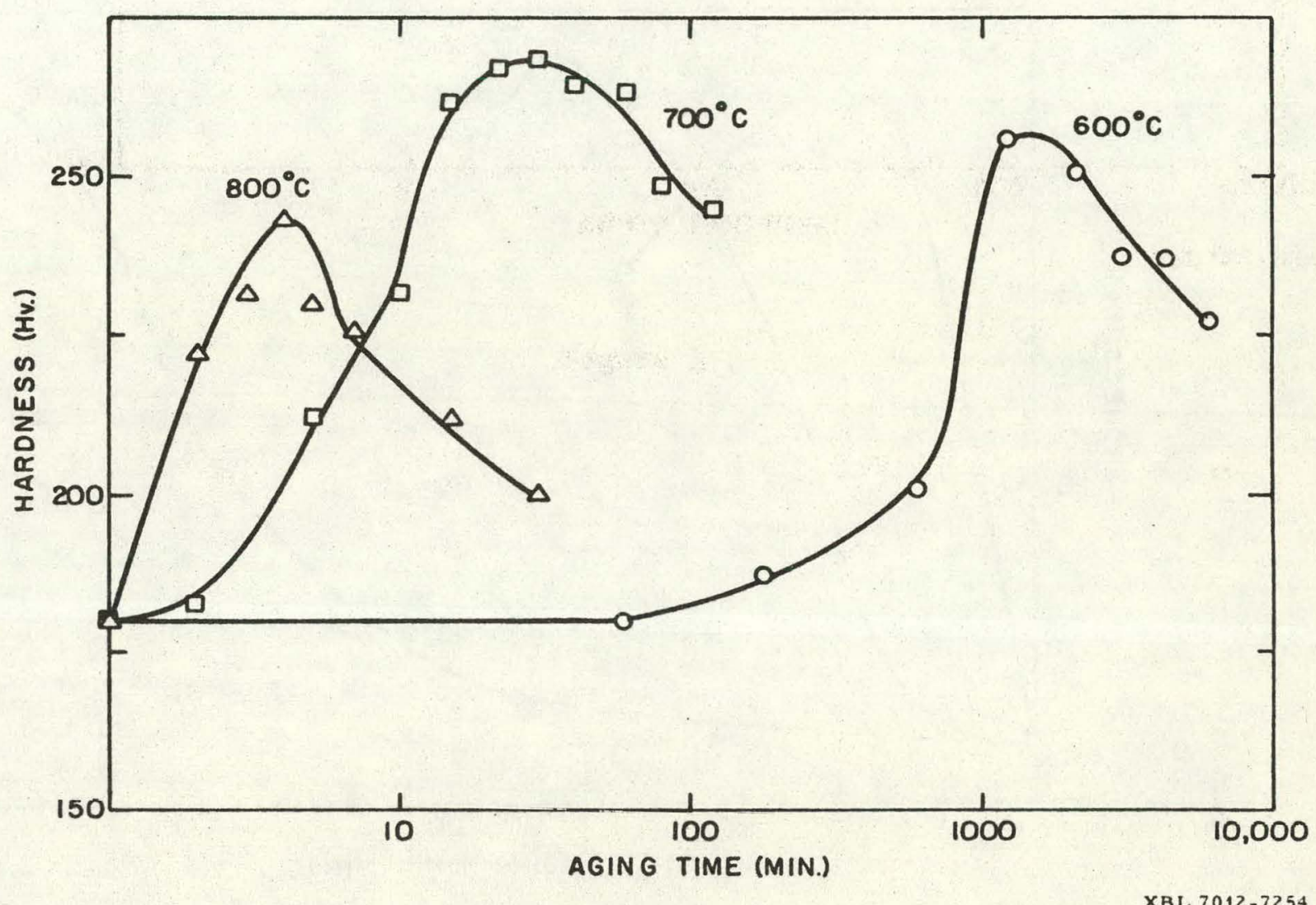

Figure 35 


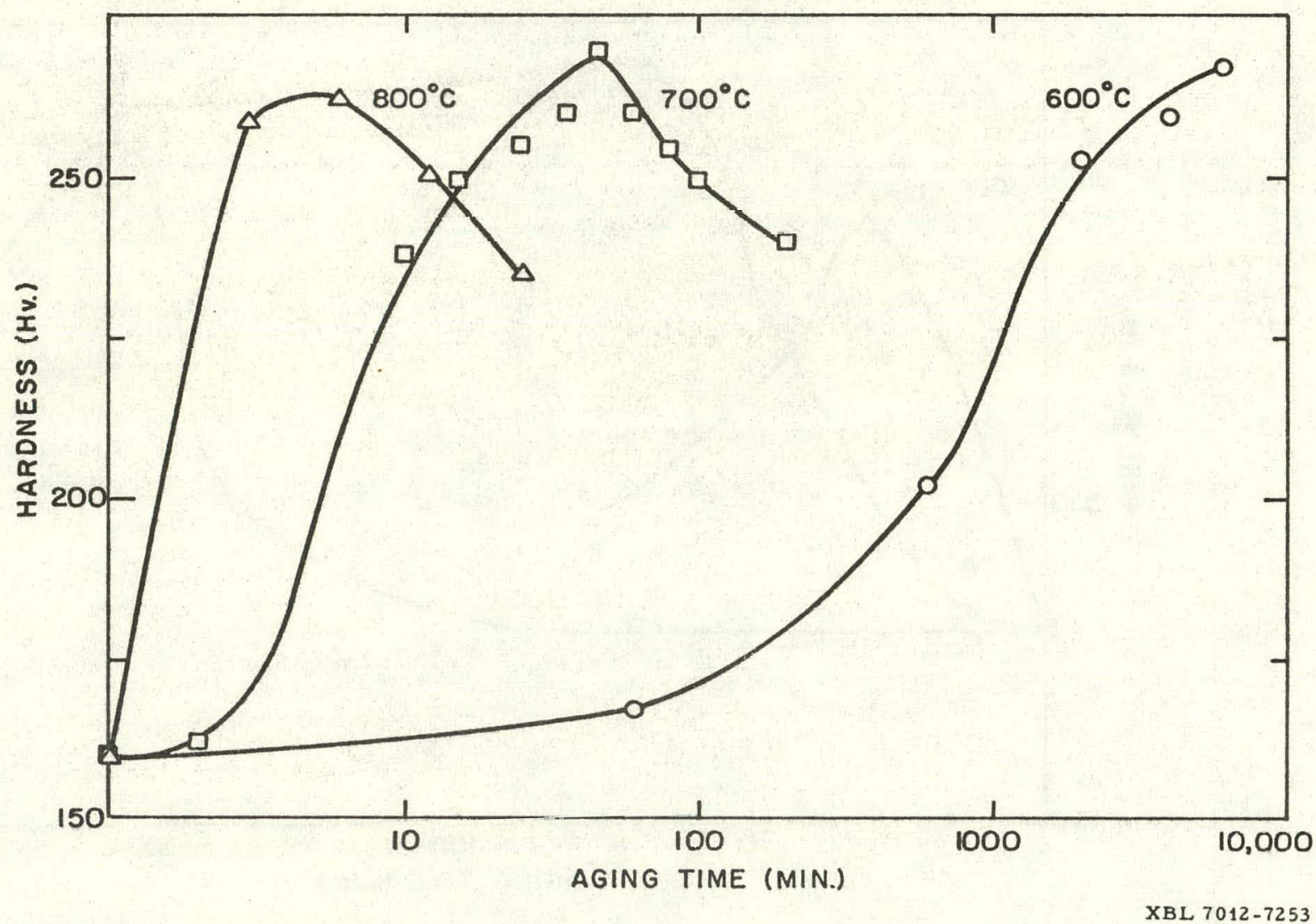

Figure 36 


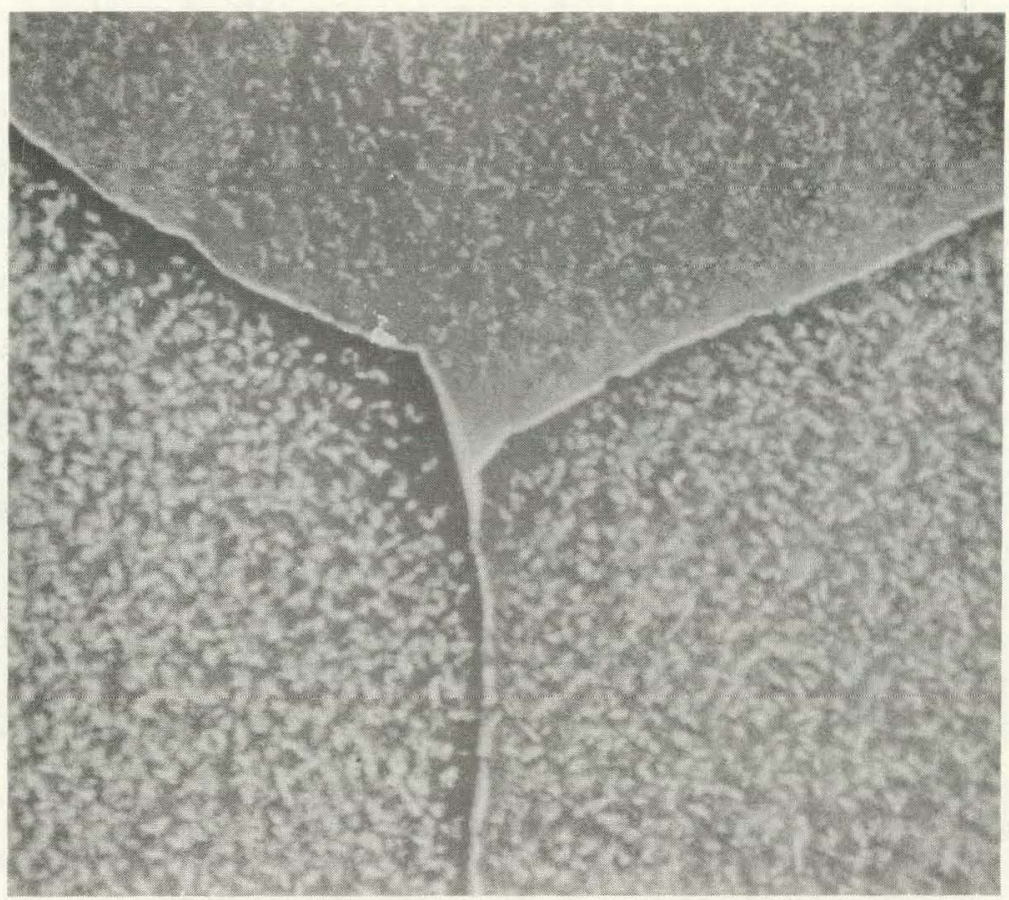

(a)

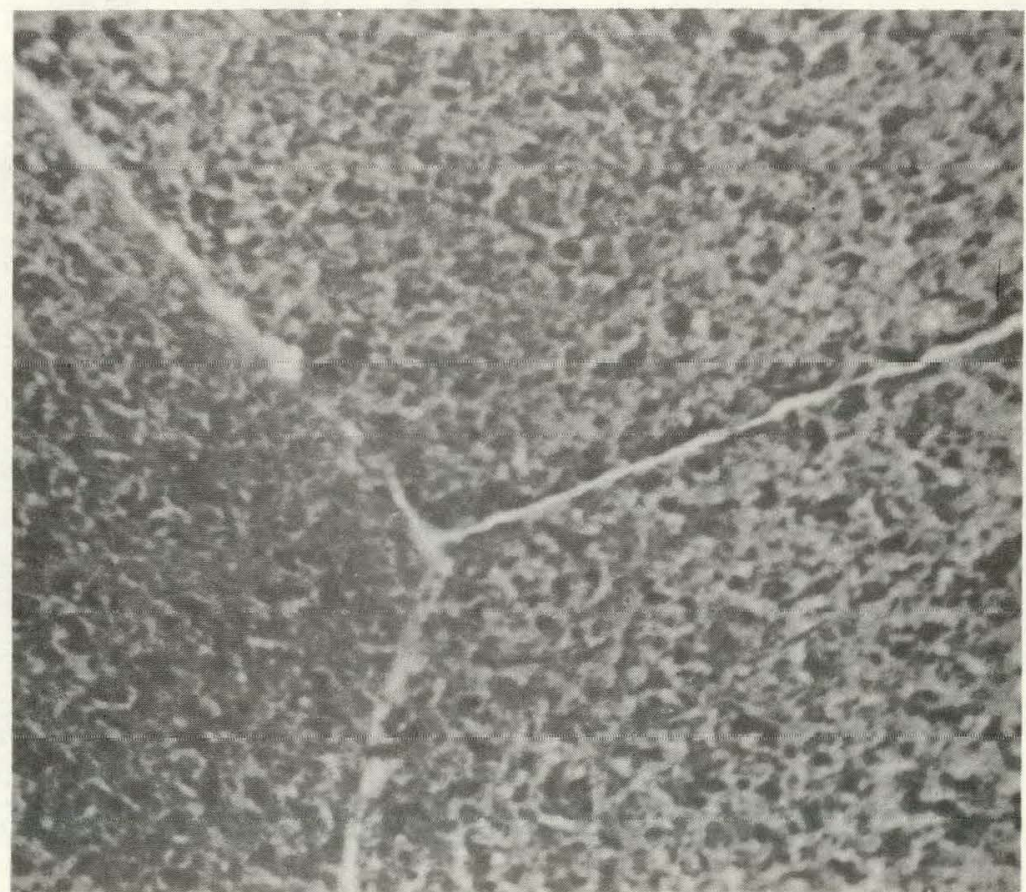

(b)

XBB7012-5429

Figure 37 


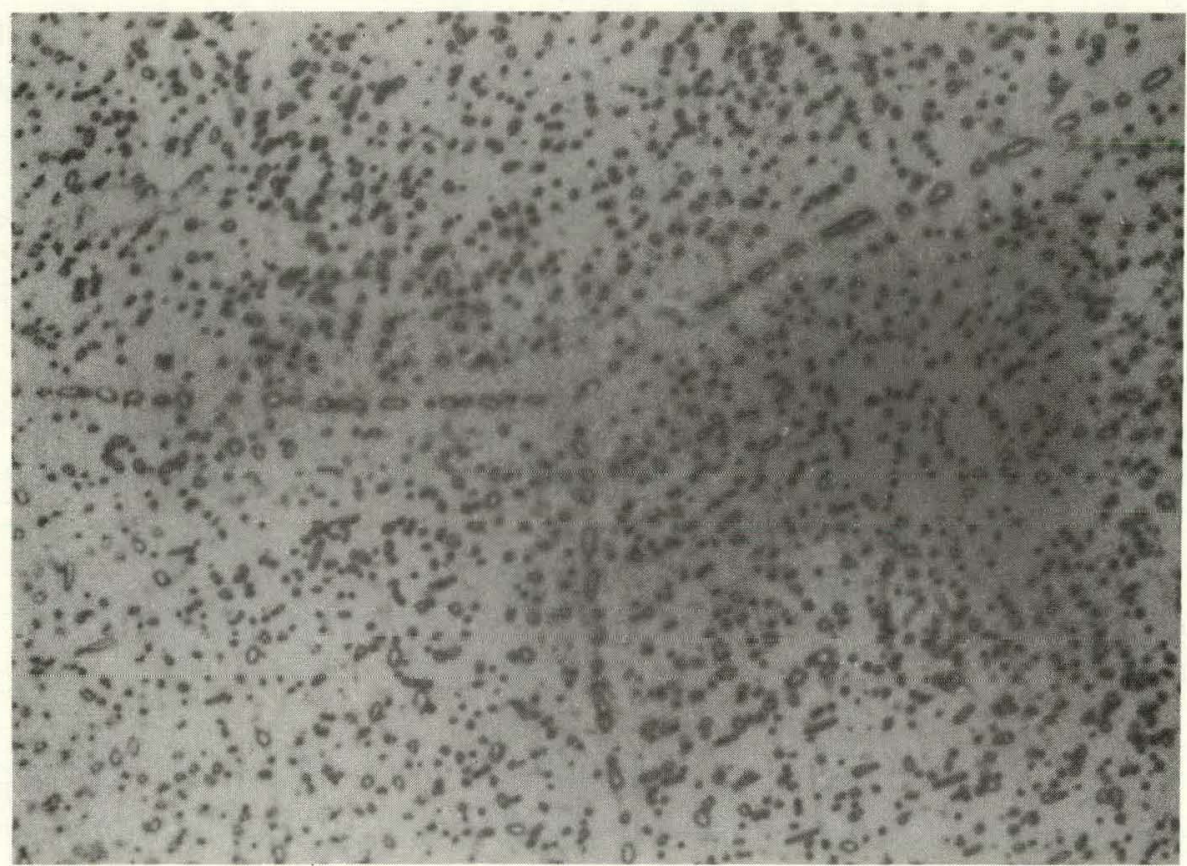

(a)

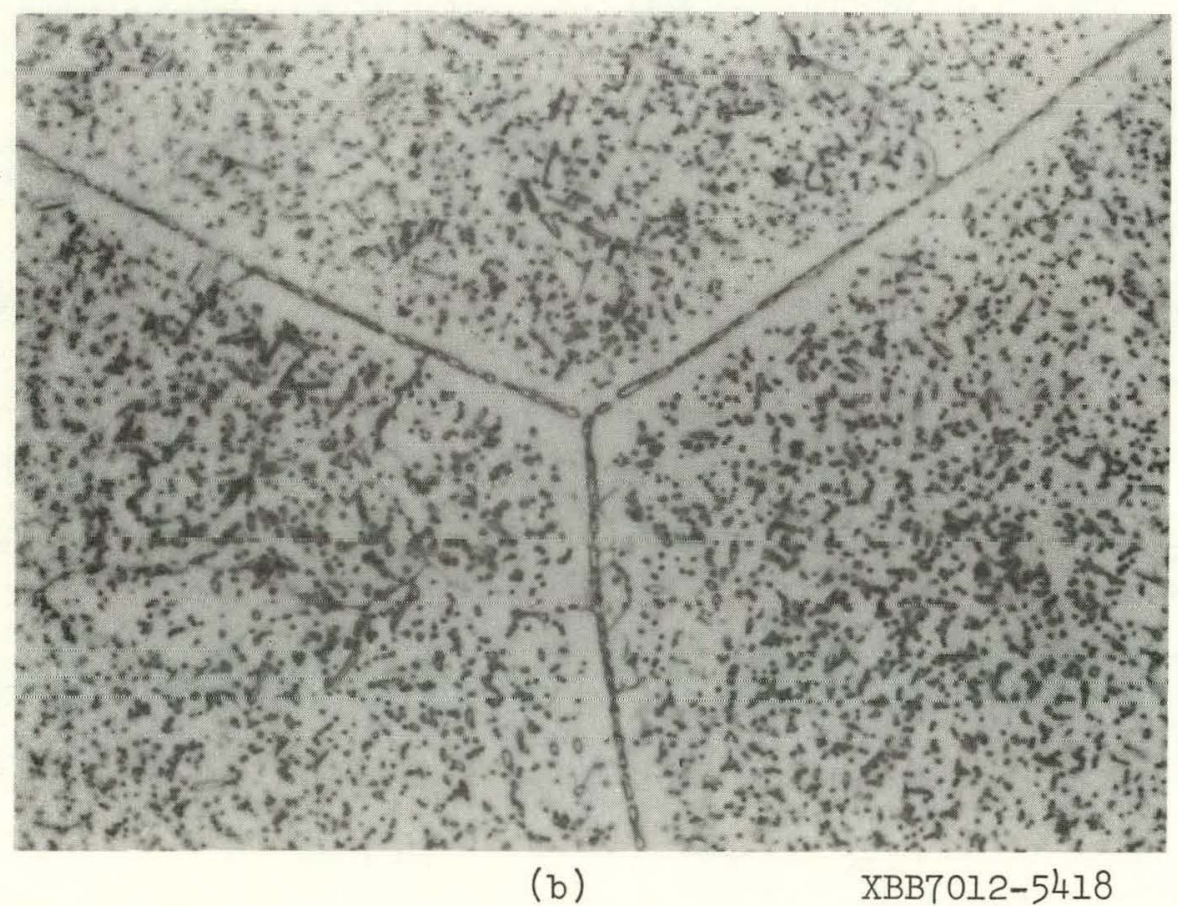

Figure 38 


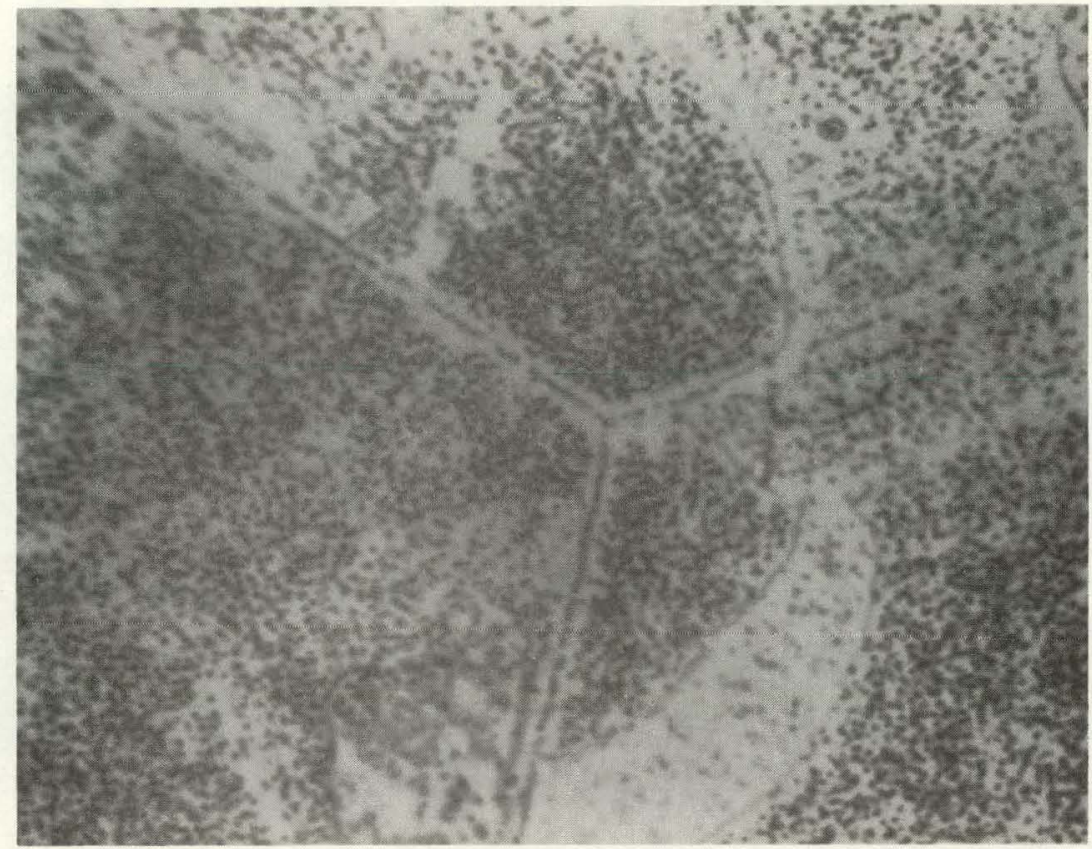

(a)

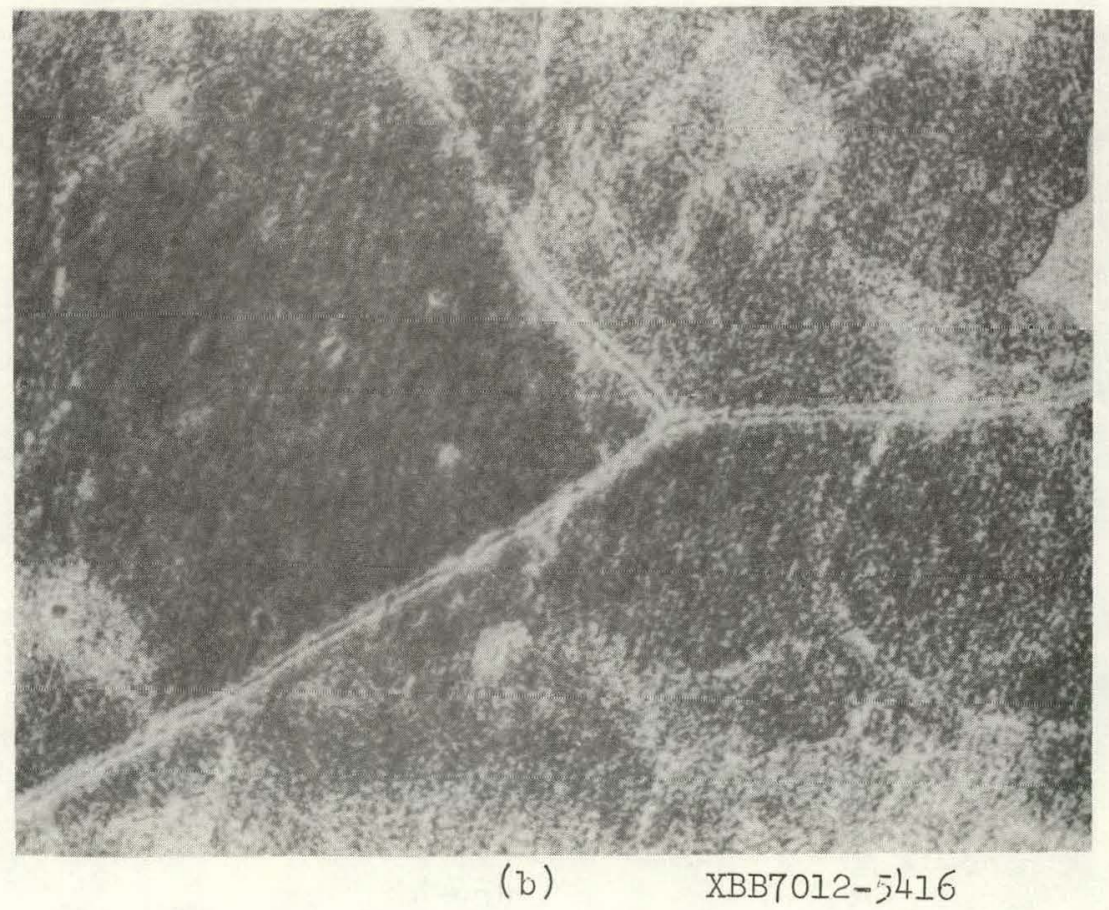

Figure 39 


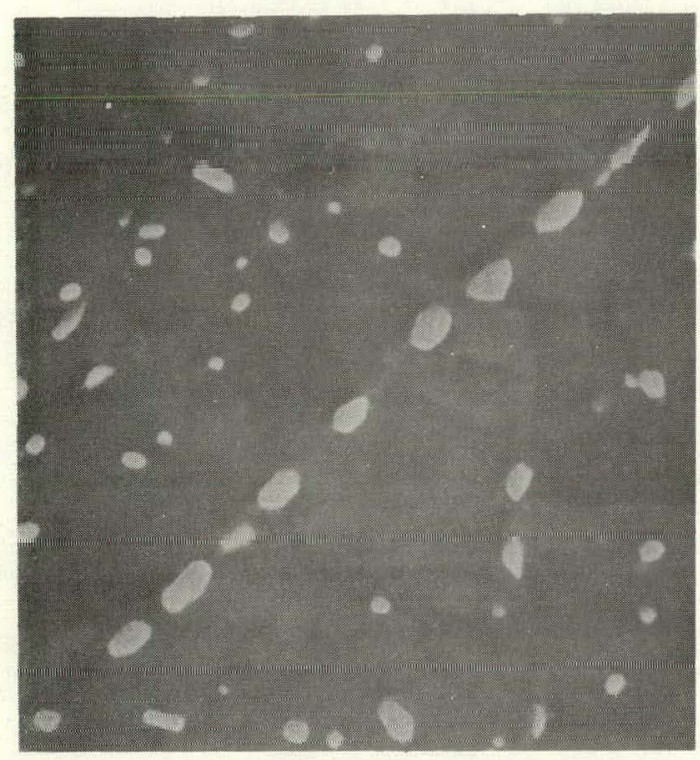

(a)

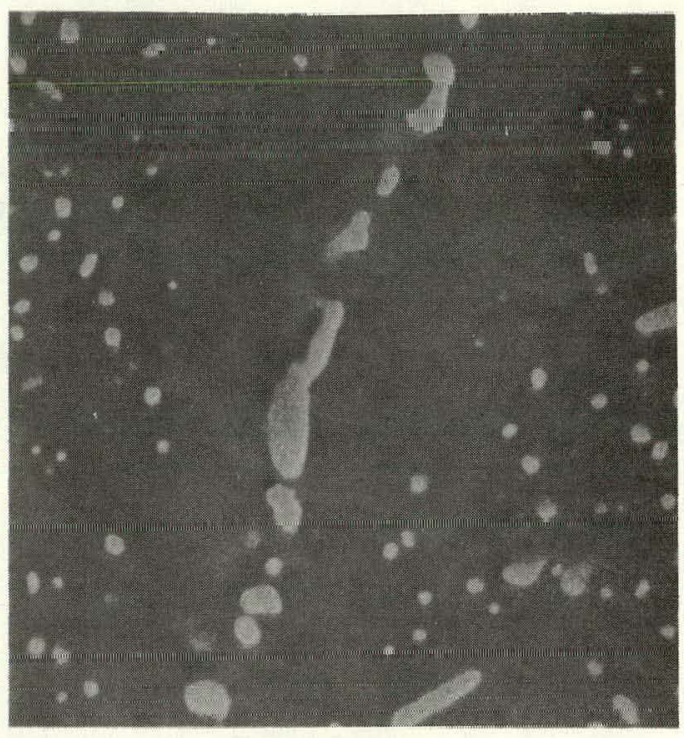

(b)

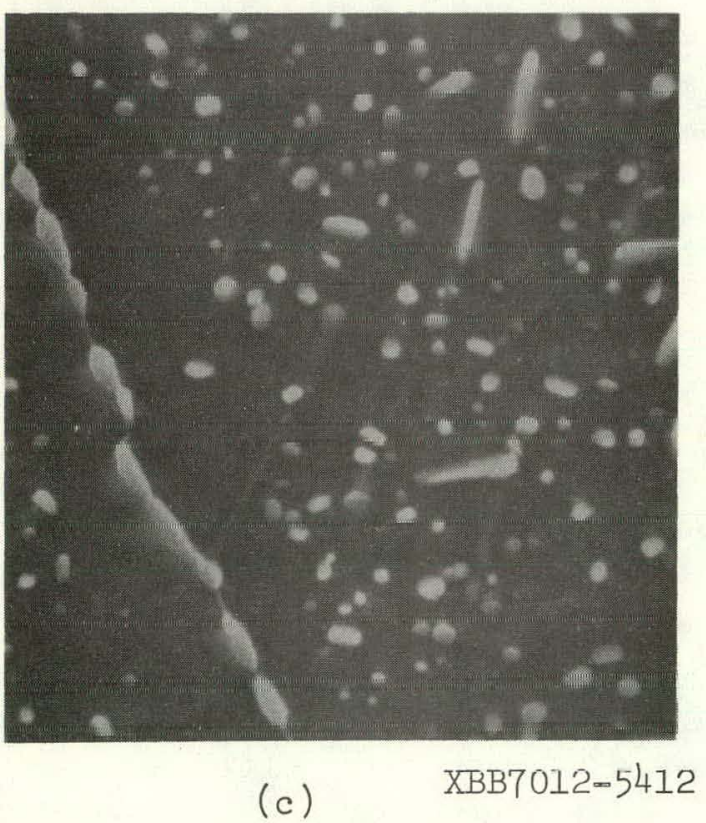

Figure 40 


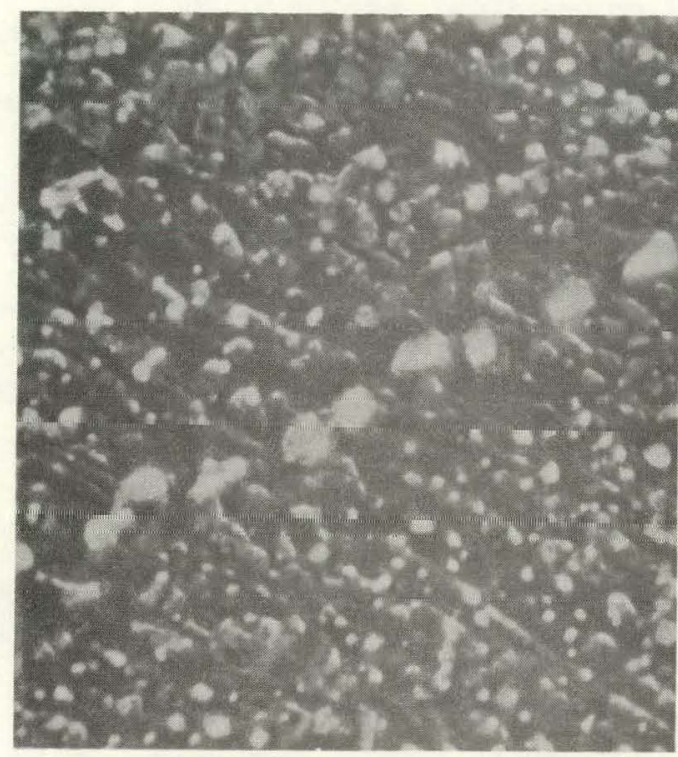

(a)

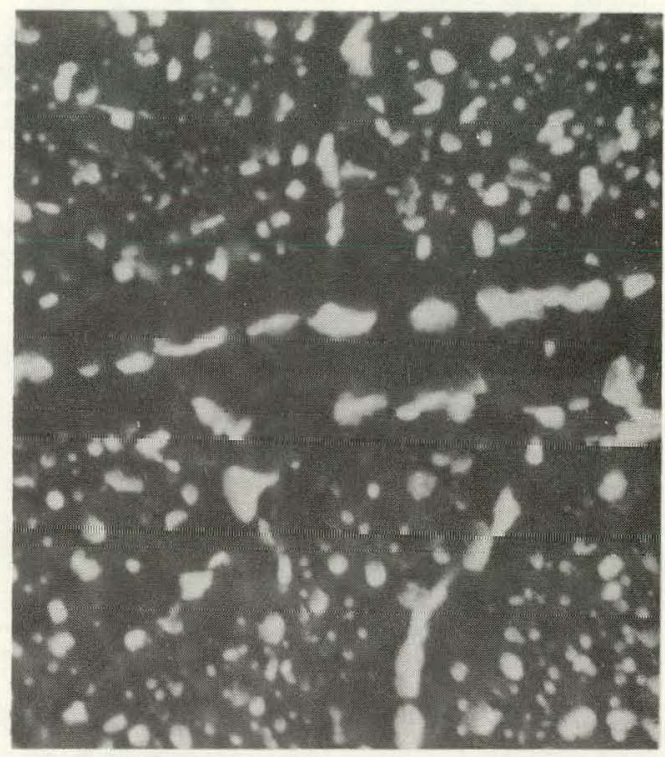

(b)

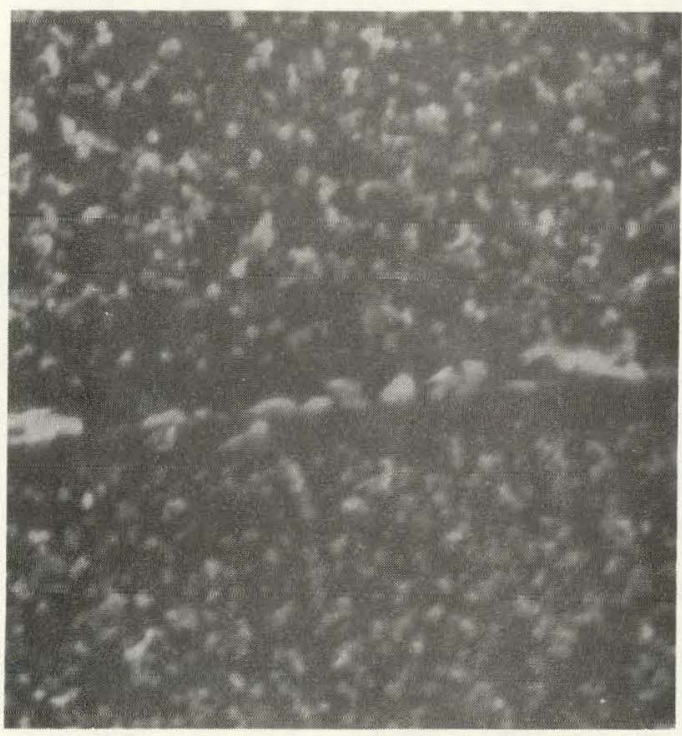

(c) XBB7012-5411

Figure !1 


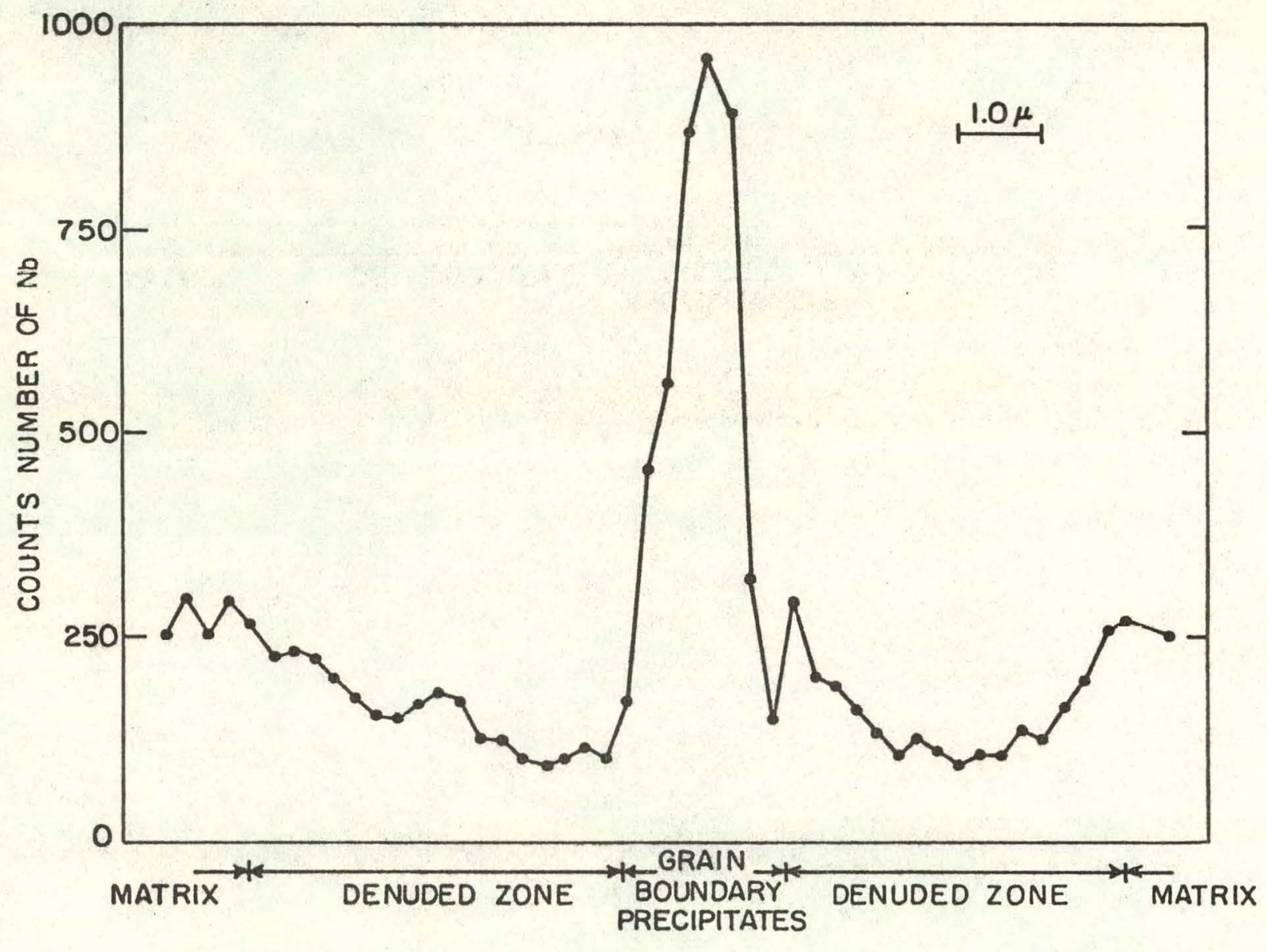

Figure 42 


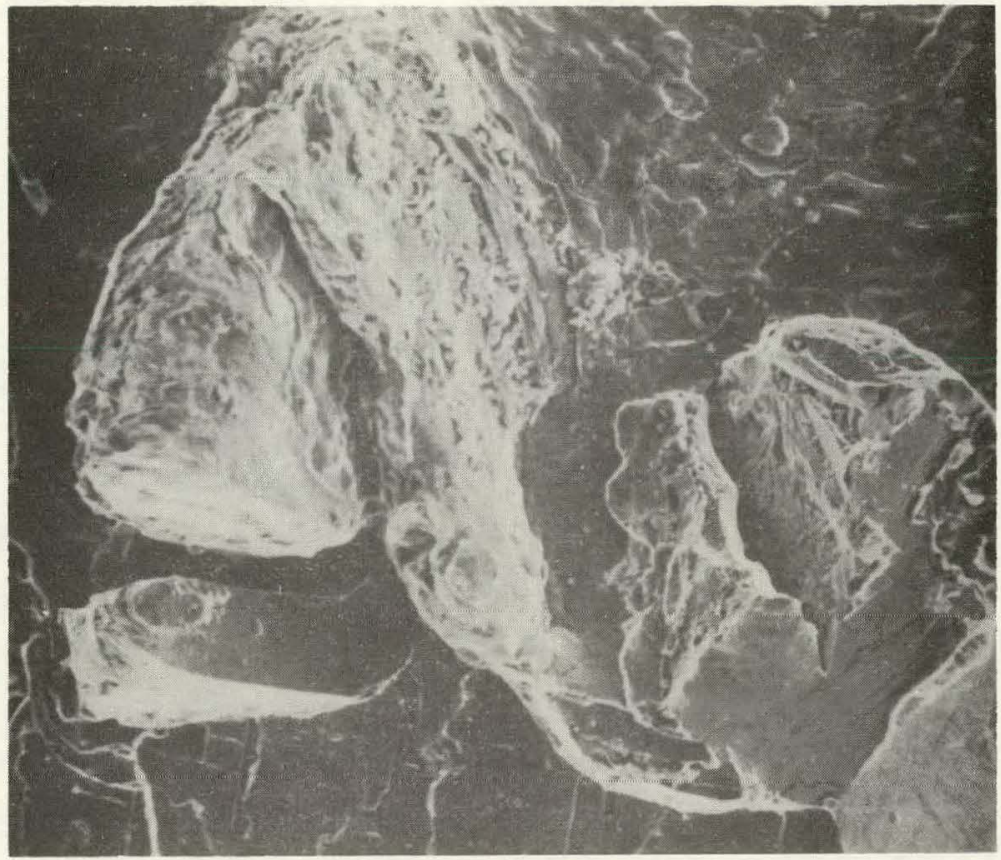

(a)

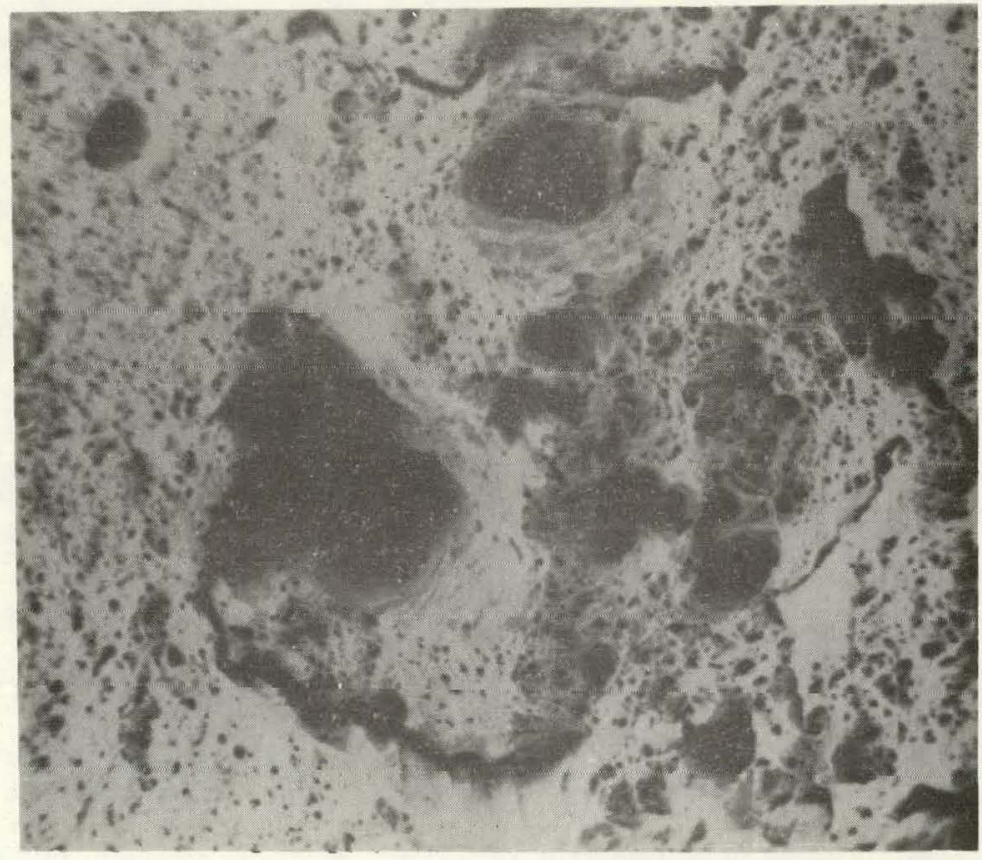

(b) XBB7012-5493 


\section{LEGAL NOTICE}

This report was prepared ds all dccuunt of Guvenintent sponsored work. Neither the United States, nor the Commission, nor any person acting on behalf of the Commission:

A. Makes any warranty or representation, expressed or implied, with respect to the accuracy, completeness, or usefulness of the information contained in this report, or that the use of any information, apparatus, method, or process disclosed in this report may not infringe privately owned rights; or

B. Assumes any liabilities with respect to the use of, or for damages resulting from the use of any information, apparatus, method, or process disclosed in this report.

As used in the above, "person acting on behalf of the Commission" includes any employee or contractor of the Commission, or employee of such contractor, to the extent that such employee or contractor of the Commission, or employee of such contractor prepares, disseminates, or provides access to, any information pursuant to his employment or contract with the Commission, or his employment with such contractor. 
